\title{
EPISTEMIC DUTIES
}

AND

\section{BLAMEWORTHINESS FOR BELIEF}

\section{CHRISTOPHER TODD GADSDEN}

MAY 2014 
The undersigned, appointed by the dean of the Graduate School, have examined the dissertation entitled

\title{
EPISTEMIC DUTIES AND BLAMEWORTHINESS FOR BELIEF
}

\author{
presented by Christopher T. Gadsden, \\ a candidate for the degree of doctor of philosophy \\ and hereby certify that, in their opinion, it is worthy of acceptance.
}

Professor Matt McGrath

Professor Peter Vallentyne

Professor Peter Markie

Professor Paul Litton 


\section{Dedications}

Kristin, you've inspired me to become a better husband, father, teacher, writer and human being. I can say, without hesitation, that there is at least one true counterfactual: I wouldn't have made it here without you. 


\section{Acknowledgments}

My heart swells with thanks to so many. To my Triune Creator and True Companion, Yahweh. To my advisor, Matt McGrath for his guidance and suggestions. To my philosophical heroes and helpers, J.P. Moreland, Greg Ganssle, Peter Vallentyne, Peter Markie, Andrew Moon, and Justin McBrayer. To my children: Phoebe Jane, Clark, Will and Julia. To my friends, my students, and my fellow Cru staff. Finally, to my father, who taught me to surf the cosmos of imagination. 


\section{TABLE OF CONTENTS}

\section{Contents}

Acknowledgements .................................................................

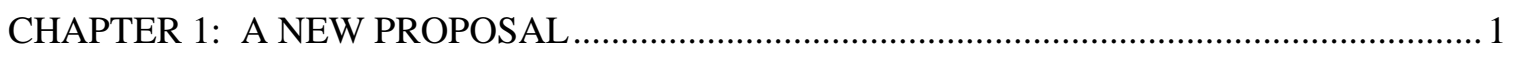

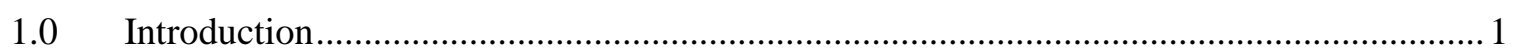

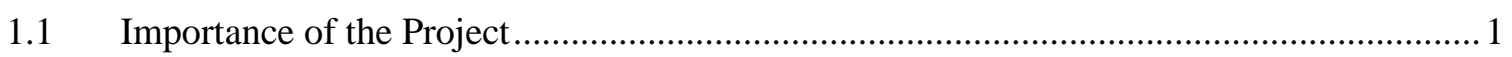

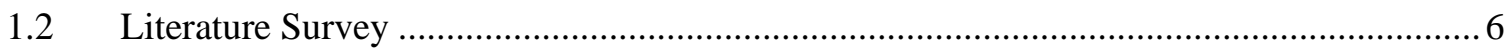

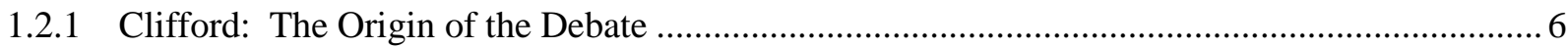

1.2.2 Feldman: Skepticism about Blameworthiness for Belief....................................................... 8

1.2.3 Hieronymi: Responsibility as Answerability ................................................................. 10

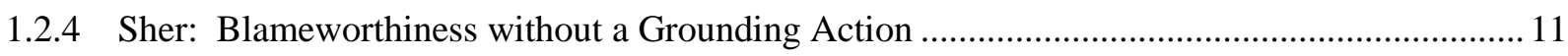

1.2.5 Alston: Derivative Blameworthiness for Belief ...................................................................... 16

1.2.6 Nottelmann: Grounding Blameworthiness in Prior Actions or Omissions ............................... 17

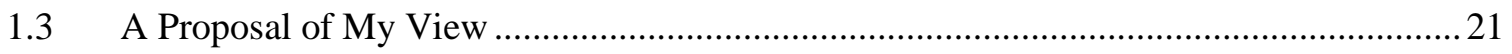

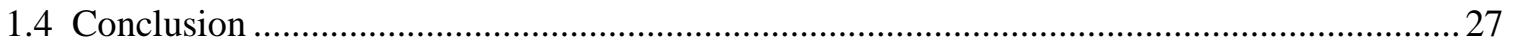

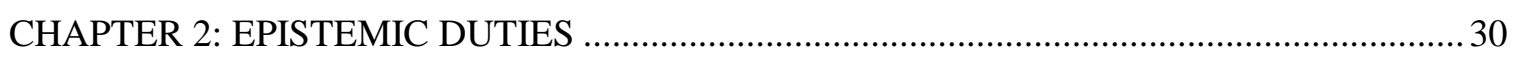

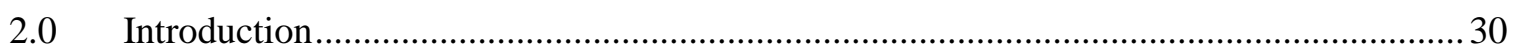

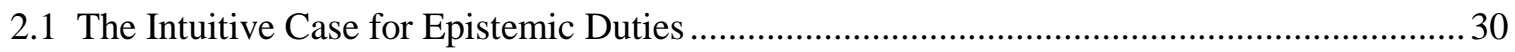

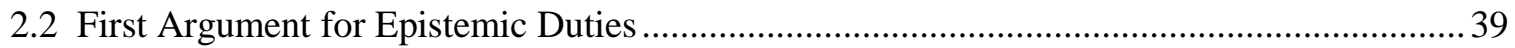

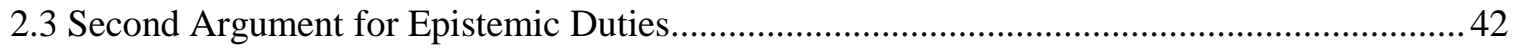

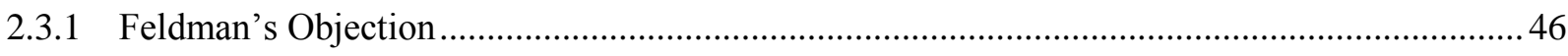

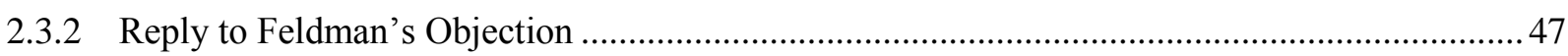

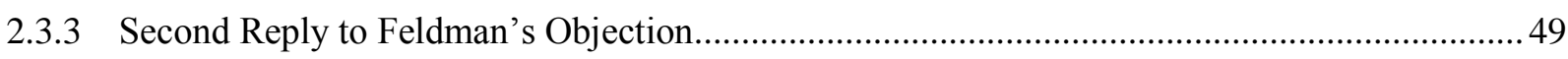

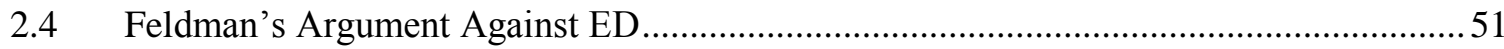

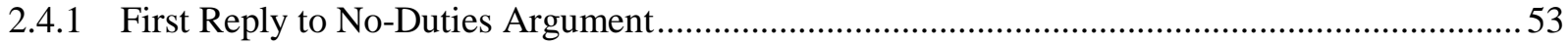

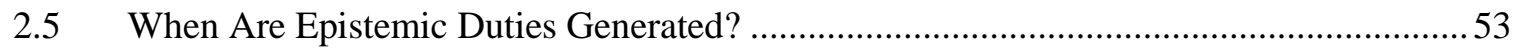

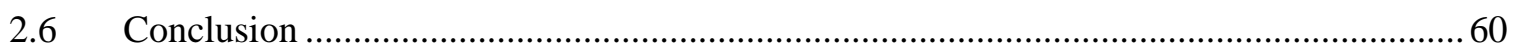

CHAPTER 3: RELIGIOUS BELIEF AND EPISTEMIC BLAMEWORTHINESS....................61

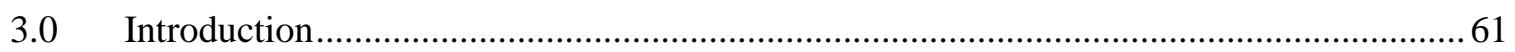

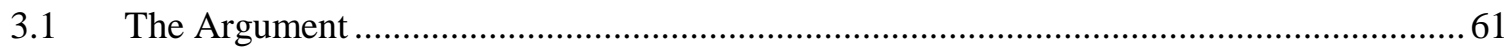

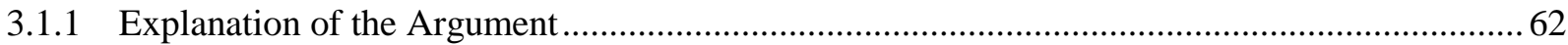

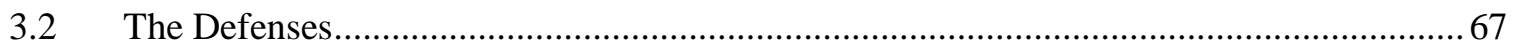

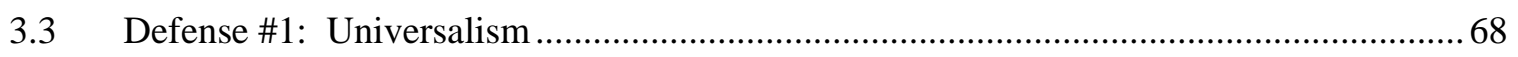

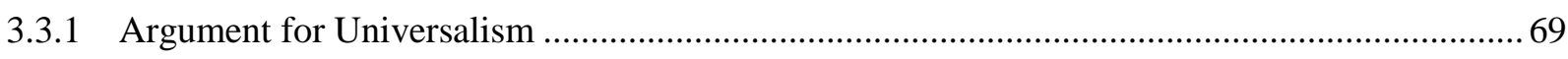

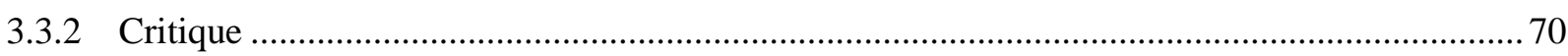




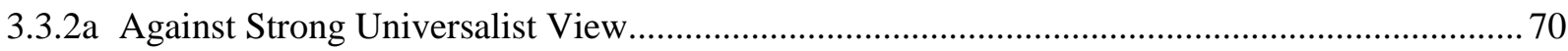

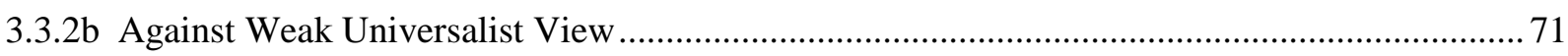

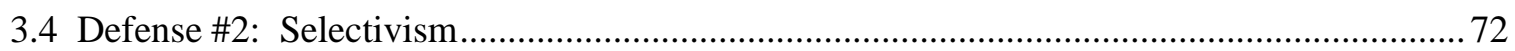

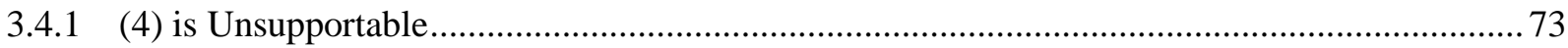

3.4.2 A Positive Argument for the Justice of God's Selection: The Ownership Argument ............... 75

3.5 Defense \#3: Responsibilism................................................................................... 79

3.5.1 Argument for the Sufficient Evidence Thesis ...................................................................... 79

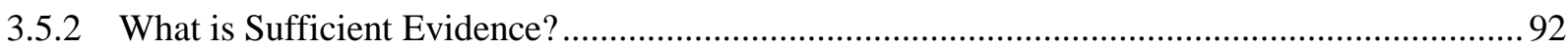

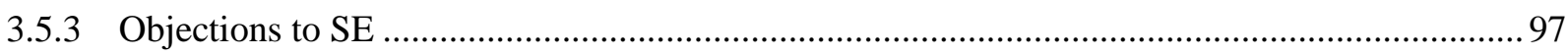

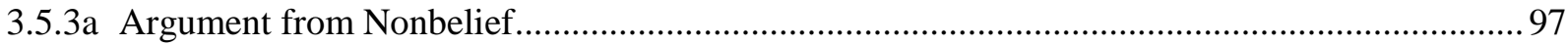

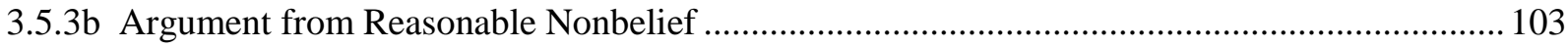

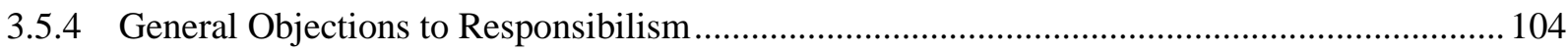

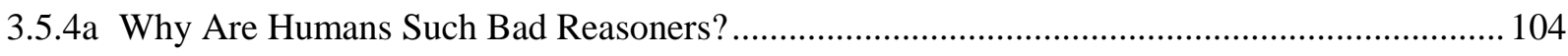

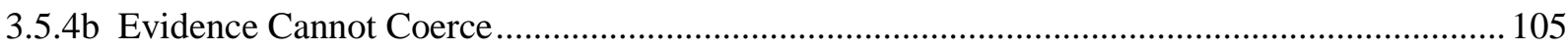

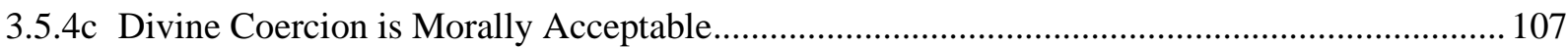

3.5.5 Implications \& Problems Concerning Blameworthiness ........................................................... 109

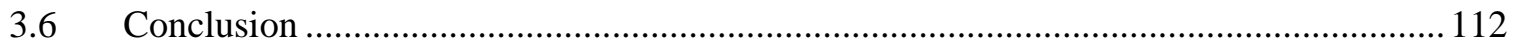

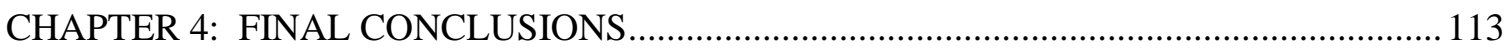

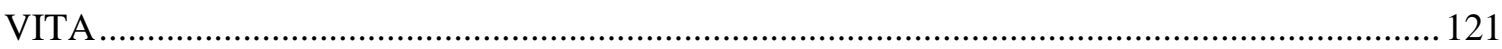




\section{CHAPTER 1: A NEW PROPOSAL}

\subsection{Introduction}

The aim of this project is to determine whether people can be blameworthy for their beliefs, what sort of blameworthiness might attach to agents in virtue of their beliefs (moral, epistemic, etc.), what the conditions for such blameworthiness might be, and what implications all this might have for religious belief. This is both a work of epistemology and deontology. It is a work of epistemology because it is concerned with the evaluation of beliefs. It is a work of deontology because it is concerned with whether we have obligations to believe or investigate in certain ways. I defend the thesis that, agents are blameworthy for a doxastic attitude D toward $p$ if, and only if they hold D and have an unexcused, unfulfilled comprehensive epistemic duty regarding $p .{ }^{1}$ Here is a plan for chapter one. In section 1.1, I explain why this project concerning blameworthiness for beliefs is important. In section 1.2, I offer some background on the debate about blameworthiness for belief, highlight some recent approaches in the literature and briefly mention some concerns with these approaches. In section $\mathbf{1 . 3}$, I offer a rough sketch of my view and explain the advantages of my approach over those mentioned in $\mathbf{1 . 2}$.

\subsection{Importance of the Project}

To begin, why is such a project important? I offer three intuitive reasons. First, certain pervasive social attitudes and practices are based on the assumption that agents sometimes are blameworthy for their beliefs. This project will help determine if and

\footnotetext{
${ }^{1}$ The epistemic duties for some $\mathrm{S}$ that I have in mind are restricted to those that might affect the epistemic status of S's belief. I am not concerned with social epistemic duties, if there are any. Thanks to Peter Vallentyne for helping to clarify this point.
} 
when such an assumption is justified. Second, in certain cases, whether an agent is morally blameworthy for some action may depend on whether that agent is blameworthy for a particular belief. And third, a clear analysis of blameworthiness for belief may help to clarify the nature of epistemic justification.

First, how might an account of blameworthiness for beliefs shed light on the appropriateness of certain pervasive social attitudes and practices? Consider two examples. In one case, your close friend announces to you that, based on an unfavorable horoscope she read on the internet, she believes her upcoming job interview will be disastrous. In another case, you meet a native living on a secluded island in the Pacific who believes that the local volcano is an angry deity. Presumably, your attitudes toward your friend and the native are different. In your friend's case, you feel a certain level of annoyance or even indignation toward them for believing the horoscope. But in the case of the native, you might be mildly amused (and feeling a little ashamed for it) or perhaps intrigued by their religious belief. Assuming that both of your attitudes are appropriate, what justifies scorn in the former case and indulgence in the latter? Presumably, it is not a difference in the truth values of the two beliefs — both beliefs seem false. What justifies the different attitudes is that your friend is blameworthy for her belief while the native is not. To further illustrate, imagine that a fellow tourist was present when you spoke with the native, and this tourist later communicated to you that they were annoyed and a little indignant toward the native. "How could he be so dumb? A volcano god! Come on!" The fellow tourist's attitude seems inappropriate, primarily because we think that given the native's environment, his animistic religious belief is quite understandable - he is not to blame. Some cases, however, are not so clear. You meet someone at a party who was 
raised in a strict Christian fundamentalist home and sincerely believes that the earth is only 6,000 years old. What is the appropriate attitude to have toward them? Annoyance or kind concern? Clear conditions for blameworthiness for belief would be beneficial in such cases.

Beyond attitudes, an agent's blameworthiness for their beliefs also affects the legitimacy of certain social practices. Take the social practice of scolding ("You shouldn't have done that!"). Scolding for beliefs involves common expressions like, “you should have known better!”, “you shouldn’t have fallen for that!”, or "you shouldn't have jumped to conclusions!" These sorts of claims are not merely used to state that the agent has gone wrong in their believing - they are also used, in my view, to blame the agent. Such practices reflect our assumption that agents are responsible, in some sense, for their beliefs. I can demonstrate this first with an example of scolding for actions, and then an example of scolding for beliefs.

Suppose Matt bakes a pie as a gift for Mom, but his brother Jim wanders into the kitchen later that evening and eats the pie. Imagine Matt's reaction (in a raised voice):

Matt: “Jim, you shouldn't have eaten that! It was for Mom!” But then suppose that Jim responds by claiming that he couldn't have known it was for Mom. As it turns out, Matt neglected to leave a note on the pie. It should now be clear that Jim is not blameworthy. But suppose now that Matt's reply to Jim goes something like this (again, with voice raised):

Matt: “Ok, I guess it's not your fault, but still, you shouldn't have eaten that pie!"

\footnotetext{
2 Thanks to Matt McGrath for this suggested term.
} 
This last bit in italics - the repeated scolding — seems somehow inappropriate given the conversation so far. But why does it seem so? It seems infelicitous to repeat the scolding because it (conversationally) implies blameworthiness, and Jim has made it clear to Matt that he is not blameworthy, even if his action was wrong. I think such an utterance violates Grice's Maxim of Quality $^{3}$, because it conversationally implies something that isn't true, viz., that Jim is blameworthy. So, while we may initially scold someone who we mistakenly consider blameworthy, we should cease to scold them once we learn that they are not blameworthy, because to scold someone is to blame them. ${ }^{4}$ So, scolding is appropriate or legitimate only if the scoldee is blameworthy. ${ }^{5}$

The extension to beliefs seems simple. Simply take any case of scolding for beliefs mentioned earlier (e.g., "you shouldn't have fallen for that!") and it is easy to imagine cases in which such a statement is appropriate and cases in which it is not. Again, the appropriateness of the scolding will depend upon whether the believer in question is blameworthy for her belief. Thus knowing if and when agents actually can be blameworthy for their beliefs is crucial in determining the appropriateness of social practices such as scolding. ${ }^{6}$

\footnotetext{
${ }^{3}$ Wayne Davis, "Implicature," Stanford Encyclopedia of Philosophy (2010).

${ }^{4}$ Now, I do not think statements such as "you shouldn't have eaten that pie!" mean that the agent is blameworthy. The simple deontic statement can be true (when the action is wrong) even if the agent is not blameworthy. It is how the statement is used in conversation that creates the implicature. In a conversation where scolding takes place, statements like the ones above are used to blame an agent. A speaker could cancel out the implicature ("You shouldn't have eaten that pie! Not that I'm blaming you."), and his statement would remain meaningful.

${ }^{5}$ It could be argued that the scolder need only believe that the scoldee is blameworthy in order to engage in appropriate scolding. But I think it is more plausible to say that when the scolder mistakenly believes the scoldee to be blameworthy, scolding remains inappropriate, but (possibly) excused due to ignorance.

${ }^{6}$ Here's how an argument for the possibility of blameworthiness for beliefs might run:

1. If agents cannot be blameworthy for their beliefs, then scolding an agent for her beliefs is never appropriate.

2. Scolding an agent for her beliefs is sometimes appropriate.
} 
The second intuitive reason to think my project is important is this: culpability ${ }^{7}$ for beliefs is sometimes required for moral blameworthiness for action. The classic example of this connection between blameworthiness for belief and moral blameworthiness for action is the case of the ship owner offered by W. K. Clifford in his essay, "The Ethics of Belief." Clifford describes a ship owner who sends his passengerladen ship to sea believing — without bothering to gather evidence — that she is seaworthy. ${ }^{8}$ Consequently, the ship sinks during the course of its journey, resulting in great loss of life. For Clifford, what makes the ship owner blameworthy for the tragedy is that the ship owner willingly neglected to obtain sufficient evidence for his belief, and thus "had no right," in Clifford's terms, to believe that the boat was seaworthy. The ship owner's moral blameworthiness depends upon his blameworthiness for his belief about the ship's seaworthiness.

Other examples abound. Nikolai Nottelmann tells of a case in which two sailors were persuaded by a British naval officer to gang rape the officer's wife, under the false pretense that the woman had given consent to the activity. The jury initially ruled that the sailors were not guilty of rape because they justifiably believed the sex to be consensual. But after appeal, another jury ultimately found the two sailors guilty of rape, saying they should not have believed the officer's story so easily. In other words, they were at fault for their belief that the sex was consensual, and this made the rape conviction possible. In a more extreme vein, John Greco writes that, "Often enough, the

3. So, agents can be blameworthy for their beliefs.

I think my example gives strong support to (1). To deny (2) seems counterintuitive, because it would mean that a whole host of common expressions are always infelicitous. So it should follow that agents can be blameworthy for beliefs.

${ }^{7}$ I will use the terms 'culpable' and 'blameworthy' interchangeably.

${ }^{8}$ Clifford assumes that the ship owner could easily have gathered evidence, but chose not to. 
morally outrageous actions of tyrants, racists and terrorists seem perfectly reasonable, even necessary, in the context of their distorted belief system. In order to find the actions blameworthy in such cases, it would seem that we have to find the beliefs blameworthy as well." 9,10

Finally, the third intuitive reason my project is important is because providing a clear analysis of blameworthiness for belief may offer some insight into the nature of epistemic justification. S's being justified in believing that $p$ or knowing that $p$ could hinge on whether $\mathrm{S}$ is blameworthy (or blameless) for believing that $p$. I.e., could blamelessness for believing that $p$ be a necessary condition for justification or knowledge? Could blamelessness for believing that $p$ even work as an anti-Gettier condition? Perhaps. However, I will leave the exploration of these extremely interesting questions about justification to others and focus primarily on the first two motivations for my project.

\subsection{Literature Survey}

\subsubsection{Clifford: The Origin of the Debate}

What we might dub the "debate" about blameworthiness for beliefs was famously launched in the late $19^{\text {th }}$ century by W. K. Clifford in his essay, "The Ethics of Belief."11 Clifford argues that "it is wrong always, everywhere, and for any one, to believe anything upon insufficient evidence." 12 So Clifford is clear that an agent can believe wrongly $^{13}$

\footnotetext{
${ }^{9}$ John Greco, Stanford Encyclopedia of Philosophy, "Virtue Epistemology” (2009).

${ }^{10}$ Cf. James Montmarquet, Epistemic Virtue and Doxastic Responsibility (Rowman \& Littlefield, 1993), p. 1. "... how are we entitled to cast such moral blame and even fairly punish these individuals unless we can sometimes find these individuals culpable for having these beliefs in the first place?"

${ }^{11}$ W.K. Clifford, "The Ethics of Belief," in Lectures and Essays, Vol. II. London: Macmillan (1879).

${ }^{12}$ W.K. Clifford, "The Ethics of Belief," in Reason and Responsibility, Feinberg \& Shafer-Landau, eds. $14^{\text {th }}$ ed., (Wadsworth: 2011), p. 121.
} 
(and not just falsely). But Clifford is also clear that agents can and should be held responsible for believing wrongly. Speaking of the ship-owner mentioned in the previous section, “. . . although in the end he may have felt so sure about it that he could not think otherwise, yet inasmuch as he had knowingly and willingly worked himself into that frame of mind, he must be held responsible for [his faulty belief]" (emphasis mine). Presumably, to be responsible (in some robust sense) for some bad state of affairs (such as a faulty belief) is to be blameworthy for it. ${ }^{14}$ So, for Clifford, an agent who knowingly and willingly believes something upon insufficient evidence is blameworthy for that belief.

So on what grounds, exactly, is the ship owner, or anyone for that matter, blameworthy for their belief, according to Clifford? Clifford takes it for granted that we have certain duties regarding belief formation. “[E]ven when a man's belief is so fixed that he cannot think otherwise, he .. . cannot escape the duty of investigating on the ground of the strength of his convictions." duty of questioning all that we believe." ${ }^{16}\left(100 ; 12^{\text {th }}\right.$ ed.) But for Clifford, this duty of proper belief seems to be an extension of the ordinary duty of beneficence. "[I]f I let myself believe anything on insufficient evidence, there may be no great harm done by the mere belief . . . But I cannot help doing this great wrong towards Man, that I make myself credulous. The danger to society is not merely that it should believe wrong things, though that is great enough; but that it should become credulous, and lose the habit of testing

\footnotetext{
${ }^{13}$ Clifford does not specify whether this wrongness is moral, prudential or perhaps epistemic. At this juncture, it is not crucial to solve this ambiguity.

${ }^{14}$ The debate over the metaphysics of responsibility, i.e., whether agents actually are responsible or are merely held responsible, was probably not salient to Clifford. So I will assume that for Clifford, agents who "must be held responsible" actually are responsible.

${ }^{15}$ ref

${ }^{16}$ ref
} 
things and inquiring into them; for then it must sink back into savagery." "17 Since I have a prima facie duty not to harm myself or others, and fostering credulity causes such harm, I therefore have a duty not to believe on insufficient evidence and thus foster credulity.

So then, for Clifford, blameworthiness for belief on insufficient evidence is moral blameworthiness for a failure to carry out a duty of beneficence. But while it seems true that we have a duty of beneficence, Clifford's argument linking this duty to the duty of not believing on insufficient evidence is questionable. The argument sounds like slippery-slope reasoning, since Clifford's expected outcome (society sinking into savagery) is not very likely given my believing on insufficient evidence. Even if I grant that I do harm myself when I believe badly, it is not at all clear that this necessarily harms others or mankind as a whole. The expected moral disutility for any instance of believing on insufficient evidence seems negligible. So, it seems false that my epistemic misstep is a moral failure on my part. However, despite the weaknesses in the reasoning, Clifford has certainly given us a good start on the problem.

\subsubsection{Feldman: Skepticism about Blameworthiness for Belief}

Richard Feldman thinks that deontological terms such as 'ought' and 'should' can be applied to beliefs, but he is skeptical about other deontological speech acts like praising and blaming.

Consider praise and blame for beliefs. While we do praise people for the effort they put into investigating propositions, praising someone by saying something like, "That was really a great bit of believing you did there" sounds bizarre. I do not think we often give out praise or blame for beliefs themselves, as opposed to behaviors associated with beliefs. (Feldman, 2008: 353)

\footnotetext{
${ }^{17}$ Clifford.
} 
Feldman tries to cast some doubt on the idea of doxastic blameworthiness by pointing out that we do often tell agents what they ought to believe, but we don't often blame agents for their beliefs. Feldman is suggesting that if we don't talk about it in ordinary discourse, then this is a reason to think the term 'blame' doesn't apply to beliefs. I have already argued in section 1.1 that we implicitly blame people for their beliefs when we scold them for believing in a certain way. But Feldman's worry here goes deeper than language use. Feldman thinks that our lack of sufficient control over belief does in fact rule out the applicability of terms like 'blame.' He writes, “[W]e are not typically responsible for our beliefs in the way we are responsible for our punishable actions." (354) Voluntary actions such as investigating or pondering evidence are subject to blame and praise because we have some measure of control over them. But we don't blame and praise people for things over which they have no control. So, if believing is involuntary, then praising someone for their "believing" would sound just as odd as praising them for their "digesting."

While I don't have space to delve into this issue of doxastic control ${ }^{18}$, I think Feldman is probably correct that we won't be able to use doxastic control to ground blameworthiness for beliefs. However, it does not automatically follow that we cannot be blameworthy for our beliefs. All that follows is that if we can be blameworthy for our beliefs, it must be grounded in something other than our exercise of doxastic control (or lack thereof). As I see it, there are at least three kinds of views in the current literature on what grounds epistemic responsibility

\footnotetext{
${ }^{18}$ And for reasons that will become clear later, I think we can solve the blameworthiness problem without taking sides in the doxastic control debate.
} 
and blameworthiness: actional-non-voluntarist, actional-voluntarist, and nonactional.

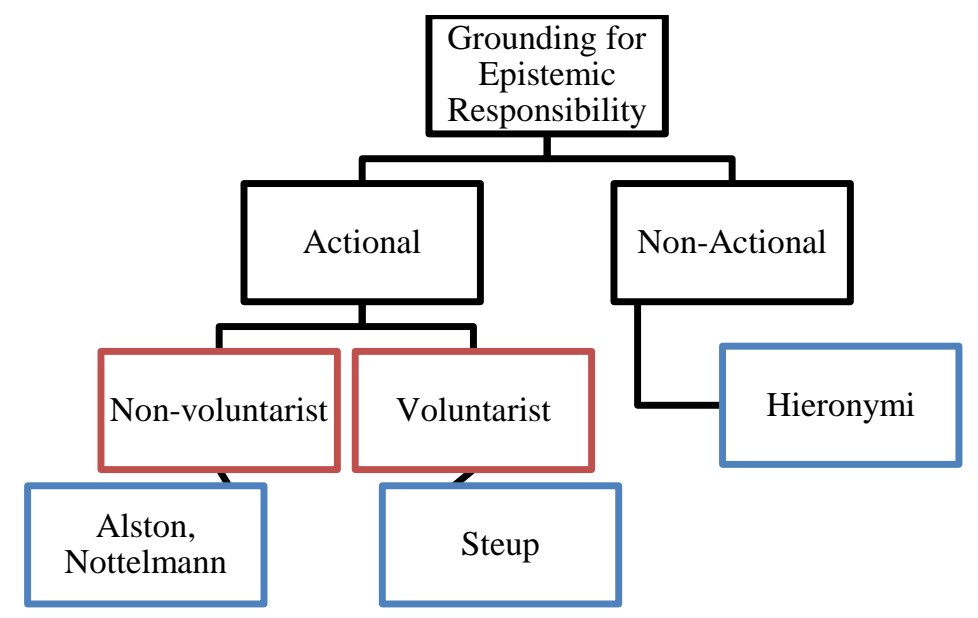

\section{Non-actional Approaches}

The first important distinction is between what I call actional and non-actional approaches. Actional approaches hold that $S$ is responsible for believing that $p$ only if $S$ is responsible for some action $\varphi$ in the past, and S's believing that $\mathrm{p}$ is connected to S's $\varphi$-ing in the right way. Non-actional approaches have no such requirement. Below I briefly examine two non-actional approaches. ${ }^{19}$

\subsubsection{Hieronymi: Responsibility as Answerability}

Pamela Hieronymi's view is an excellent example of a non-actional approach. In her paper, "Responsibility for Believing," she argues that a belief need not be formed by means of an intentional choice in order for a believer to be responsible for it. $^{20}$ She argues forcefully, in fact, that beliefs and other "commitment-centered attitudes" (e.g.,

\footnotetext{
${ }^{19}$ Robert Adams and Michael Bergmann also hold views that could be considered non-actional, but they are quite similar in nature to the ones presented here. For more on them, see Adams' "Involuntary Sins," The Philosophical Review, Vol. 94, No. 1 (Jan., 1985), pp. 3-31; and Bergmann's Justification Without Awareness (2006), p. 92.

${ }^{20}$ Pamela Hieronymi, “Responsibility for Believing," Synthese (2008), Vol. 161, p. 357.
} 
intentions, resentment and gratitude) are not voluntary. On her view, the nonvoluntariness of beliefs, far from being a problem for responsibility, actually allows agents to have a much tighter connection to their beliefs (as opposed to their actions, for instance) in the sense that beliefs more accurately reveal something about the quality of the agent's will and the agent's take on the world. While we can sometimes choose to perform an action we do not take to be morally right or prudent, we cannot choose to believe something that we do not actually take to be true. Thus, beliefs are the sorts of things for which we are "most fundamentally responsible.", 1

So, what, exactly renders us responsible for a belief? She argues that "the feature which renders an attitude a fundamental object of responsibility [is] that the attitude embodies one's take on the world and one's place in it." Hieronymi thinks that when we believe that $\mathrm{p}$, and we are "answerable" for $\mathrm{p}$ (we can rightly be asked for our reasons for p), then our belief reveals what we take to be true or important or worthwhile, which in turn reveals the quality of our will. This approach is similar to some compatibilist accounts of responsibility for action (Watson, 1996) in which responsibility hinges, not on control, but on whether the action reveals something about the agent's true self.

\subsubsection{Sher: Blameworthiness without a Grounding Action}

George Sher also argues that a grounding action is unnecessary. (Sher's project is about responsibility for actions, but it can be extended to illuminate the debate about beliefs as well.) I understand Sher this way: the agent can be responsible (and thus blameworthy) for some $\mathrm{X}$ (for our purposes, let $\mathrm{X}$ be a bad belief) even if it was not the direct result of some clear action/omission performed by the agent prior to the obtaining of $\mathrm{X}$. The agent

\footnotetext{
${ }^{21}$ Hieronymi, p. 371.
} 
will be responsible/blameworthy for $\mathrm{X}$ as long as it was "caused by the interaction of some combination of his constitutive attitudes, dispositions and traits."22 (Sher: 88) Sher thinks that cognitive lapses which result in blameworthy actions are causally determined by "subpersonal states,",23 and that these subpersonal states "are so closely related to [the agent] that it is reasonable to view the cognitive failures to which they give rise - and so, by extension, the ensuing wrong or foolish acts — as originating in him." (Sher, 118) ${ }^{24}$

Sher argues that we can be responsible even when we fail to be aware of the wrongness (or imprudence) of our actions, as long as (1) the failure of awareness is caused by those same constitutive traits that normally support our reasoning processes; and (2) we should have been aware of the wrongness, i.e., we were capable of being aware, given our normal cognitive capacities, and there was some duty that gave us good reason to be aware. (Sher 2009, 112-113) ${ }^{25}$

\footnotetext{
${ }^{22}$ Must the agent be responsible for these constitutive attitudes in order for her to be responsible for the action caused by them? This is not clear. See Kane on "ultimate responsibility." The Significance of Free Will (OUP: 1996); A Contemporary Introduction to Free Will (OUP: 2005), pp. 120-131.

${ }^{23}$ I take "subpersonal states" to refer mental/brain-states of which the agent is not aware and which may not be directly attributable to the agent. However, these states might be the result of 'personal' desires, choices, etc. made repeatedly over time. Sher is not exactly clear on this point.

${ }^{24}$ Sher's full view on responsibility is as follows (p. 143): When someone performs an act in a way that satisfies the voluntariness condition, and when he also satisfies any other conditions for responsibility that are independent of the epistemic condition, he is responsible for his act's morally or prudentially relevant feature if, but only if, he either

(1) Is aware that the act is wrong or foolish when he performs it, or else

(2) Is unaware that the act is wrong or foolish despite having evidence for its wrongness or foolishness the failure to recognize which

c. Falls below some applicable standard, and

d. Is caused by the interaction of some combination of his constitutive attitudes, dispositions and traits; or else

(3) Is unaware that the act is right or prudent despite having made enough cognitive contact with the evidence for its rightness or prudence to enable him to perform the act on that basis

${ }^{25}$ Sher's model seems compatibilist with regard to free will. There is no need to cite free choices-they can be deterministically caused and the agent can still be responsible for them. Montmarquet, et al., however, seem to leave room for free choices. We can still hold you responsible even if you don't have the mental states that a reasonable person would have had. Sher rejects the "reasonable person" test because there is no use, he says, in blaming you for failing to have mental states other than those you had.
} 
There is at least one clear advantage to Sher's model. There are many cases in which it is difficult or even impossible to identify an action or omission prior to $\mathrm{X}$ that can serve as a cause or grounding for X. Consider a case suggested by Sher. Alessandra goes to pick up her kids at school, leaving her dog in the hot car. ${ }^{26}$ She is distracted by a lengthy and important conversation with a teacher, and forgets about the dog. When she returns, the dog is unconscious. It seems right to blame Alessandra for the dog's condition, but there does not seem to be a particular action or omission prior to her act of neglect that can ground her blameworthiness. ${ }^{27}$ So, if some grounding-action is necessary for blameworthiness, then Alessandra is not blameworthy. But clearly, she seems blameworthy. Sher solves this puzzle by grounding her blameworthiness, not in a prior action or omission, but in the psychological and physiological traits that are constitutive of her- the very traits that cause her to forget about the dog.

Now consider the case for beliefs. Suppose that Kevin believes that the evolutionary theory of common descent is false and suppose that this belief is bad (epistemically speaking), that is, he has no good reasons for holding it. But Kevin has never avoided his biology classes or ignored evidence—in fact he has been exposed to plenty of evidence. However, Kevin is extremely stubborn and simply is unable to see either the force of the evidence or the lack of evidence in favor of his own view. Intuitively, Kevin seems blameworthy for his belief about evolution, but there just doesn't seem to be any prior blameworthy action we can identify that will ground his

\footnotetext{
${ }^{26}$ Sher, p. 24.

${ }^{27}$ Alessandra may have an excuse for her neglect that mitigates blame, but she is at least morally responsible for it.
} 
blameworthiness for the belief in question. Kevin seems blameworthy in virtue of his stubbornness.

Sher gives us the resources to handle such a case. Kevin's stubbornness can be seen as a constitutive psychological trait for him, a trait which causes his failure to see the force of the evidence against his belief. Also, Kevin's failure to recognize his breach of intellectual duty falls below a standard which is a function of his cognitive capacities (he was cognitively able to grasp the information) together with his intellectual duties (a duty to be impartial or open minded). And these facts are sufficient, on Sher's view, to ground Kevin's blameworthiness, even if Kevin has no idea that he has been resisting the forces of reason or that he has done anything to make himself stubborn.

Despite these advantages, some may nevertheless find non-actional approaches problematic. This is because they make it possible to blame an agent whose dispositions and traits were formed by forces beyond his control. For example, suppose $\mathrm{S}$ has embraced the unwarranted and twisted beliefs of his community due to S's having grown up under severe indoctrination with no exposure to differing viewpoints. On views like Sher's and Hieronymi's, S would still be blameworthy for such beliefs. Even if S's brain had been altered by some technological means (resulting in certain beliefs and desires), she could be blamed for her beliefs as long as these new technologically-fabricated traits and attitudes are currently part of what constitute her as an agent (which also could be guaranteed by technological means, it seems).

In addition, non-actional approaches such as Hieronymi's face another difficulty. In explaining what it means to be responsible, she comes close to circularity. She writes, 
". . . to be (more robustly) responsible for something is to be open to (moral or epistemic) assessment or judgment on account of that thing and, depending on the outcome of that assessment (whether it is positive, negative, or neutral), the appropriate target of certain reactions on account of it."

So, to be responsible requires that I am an appropriate target of the reactive attitudes, but what are the criteria for determining that? Hieronymi offers no criteria, but intuitively, Jones is an appropriate target for certain reactive attitudes indicative of responsibility only if Jones is actually responsible.

\section{Actional Approaches}

Actional approaches seek out grounding for responsibility in something the believer has control over, namely her actions. The actional approach also has two distinct branches: voluntarist and non-voluntarist approaches. ${ }^{28}$

Earlier I claimed that actional approaches hold that $\mathrm{S}$ is responsible for believing that $\mathrm{p}$ only if $\mathrm{S}$ is responsible for some action $\varphi$ in the past, and $\mathrm{S}$ 's believing that $\mathrm{p}$ is connected to S's $\varphi$-ing in the right way. For the voluntarist, the connection between S's believing that $p$ and S's $\varphi$-ing is simple: they are identical. Matthias Steup holds such a view. ${ }^{29}$ But the claim that we have direct, voluntary control over our beliefs is highly controversial. Rather than review the arguments for and against such a claim, I will sidestep it and suggest that if we can find a view which accommodates our intuitions but avoids highly-controversial claims, then we should prefer that view.

\footnotetext{
${ }^{28}$ A more precise term would be "doxastic voluntarist," but I have shortened it for simplicity. ${ }^{29}$ See Steup, "Steup, M. "Doxastic voluntarism and epistemic deontology." (2000) Acta Analytica, 15, 2556 ;

Knowledge, truth, and duty. Oxford: Oxford University Press (2001); "Doxastic Freedom." Synthese, (2008) 161:375-392.
} 
This leads us to the actional, non-voluntarist views of Alston (1988) and Nottelmann (2007). For the non-voluntarist, spelling out the connection between S's $\varphi$ ing and S's believing that $\mathrm{p}$ is the key. Both Alston and Nottelmann agree that we do not have direct, voluntary control over our beliefs ${ }^{30}$, but they do think we have a kind of indirect influence over our beliefs that can ground responsibility. Both think that there is a causal chain that runs from my present epistemically undesirable belief back in time to some action or omission that constituted a failure to fulfill an intellectual obligation. Below, I consider Alston's and Nottelmann's views in turn.

\subsubsection{Alston: Derivative Blameworthiness for Belief}

William Alston thinks we do have the right kind of control over the actions and omissions in the causal ancestry of (some of) our beliefs. In this way, we have a kind of long-range control over belief formation, much as we have long-range control over our cholesterol levels. Thus, deontological terms like 'required', 'should' or 'blameworthy' apply to beliefs, but only in a derivative sense: the "propositional attitude that eventuates is blameworthy or the reverse only by derivation from the voluntary acts that give rise to it." ${ }^{, 31}$ So Alston seems to endorse a slightly weaker form of the claim that agents can be blameworthy for their beliefs.

What sort of blameworthiness is this? Unlike Clifford, who seemed to say that agents are morally blameworthy irresponsible beliefs, Alston appeals to a different sort of norm for judgments about doxastic blame. In his important work on the deontological conception of epistemic justification, he proposes an account of "intellectual" blameworthiness:

\footnotetext{
${ }^{30}$ Alston, 1988, p. 263-268.

${ }^{31}$ Alston (2005), p. 74.
} 
$S$ is intellectually to blame for believing that $\mathrm{p}$ iff if $S$ had fulfilled all her intellectual obligations, then $S$ 's access to relevant considerations, or $S$ 's belief-forming habits or tendencies, would have changed in such a way that $S$ would not have believed that $\mathrm{p}^{32}$

One concern, however, is that Alston's account may be vulnerable to counterexamples involving luck. An agent may form a belief —one that he would have formed even if he had fulfilled all his intellectual obligations - by sheer luck, and yet still be blameworthy for it. Suppose I engage in some silly way of deciding whether to eat French fries or apples, such as turning on the TV for divine guidance-somehow I will interpret whatever comes on as guidance from God. Then, by sheer luck, I see a show describing the nutritional benefits of apples over French fries. So I form the belief that it would be better to eat apples than French fries, based on the information from the show. It seems false that had I performed all my intellectual duties, I would not have believed this. And yet, I still seem intellectually blameworthy for my belief - it was formed in a bizarre and unreasonable fashion.

\subsubsection{Nottelmann: Grounding Blameworthiness in Prior Actions or Omissions}

Nikolaj Nottelmann, in his recent (2007) book Blameworthy Belief, gives us the most developed account of blameworthiness for beliefs yet. His account is as follows.

Blame $_{\text {epist }}$ : An agent is epistemically blameworthy for holding the belief that $p$ if, and only if,

1. She believes that $p$.

2. Her holding of the belief that $\mathrm{p}$ is epistemically undesirable.

3. She enjoyed some mode of doxastic control $M$ belonging to the set $\mathbf{M}^{*}$ over her holding of the belief that $\mathrm{p}$ and it is either the case that

a. The epistemic undesirability of her holding of the belief that $p$ was caused by an exercise of $\mathrm{M}$. Or

b. The epistemic undesirability of her holding of the belief that $p$ was caused by a failure to exercise $\mathrm{M}$.

${ }^{32}$ Alston, 1988, p. 282. 
4. By performing the action or omission A constituting either the exercise of $M$ mentioned in $3 \mathrm{a}$ or the failure to exercise $\mathrm{M}$ mentioned in $3 \mathrm{~b}$, she violated an intellectual obligation incumbent upon her, and did this with either

a. relevant foresight

b. relevant blameworthy inadvertence to risk

5. She had no appropriate excuse for performing A under the above circumstances. ${ }^{33}$

Like Alston, Nottelmann's strategy is to ground blameworthiness for belief in some previous action or omission that contributed to the forming of the belief. But as Nottelmann points out, and as Alston would likely agree, the kind of long-range control depicted in Alston's account affects a very small number of our beliefs. So, Nottelmann's contribution is a new way to think of doxastic control that can affect a larger number of our beliefs.

On Nottelmann's view, to be blameworthy the agent must be able to "indirectly influence her belief-formation so as to control the instantiation or non-instantiation of properties of her beliefs relevant to their level of epistemic desirability." (95, emphasis mine) In other words, I may not have (much) control over whether I come to believe that $p$, but I do have significant control over whether my belief that $p$ is reasonable or based on/supported by my evidence. This is a departure from the usual discussion of doxastic control, which doesn't seem to get past the debate about control over the content of one's beliefs. It is these properties that determine whether our beliefs are bad, and it is the badness of our beliefs for which we can be blameworthy. It is easy to see how an agent can, by reflecting, gathering new evidence, etc., affect the badness or goodness of her belief that $p$, even if she couldn't help having the belief that $p$.

\footnotetext{
${ }^{33}$ Nottelmann, 2007.
} 
Let me briefly sketch three concerns I have with Nottelmann's account. First, he grounds epistemic blameworthiness in previous actions/omissions, but he hasn't made clear whether these previous actions/omissions must themselves be morally wrong, or whether it suffices that they are epistemically wrong. If it is the latter, then an account is needed of how actions can be evaluated epistemically. Second, as I discuss below, there seem to be some cases in which an agent is intuitively blameworthy for a belief, and yet there simply is no previous action or omission in the causal history of that belief that grounds this blameworthiness. Third, Nottelmann requires some foresight or inadvertence to risk on the part of the blameworthy agent, so that he could see (or should have seen) how his actions might bring about a bad belief. But it is dubious whether agents even have or ought to have such foresight.

But regardless of the merits or particular peccadilloes of accounts like Alston's and Nottelmann's, these views share a common, problematic assumption: that there was some set of actions which I could have performed that would have been sufficient to prevent my holding of an epistemically undesirable belief. ${ }^{34}$ They rely on what I will call the sufficiency thesis (ST).

ST: $\mathrm{S}$ is blameworthy for an epistemically bad doxastic attitude $\Delta$, only if there was some set of actions $\Sigma$ available to $\mathrm{S}$ which was sufficient to bring it about that $\mathrm{S}$ did not hold the epistemically bad doxastic attitude $\Delta$.

It is important to note that $\Delta$ could be a belief that $\mathrm{p}$, the lack of a belief that $\mathrm{p}$, or a state of withholding on $\mathrm{p}$. Furthermore, $\Delta$ 's being epistemically bad means that the belief is

\footnotetext{
${ }^{34}$ Alston (1988) writes: "we might still be held responsible for [the beliefs], provided we could and should have prevented them; provided there is something we could and should have done such that if we had done it we would not have had the attitude in question." (278)
} 
not based on evidence, not reliably formed or subject to some other negative epistemic evaluation. When I say that $\Sigma$ would have brought it about that $\mathrm{S}$ did not hold the epistemically bad $\Delta$, I mean that $\Sigma$ would have either brought about a different doxastic attitude or that it would have brought it about that $\Delta$ was not epistemically bad. In other words, ST requires that S could have prevented or changed the negative epistemic status of $\Delta$, presumably by acquiring better evidence for $\Delta$ or the like.

Alston's account of intellectual blame clearly implies ST. On his account, blameworthiness requires that the bad belief in question would have been avoided had the agent acted differently. Thus, it was in the agent's power to prevent the holding of the bad belief. Similarly, Nottelmann's account of blameworthiness requires that the agent had it within her power to prevent the holding of the bad belief. "[The agent] enjoyed some mode of doxastic control $\mathrm{M}$ [such that] the epistemic undesirability of her holding of the belief that $\mathrm{p}$ was caused by an exercise of $\mathrm{M}$ [or] by a failure to exercise M. ${ }^{35}$ Had the agent exercised M-control in the appropriate way, the agent would not have held a bad belief.

Unfortunately, ST seems false because an agent may be so constituted that there is nothing they can do about their epistemically bad doxastic state. An agent may be so emotionally committed to a belief, for example, that no amount of evidence gathering or reflection will justify it or cause her to give it up. ${ }^{36}$ Fortunately, there is another approach to epistemic responsibility and blameworthiness that does not require the truth of ST. I call this the "epistemic duty" approach. The diagram below shows where this falls on our tree.

\footnotetext{
${ }^{35}$ See footnote 32 .

${ }^{36}$ For example, see Daniel Dennett's (1984) Martin Luther case: "I can do no other."
} 


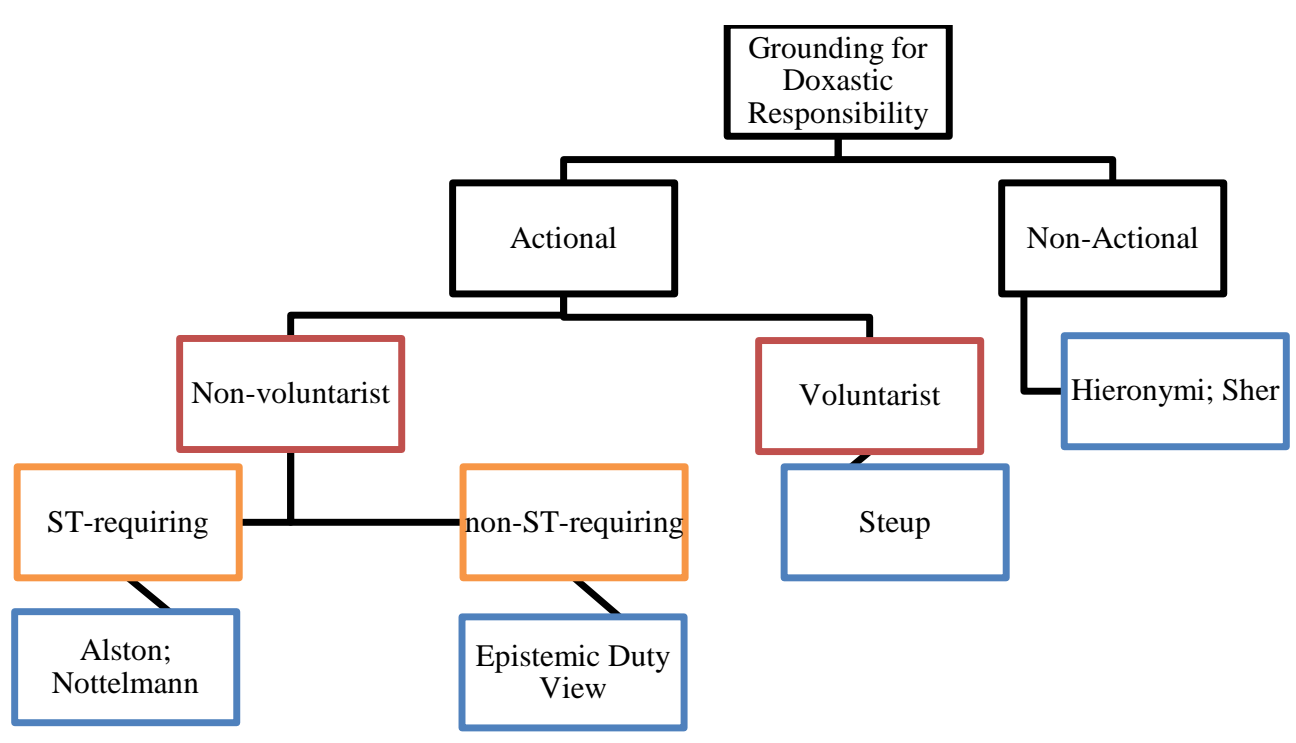

\subsection{A Proposal of My View}

As mentioned in the introduction, I wish to defend the following thesis (EB):

EB: $\mathrm{S}$ is epistemically blameworthy for their doxastic attitude $\mathrm{D}$ toward $p$ if, and only if $\mathrm{S}$ holds $\mathrm{D}$ and $\mathrm{S}$ has an unexcused, unfulfilled comprehensive epistemic duty regarding $p .^{37,38}$

In what follows, I will clarify my thesis and offer a few considerations in favor of my

view that will be developed in the following chapter. The bulk of my defense will be in

Chapter 2 because EB stands or falls on this notion of comprehensive epistemic duties.

As a preliminary, let me mention that I assume doxastic voluntarism is false, that

is, the control we have over our beliefs is not analogous to the control we have over

actions. I will offer more explanation for this assumption in Chapter 2. I will comment,

however, that my view may in fact be neutral with regard to the debate over doxastic

\footnotetext{
${ }^{37}$ Thanks to Andrew Moon, whose recent paper, "Gibbons on Internalism," provided the inspiration for this account of blameworthiness for belief. Cf. Mind (2010) 119 (473): 143-151.

${ }^{38}$ Perhaps another way we could put this is suggested by Hieronymi (in discussing your responsibility for the mess in the kitchen): "Likewise, if we hold you responsible for the perdurance of the mess-if its continued existence is taken to reflect something about your moral personality-it seems plausible to say that eliminating the mess must be something you can do by deciding to expend effort to that endsomething you can do voluntarily." So perhaps what I am concerned with is an agents responsibility for the perdurance of the belief, which the agent can certainly do something about voluntarily.
} 
voluntarism since my focus is on obligations to consider evidence and not control over beliefs.

I understand epistemic blameworthiness as analogous to, but distinct from, moral and prudential blameworthiness. Philosophers such as Trent Dougherty (and myself) hold that, intuitively, all putative cases of responsibility must fall into one of the "big three" categories of normativity: moral, prudential or epistemic. ${ }^{39}$ If this is right, then if there are cases in which an agent is clearly responsible for something bad (and thus blameworthy), but his blameworthiness is neither moral nor prudential, it may follow that he is epistemically blameworthy. I believe there are such cases. Much more will be said about this in Chapter 2, but consider the following case:

PILL: Clyde is given overwhelming evidence that his wife, Bonnie, had an affair one year ago. Clyde is also offered a pill that will erase all memory of this evidence, returning him to his previous ignorant state. Being a good consequentialist, Clyde judges that the benefits of ignorance outweigh any benefits of knowledge (he knows that his wife is now committed to total faithfulness), and he takes the pill.

Most people have the intuition that Clyde did something bad by taking the pill, that he is responsible for this bad action, and that he is thus blameworthy. But this badness seems neither moral (no other person is harmed or rights violated), nor prudential (he expects it will benefit him greatly). Moreover, the wrongness here seems to be simply a failure to achieve the truth-goal—a purely epistemic norm. Thus, the wrongness seems epistemic and this opens the conceptual space for epistemic blameworthiness.

\footnotetext{
${ }^{39}$ In Dougherty 2010, he argues as follows: "The irresponsibility alleged is that embedded in charges of 'You should have known better!' However, I argue, either there is some interest at stake in knowing or there is not. If there is not, then there is no irresponsibility. If there is, it is either the inquirer's interests - in which case it is a prudential shortcoming — or someone else's interests are at stake—in which case it is a moral shortcoming." (p.1)
} 
Here is a flow chart of my view, with explanation following:

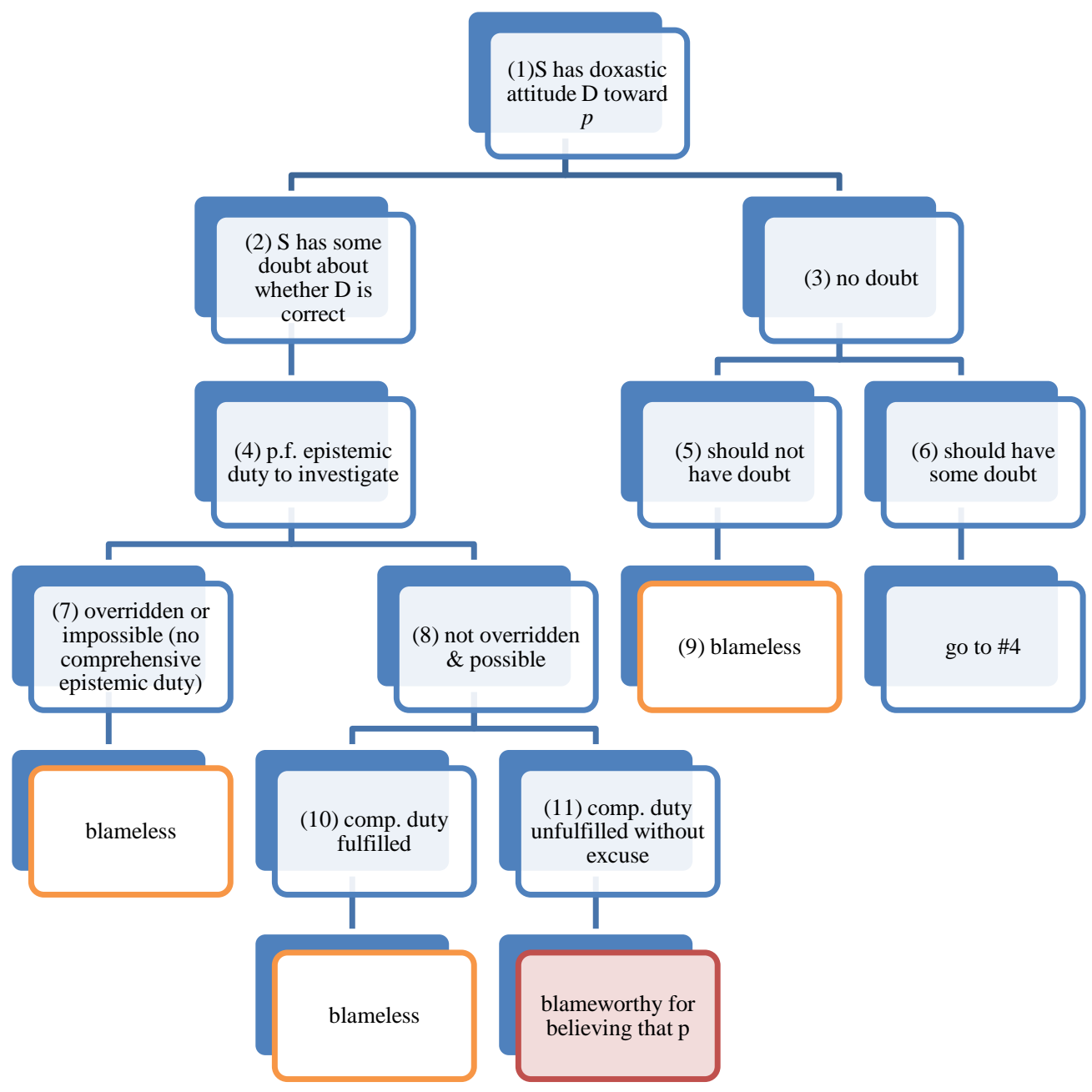

A prima facie epistemic duty is generated when the agent has some doxastic attitude D toward $p$ and has some doubt about whether D is correct. For example, suppose I believe that there is life on the moon, but later hear from a teacher that there is no atmosphere on the moon. I would (or should) now have some doubt whether my belief is correct. Or suppose that I withhold on the claim that non-terrestrial intelligent life exists somewhere in the universe, and then I learn that there are billions of lifesupporting planets. I would (or should) have some doubt about whether withholding is 
the correct stance. ${ }^{40,41}$ I will develop this further in Chapter 2. There may be nonevidential reasons to have some doubt about $\mathrm{D}$ as well, such as realizing that you have a strong desire that $p$ be true (bias toward $p$ ) or that the stakes regarding $p$ 's being true are incredibly high.

The duty that is generated in such cases is a duty to (at least try to) gather additional evidence, investigate, reflect, or otherwise reconsider one's doxastic attitude. These are the very things we think the ship-owner or the naval officer's friends should have done. And since these are obligatory actions, then we can be blameworthy for failing to do them. I take S's epistemic duties regarding $p$ to be restricted to those actions that can affect the epistemic status of S's doxastic attitude in the appropriate way. I want to rule out bizarre cases of causal deviance, such as a case in which I can improve the epistemic status of my belief that Paul is dead by killing Paul. So, 'appropriate' ways of improving the epistemic status of $\mathrm{D}$ will be attempts to adjust my mind to fit the world, and not vice-versa. The 'epistemic' nature of epistemic duties also rules out the possibility of social epistemic duties, such as the duty to help others have true beliefs. Such actions do not appropriately affect the epistemic status of my belief.

On my view, epistemic duties always start out as prima facie duties and may be overridden by other duties or nullified by impossibility. The duty becomes a

\footnotetext{
${ }^{40}$ Having some doubt about $p$ and having some doubt about my attitude toward $p$ are not the same attitude. I may have one without the other, as when I believe that $(p)$ God exists and have some doubt about $p$, but have no doubt whether my doxastic attitude toward $p$ is correct. I.e., I am convinced that the evidence heavily favors $p$ over not- $p$. However, I'm not sure it is possible to have doubt about one's attitude toward $p$ without any doubt about $p$, unless perhaps we are counting pragmatic doubts.

${ }^{41}$ By 'correct' I simply mean 'in accordance with my evidence.' To doubt that I have the right doxastic attitude toward $\mathrm{p}$ is to doubt that I am believing according to the evidence I have.
} 
comprehensive epistemic duty only if it is neither overridden nor nullified. ${ }^{42}$ If unfulfilled without excuse, the agent is blameworthy for her doxastic attitude. Excuses may be rare, since comprehensive duties are always possible to perform and have no conflicts with other duties. A young child who doubts his belief that $\mathrm{p}$ and has a comprehensive duty to investigate may not be blameworthy for failing to investigate. A man who is blameless in (falsely) believing that investigation is not possible may also be excused from blameworthiness.

Let me say a bit more here about the relation between blameworthiness and unfulfilled duties. The epistemic duty to investigate, etc. can be compared to a standing duty of beneficence. The duty of beneficence is, roughly, a duty I have to do good to others when I can as long as the costs are not unreasonable. If I see a child drowning in a shallow pond, pace Peter Singer, I can help him and the costs are minimal, then I ought to do so. At the moment I come to understand the situation and fail to try to save the child, I become morally blameworthy. I remain blameworthy just as long as this duty goes unfulfilled (and unexcused). Once I sincerely try to save the child, my blameworthiness disappears. Similarly, once I fulfill a duty to (at least try to) investigate, my epistemic blameworthiness disappears. Alternatively, if the source of my duty disappears, my blameworthiness also disappears. Perhaps the child in the pond turns out to be an illusion. Epistemically, perhaps my doubts appropriately resolve themselves (I realize that they were unfounded) or I simply lose my doxastic attitude D.

\footnotetext{
${ }^{42}$ Prima facie epistemic duties can be overridden either by other epistemic duties or by moral and prudential duties.
} 
Where my view becomes novel is in avoiding the Sufficiency Thesis (the claim that there is some action A that $\mathrm{S}$ could have performed to in order to prevent the bad epistemic state). My view is more thoroughly deontolgical in this way than those of other actional, non-voluntarist views. On my view, the potential consequences of one's investigation or reflection (or whatever action the epistemic duty requires) do not affect one's responsibility for the doxastic state. All that matters is whether one has done her epistemic duty. For example, Sara, who is very fond of conspiracy theories, became utterly convinced that Starbuck's coffee is toxic based on something she saw on a blog. After forming this belief, she failed to do any further research or reflection, despite the fact that she knew it sounded a bit far-fetched. But due to Sara's constitution and psychology, once she becomes convinced of something like this, no amount of evidence can sway her. So, even if she had investigated further, it would have made no difference regarding her belief about the toxic coffee. On my view, she is still blameworthy. ${ }^{43}$ On Alston and Nottelmann's, she isn't. I take this to be an advantage for my view.

Let me address one additional worry before moving on. Most views on epistemic blameworthiness, such as the ones above, require that the doxastic state in question be epistemically bad in some way_-false, unjustified, etc. My view makes no such explicit requirement. Implicitly, the existence of doubt in the mind of the believer does usually indicate undesirable epistemic status. The belief is something less than knowledge. But there may be cases where the agent's doubt is irrational and reveals nothing epistemically bad about the belief. For example, Peter assesses the evidence for $\mathrm{p}$ (which is objectively

\footnotetext{
${ }^{43}$ In Ch. 2 I will suggest that one necessary condition for having an epistemic duty is that investigating further would actually help $\mathrm{S}$ to better judge whether p. This is an objective notion, however. Even if Sara is psychologically incapable of changing her belief, further investigation would be helpful under normal conditions.
} 
even, for and against) and withholds on $\mathrm{p}$. But he irrationally doubts that he has the right doxastic attitude. On my view, if he fails to investigate, he is blameworthy (assuming no conflicts or impossibility) for his doxastic attitude. By way of analogy with the moral realm, my view is that if someone sincerely believes that an action is wrong, and does it anyway, he has acted in a blameworthy fashion. One ought not violate one's own conscience. Even if one simply worries that an action might be wrong but does it anyway, that person has acted in a blameworthy way. For example, suppose I am at a restaurant with Smith, and I am worried that he is an alcoholic. I just can't shake this worry, though I have no good evidence. If I proceed to order a beer (which I would ordinarily consider wrong in the presence of an alcoholic friend), I am acting in a blameworthy fashion. Similarly, if I persist in my doxastic state despite worries that I've missed something, and do nothing to rectify my worry, then my persistence is epistemically blameworthy.

\subsection{Conclusion}

To sum up, I think the view I am proposing embodies the virtues of the models already discussed above, but avoids the problems present in each. Contrary to Feldman, my view is consistent with the intuitive idea that people can be blameworthy for their beliefs and that terms like 'blame' (and perhaps even 'praise') can be appropriately applied to discussions of belief. Like Alston and Nottelmann, I do not require that an agent possess direct volitional control over the content (or properties) of their beliefs in order to be blameworthy. But unlike Alston's account, mine is not subject, so far as I know, to counterexamples involving luck. Take the counterexample to Alston I mentioned above. Alston would agree that $\mathrm{S}$ did not fulfill his epistemic obligations regarding his belief, but 
on Alston's account, $\mathrm{S}$ is not blameworthy because fulfilling said obligations would not change the agent's belief. On my view, S would be blameworthy for his belief simply because he had not fulfilled his epistemic obligations. This seems to be the correct result, intuitively. ${ }^{44}$ And unlike Nottelmann's approach, the agent's blameworthiness need not be grounded in some action or omission in the causal history of the belief or its properties. Nor is the agent required to have foresight of the consequences of her bad epistemic actions/omissions. Furthermore, my view does not rely on ST. An agent can be blameworthy or blameless for her belief that $\mathrm{p}$ even if there is nothing they could have done to avoid believing that $p$ or to alter their belief's bad epistemic status. Finally, like Sher and Hieronymi, I think agents can be blameworthy for bringing about a state of affairs even if they were not aware that they were doing so and there was no conscious choice in the causal history of the state of affairs. But while Sher and Hieronymi cannot accommodate cases of extreme indoctrination or techno-brain-tampering, my view can, as we will see in Chapter 2.

Four additional virtues are worth brief mention. First, by giving evidence a central role, my account gives blameworthiness for beliefs a clear epistemic flavor. It has been argued by some philosophers, such as Trent Dougherty, that cases of putative epistemic blameworthiness seem to be cases of either moral or prudential blameworthiness. ${ }^{45}$ But on my account, the epistemic nature of the blameworthiness is explicit and does not seem easily reduced. Second, my view completely avoids the

\footnotetext{
${ }^{44}$ Another contrast between Alston's model for doxastic blameworthiness and my own is this: Alston concentrates on the relation between fulfilling one's epistemic duties (call this F) and the belief (B) that results, while I focus solely on the fulfilling of the epistemic duties (F). So for Alston, blameworthiness depends on the obtaining of a certain relation between $\mathrm{F}$ and $\mathrm{B}$, while for me, blameworthiness depends finally on $\mathrm{F}$ alone.

${ }^{45}$ See Trent Dougherty, “Reducing Responsibility: An Evidentialist Account of Blame,' European journal of Philosophy, Volume 20, Issue 4, pages 534-547, December 2012.
} 
debate over doxastic voluntarism which has been a major factor, in my view, in preventing progress on the topic of blameworthiness for belief. My view avoids this problem because it does not require that agents have any control whatsoever (direct or indirect) over their beliefs. Once an agent has fulfilled her comprehensive epistemic duties regarding $p$ and appropriately extinguished her doubts, her obligation is satisfied and she is exonerated from blameworthiness no matter what the doxastic outcome- even if the belief is false and unjustified. Third, my view is neutral on whether the doxastic state in question must be 'bad' in order for S to be blameworthy in holding it. My view leaves open the possibility that $\mathrm{S}$ may have a reasonable, true belief and yet still have an unexcused, unfulfilled duty to investigate (making $\mathrm{S}$ epistemically blameworthy). This is because I may have good reasons for believing some true $p$, but still have some doubts about $p$. In any case, I don't see any reason to insert such a requirement into my thesis at this juncture. Finally, my view is far simpler than those described above. I have only two conditions for epistemic blameworthiness, one of which does nearly all the work. 


\section{CHAPTER 2: EPISTEMIC DUTIES}

\subsection{Introduction}

Kevin believes that the evolutionary theory of common descent is false and this belief about evolution is bad (epistemically speaking). That is, he has no good reasons for holding it. If asked, he becomes flustered and angry, but can't even tell you why he rejects the theory. Coincidentally, Kevin lives in a house with three intelligent biology majors, and the house is overrun with books and periodicals giving evidence for common descent. Every night, while Kevin plays video games, his roommates sit around the dinner table and discuss this evidence. Intuitively, Kevin seems to be acting irresponsibly by failing to look into the evidence surrounding him. He is failing to do his epistemic duty. Philosophers such as Mark Nelson (2010) and Trent Dougherty (2010) have argued, however, that we have no epistemic duties. If this is right, then why are we critical of Kevin?

In Chapter 1 I argued for the following thesis: (EB) an agent is epistemically blameworthy for her doxastic attitude D toward p if and only if she holds D and has an unexcused, unfulfilled comprehensive epistemic duty regarding $p$. Crucial to EB, though, is the claim that there are such things as epistemic duties. In this chapter, I argue for and defend the claim that agents sometimes have epistemic duties. In section 2.1, I offer an intuitive case for the existence of epistemic duties. In section 2.2, I offer a positive argument for ED and respond to objections. In 2.3, I consider an argument against ED from Richard Feldman and offer two replies. Finally, in 2.4, I briefly outline the conditions under which we would have an epistemic duty.

\subsection{The Intuitive Case for Epistemic Duties}


The claim that we have epistemic duties is controversial, and many reject it outright because they think that epistemic duties could only be duties to believe (or not to believe) in a certain way. ${ }^{46}$ But this neglects the possibility that epistemic duties could be duties to act (or not act) in a certain way—actions that are not themselves instances of belief formation. What I intend to show is that there are cases where it seems, intuitively, that agents ought to act in a certain way, and that this 'ought' is neither moral nor prudential, but rather epistemic. I take these 'oughts' to be epistemic because they involve situations where the only things at stake are objects of epistemic value (e.g., truth and rationality).

Finally, I suggest that it is a small and plausible step from a true epistemic ought-claim to a true epistemic duty-claim.

Consider the following thought experiments.

BIRD: Two avid bird-watchers, Jack and Jill, who take one another to be peers regarding bird-identification, see a yellow bird at a distance without binoculars (although Jack has binoculars in his bag). Jack believes rationally that it is a canary, but Jill points at the yellow bird and exclaims, "Look at that lovely goldfinch!" Jack hears Jill clearly, but maintains his firm belief that the yellow bird is a canary, and simply turns to look for other birds in a new direction.

PILL: Clyde is given overwhelming evidence that his wife, Bonnie, had an affair one year ago. Clyde is also offered a pill that will erase all memory of this evidence, returning him to his previous ignorant state. Being a good consequentialist, Clyde judges that the benefits of ignorance outweigh any benefits of knowledge (he knows that his wife is now committed to complete faithfulness), and he takes the pill. ${ }^{47}$

THEO: Theo has believed in God since he was young, but is not aware of any good reasons for his belief. He meets Alvin, a philosopher who has written extensively on evidence for God's existence, and Alvin offers to meet him for lunch and explain his research. Theo declines, saying that faith doesn't need reasons.

In each of these cases, the agent acts in a way that seems undesirable, to varying degrees.

Intuitively, we think that Jack ought to at least pull out his binoculars and look more

\footnotetext{
${ }^{46}$ Mark T. Nelson, "There Are No Positive Epistemic Duties," Mind 2010.

${ }^{47}$ Thank to Matt McGrath for the suggestion in parentheses.
} 
carefully at the bird. Similarly, in PILL, there's some sense in which it is bad for Clyde to erase evidence from his memory. And in THEO, we find ourselves disapproving of Theo's irrational disdain for evidence. There is something intuitively wrong in all four cases. But is this wrongness an epistemic wrongness? That is, is the kind of norm in play here a distinctively epistemic norm $?^{48}$

Claims that employ terms like 'ought' and 'should' are typically moral or prudential claims, but are sometimes concerned with other kinds of norms. Usually, it is not difficult to determine the sort of norm in play. 'Clark ought to share his Legos with his brother' is probably a moral claim. 'Phoebe should put the spoon to the right of the plate when she sets the table,' is clearly an appeal to a norm of etiquette. But sometimes, as in Jack's case in BIRD, it is not clear what sort of norm is being violated. Perhaps a few rough 'rules of thumb' for identifying norms would be helpful. Moral oughts are those that involve obligations to help and not to harm other persons. (roughly). For example, "Clark ought to stop teasing his brother." Prudential oughts are those involving obligations to ourselves —obligations to help and not to harm ourselves (roughly). E.g., "Julia ought to brush her teeth more thoroughly." However, in the case of Jack, investigating the identity of the yellow bird doesn't seem to involve any obligation to himself or others, any more than investigating the number of stars in the universe does. One could suggest that gaining any new bit of knowledge, no matter how small or trivial, "helps" Jack prudentially. But while I can affirm the inherent value of knowledge, I do not think the acquisition of tiny bits of trivia confers enough benefit to generate a

\footnotetext{
${ }^{48}$ Another interesting case of apparent epistemic duty is discussed by Suzanna Siegel in her paper "Cognitive Penetration and Perceptual Justification." On p. 217, she talks about situations in which we ought to "double check" the belief we have formed.
} 
prudential obligation to pursue them. Perhaps this is because the prudential benefit ${ }^{49}$ gained in acquiring the bit of knowledge is not equal to the energy or time required to pursue it. So, it seems that the 'ought' in Jack's case is neither a moral nor a prudential 'ought. ${ }^{50}$ I have not quite shown that the 'ought' is epistemic, but we have eliminated to major competitors.

On the contrary, Trent Dougherty (2010) claims that these cases must be reducible to moral or prudential oughts. He thinks, like Feldman, that the only thing that matters epistemically is whether your beliefs fit your evidence. Any other concerns about what an agent should or should not have done will end up being non-epistemic. Dougherty thinks that epistemic evaluation applies to beliefs only and that "it's the behavior that's properly blameworthy." ${ }^{, 51}$ I think this is where Dougherty goes wrong. Actions (behaviors) are not the objects to which blameworthiness properly attaches. Rather, it is agents that can be blameworthy or praiseworthy, and they are blameworthy or praiseworthy in virtue of some state of affairs or action. The kind of blameworthiness we attribute to the agent corresponds to the state of affairs or action in question: moral blameworthiness for morally wrong actions, etc. Dougherty mistakenly tries to carve up the landscape by putting beliefs on one side of the line and actions on the other. Instead, we ought to simply divide the landscape into good and bad, cutting across beliefs, actions, etc. Then we assess responsibility and assign blame or praise (of the corresponding kind) to the agent accordingly. On my view, agents are epistemically

\footnotetext{
49 "Prudential benefit" can be understood as either physical, emotional, psychological or spiritual benefit to oneself. Merely having an additional bit of trivial knowledge about the number of stars in the universe doesn't seem to confer any benefit of these sorts.

${ }^{50}$ One might wonder whether there is a norm of bird watching that Jack is violating, as opposed to an epistemic norm. But this seems to be over-specifying norm types. I think the best approach is to find as many 'natural' norms as possible and see if any alleged norm is actually a species of a natural norm.

${ }^{51}$ Dougherty (2010), p. 5.
} 
blameworthy when they hold a certain doxastic attitude and have failed to perform their epistemic duty regarding that attitude. Once we clear up this confusion we can open up the conceptual space for epistemic blameworthiness.

Are there positive reasons to think the above cases feature violations of epistemic 'oughts?' Perhaps the cases reflect our intuitive ideas about epistemic norms. What are these intuitive ideas? William Alston writes:

What distinguishes epistemic principles from moral principles? Well, the "epistemic point of view" is characterized by a concern with the twin goals of believing the true and not believing the false. ${ }^{52}$

Other philosophers have characterized the "epistemic point of view" differently, but in a way that is consistent with Alston's, I think. Richard Feldman thinks that the "epistemic point of view" is characterized by a concern with the goal of believing according to one's evidence, or believing rationally. ${ }^{53}$ For now, I will simply point out that Feldman's view is not necessarily inconsistent with Alston's because we can understand rational belief as being instrumental to the goal of believing the true and not believing the false. We want to have beliefs supported by evidence because we think this is a great way of getting true beliefs rather than false ones. But regardless of which goal is more fundamental, I am happy to admit that we have both intuitions, and that we can combine the goals by saying that the "epistemic point of view" is characterized by a concern for both truth and rationality, i.e. knowledge, and epistemic goods are those things that are knowledgeconducive (roughly). ${ }^{54}$

\footnotetext{
${ }^{52}$ William Alston, “The Deontological Conception of Epistemic Justification,” Philosophical Perspectives, Vol. 2, Epistemology (1988), p. 258.

${ }^{53}$ See Richard Feldman, "Modest Deontologism in Epistemology," Synthese (2008) 161:347-52.

${ }^{54}$ I will defend this claim in the next two sections.
} 
So, are the norms in play in the above cases examples of epistemic norms, as I have construed 'epistemic?' I think it is clear that they are —or at least that the primary norms in play are epistemic ones, whatever other norms might be in play. If so, then I think we can move from merely saying that 'Jack ought to investigate the bird's identity' and 'Clyde shouldn't take the pill' to saying 'Jack epistemically ought to investigate the bird's identity' and 'Clyde epistemically shouldn't take the pill.' So there are epistemic oughts.

But even if there are epistemic 'oughts,' it may not follow that these are instances of epistemic duties (which is what we're after). I take the claim that $S$ has a duty to $A$ to be weightier than the claim that Sought to do A. Certainly it is true that if I have a duty to A, then I ought to A, but what about: if I ought to A, then I have a duty to A? Perhaps we could simply adopt this entailment relation for epistemic duties, i.e.:

$\mathrm{D}_{1}$ : If S epistemically ought to A, then S has an epistemic duty to A.

However, there are good reasons to reject this entailment claim. It is a plausible principle that we cannot have duties to perform impossible tasks. With this in mind, consider the following case. Smith believes that $p$. But Smith then acquires excellent evidence for not- $p$, and he can see that it is excellent evidence, and he has no defeaters for not- $p$ or for his new evidence. Plausibly, Smith epistemically ought to believe that not- $p$. However, it is not in Smith's direct, voluntary control to stop believing that $p$ and start believing that not- $p$. That is, believing is not an action. Thus, Smith epistemically 'ought' to shift his doxastic state to not- $p$, but he does not have an epistemic duty to do so. ${ }^{55}$

\footnotetext{
${ }^{55}$ See Feldman, 2001.
} 
So $\mathrm{D}_{1}$ seems false. Epistemic oughts can only become epistemic duties if they involve actions the agent can perform. The cases above (BIRD, PILL, etc.) seem to be just these kinds of scenarios. They are cases in which an agent epistemically ought to A, and $\mathrm{A}$ is an action that the agent can perform. So, a more plausible claim would be:

$\mathrm{D}_{2}$ : If $S$ epistemically ought to $A$, and $A$-ing is an action that $S$ can perform, then $S$ has an epistemic duty to A.

Let us call actions that we epistemically ought to perform actional epistemic oughts. $\mathrm{D}_{2}$ claims that actional epistemic 'oughts' are epistemic duties. As a general principle of duty, this would be too strong. Intuitively, there are many things that would be (epistemically or otherwise) good for me to do — that I, in some sense ought to do- - but are not full-fledged duties for me. For example, it would be good for me to pick up every piece of litter in my city, and in some sense I ought to do this. But if someone said it was my duty, I would think them crazy. I ought to chew my food more, but I don't think this is a duty. Additionally, one might worry that $\mathrm{D}_{2}$ would generate a host of trivial epistemic duties - we would be required to investigate ad infinitum. I probably have thousands of beliefs that could epistemically benefit from more evidence or research. So, if the idea of epistemic duties is going to be plausible, it needs to be limited in some way.

I can see two ways in which one's epistemic duties could be limited. Within the epistemic domain, there might be a ranking of epistemic importance that would allow some epistemic oughts to override others, so that we are not required to investigate multiple beliefs at the same time. One way to think of this is to adopt W. D. Ross' idea of prima facie duties. According to Ross, prima facie duties are real duties or 
responsibilities which can be overridden by other, weightier duties. ${ }^{56}$ Prima facie duties which are not overridden by other duties are absolute (or ultimate, as I will call them) duties. Roughly then, we could say that every actional epistemic ought does generate a prima facie epistemic duty, but that only a subset of them are ultimate epistemic duties. When prima facie duties within the epistemic domain conflict in some way, there could be a hierarchy or method for deciding which ones are binding and which may be set aside or ignored.

The second way in which epistemic duties could be reigned in is to allow moral and prudential duties to override them as well. On this sort of view, we might weigh moral, prudential, epistemic, etc. duties against one another, and thus determine what our comprehensive epistemic duties are. The prima facie epistemic duty that survives the gauntlet becomes the comprehensive epistemic duty in a given situation.

One worry raised by Richard Feldman here is that we simply cannot weigh these different norms against one another in any meaningful way. There is what we epistemically ought to do, and there is what we morally ought to do, but there is no just plain ought. ${ }^{57}$ Feldman does mention a challenge to his view offered by Stewart Cohen (in conversation):

Suppose a child comes to her parents with a problem. She is contemplating some action and she's figured out that it is the prudent thing to do but not the moral thing to do. In other words, she realizes that she prudentially ought to do it, but she morally ought not do it. She asks, "What ought I do?" She is clearly looking for a way to resolve the apparent conflict. ${ }^{58}$

\footnotetext{
${ }^{56}$ Anthony Skelton, Stanford Encyclopedia, 2012.

${ }^{57}$ Feldman, 2000, p. 693-4.

${ }^{58}$ Ibid, 694.
} 
Feldman admits that we would be tempted to give advice here, and I agree. While I don't have the space to argue for the commensurability of norms, I will simply appeal to the intuition that most of us have that there is an answer to the child's question. We often think that our duties to other people trump duties to ourselves or other norms. For instance, it seems clearly right for me to sacrifice sleep in order to care for my baby in the middle of the night. This is what I ought to do. It seems odd to say that it remains true, in any sense, that I ought to go back to bed and ignore my baby's cries. Such examples show that in some cases, when we ask the general "what ought I to do?" question, there is an answer. I take this to be evidence that Feldman's view - that there is never such an answer-it incorrect. This does not amount to a substantial argument for all things considered oughts, but it seems plausible enough to proceed.

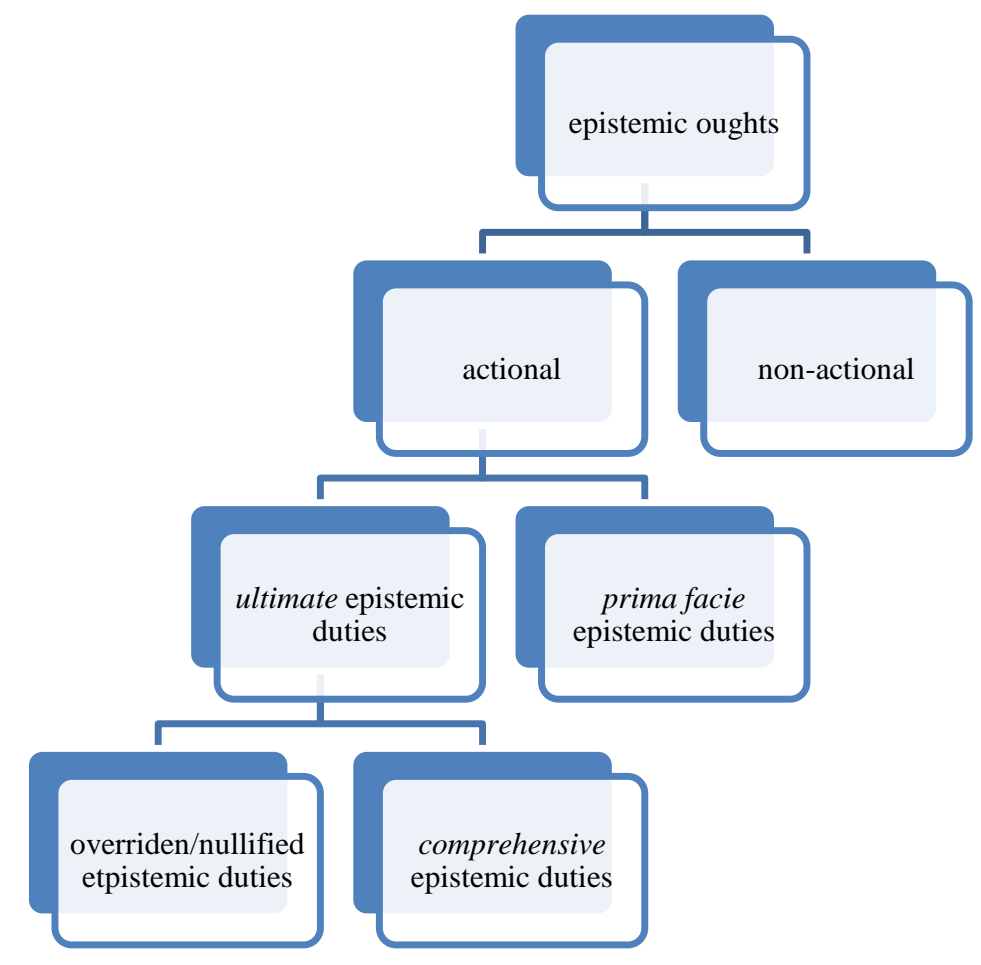

So, to sum up thus far, there are cases in which an agent ought to do something, but this 'ought' is neither moral nor prudential. The 'oughts' in such cases are best 
understood as epistemic. Furthermore, when an epistemic 'ought' (e.g., S ought to investigate whether $p$ ) is an action that an agent can perform, that agent has a prima facie epistemic duty to perform that action. Prima facie epistemic duties which are not overridden by any other epistemic duties are ultimate epistemic duties for us. ${ }^{59}$ Ultimate epistemic duties which are not overridden by moral or prudential duties are comprehensive (epistemic) duties. It is these comprehensive duties which are binding on us, and we can be blamed or praised for either shirking or fulfilling them, respectively. Having given an intuitive case for epistemic duties, in the sections below, I offer several formal arguments for the claim that we sometimes have epistemic duties.

\subsection{First Argument for Epistemic Duties}

Richard Feldman suggests that one way to explain why we ought to do something "is to show that it is a means to some valuable result." ${ }^{.60}$ Why should I take a Tylenol? Because it will reduce my pain, and this is a valuable goal or result. So, if $\mathrm{X}$ is a means to valuable result $\mathrm{Y}$, then you ought to try and do or bring it about that X. Richard Hall and Charles Johnson go a bit further, using the term 'duty:' "if you accept a goal G, and action $A$ is the best way of achieving $G$, then there is a sense in which you ought to do A. . A is a duty relative to G. ${ }^{, 61}$ This seems about right, with one difference. I do not think that one must accept the valuable goal as her own in order to have a duty to achieve it.

\footnotetext{
${ }^{59}$ Roderick Chisholm takes epistemic duties to have lower priority than moral and prudential duties, and this seems correct. For example, suppose that if I have a doubt about my belief that tonight is the Leonid meteor shower, I have a prima facie epistemic duty to seek out the truth about this. But suppose at the same time, I have a prima facie moral duty to visit my sick child in the hospital. Assuming that I cannot fulfill both duties, I should fulfill the moral duty and set aside the epistemic duty. For more, see Chisholm's Theory of Knowledge, 1989.

${ }^{60}$ Richard Feldman, "The Ethics of Belief," Philosophy and Phenomenal Research, Vol. LX, No. 3, May 2000 , p. 682.

${ }^{61}$ Richard J. Hall \& Charles R. Johnson, “The Epistemic Duty to Seek More Evidence,” American Philosophical Quarterly, Vol. 35, No. 2, April 1998, p. 129.
} 
Hall and Johnson echo my case in section 2.1 by implying that for A-ing to be a duty, Aing must be something the agent can $d o$. So, if I am to show that there are epistemic duties (Xs), then I need to show that they are means to a valuable epistemic goal (Y). ${ }^{62}$ But what would be an epistemically valuable goal?

While pain-reliever certainly possesses prudential value, and many would assign moral value to things like happiness or justice, what things have epistemic value? One intuitive candidate is truth, or to be more precise, believing the truth and avoiding error. We sometimes care about truth for moral or prudential reasons, but there are cases in which we care about truth for its own sake. A man in Oregon who lives near a disputed site of Sir Francis Drake's landing in America (the competing site is in California), when asked why he has invested enormous personal resources to prove the case, replied, "Because it's the truth." 63 In other cases, we want to know the correct sum or the right answer to some question of history simply because of our curiosity and our distaste for believing falsehoods. One powerful reason for rejecting Nozick's Experience Machine is because the experiences one would have if one plugged into it would not be veridical or true. And while true belief may be instrumentally valuable in some cases, it is not so in all cases. When it is simply valued for itself, I take this to be epistemic value.

So if truth is epistemically valuable, then we have at least a prima facie duty to do what we can to secure it. And there are clearly some cases in which we can do something to bring ourselves closer to knowing the truth. When I withhold on a proposition, investigating (e.g., gathering more evidence) can help me to either believe the proposition

\footnotetext{
${ }^{62}$ For this argument, I am assuming a kind of instrumentalism regarding duties. Since my primary interlocutor is Feldman (and perhaps other evidentialists), and they assume this as well, I wanted to construct an argument "on their turf," so to speak.

${ }^{63}$ http://www.npr.org/2012/06/17/155194143/states-stake-claim-on-sir-francis-drakes-landing
} 
if true or disbelieve it if false. Presumably, as I gather more evidence, it may become increasingly clear whether $\mathrm{p}$ is true or false, and my doxastic attitude toward $\mathrm{p}$ will very likely adjust accordingly. ${ }^{64}$ Believing rationally may also be a means to believing truth and avoiding falsehood — it is certainly a (generally) truth-conducive practice — but as Feldman points out, 'believing' is not an action (on the standard view), and thus not a candidate for being a duty. ${ }^{65}$ So, it follows that, in some cases, we have a prima facie duty to investigate.

Formally:

1. If doing $\mathrm{A}$ is an effective means toward some valuable $\mathrm{x}$-ish goal and I have not yet reached that goal, then I have at least a prima facie $\mathrm{x}$-ish duty to do A. ${ }^{66}$

2. In certain cases ${ }^{67}$, investigating ${ }^{68}$ whether a proposition $p$ is true is an effective means toward the valuable epistemic goal of believing truth and avoiding falsehood.

3. So, in certain cases, if I have not yet believed the truth or avoided falsehood with regard to $\mathrm{p}$, then I have at least a prima facie epistemic duty to investigate whether $\mathrm{p}$.

In his book, Knowledge in a Social World, Alvin Goldman offers a more precise explanation of why investigation/gathering more evidence may be epistemically required at times. Goldman takes believing truth and avoiding falsehood as the (two-pronged) fundamental epistemic goal, just as I have suggested above. ${ }^{69}$ He then assigns value to

\footnotetext{
${ }^{64}$ This is by no means guaranteed, but it seems very likely. For more on this, see Hall \& Johnson, 131ff. ${ }^{65}$ Ostensibly, $\mathrm{X}$ is a duty only if $\mathrm{X}$ is an action.

${ }^{66}$ One need not know that A-ing is an effective means. The prima facie duty is generated by the objective fact. Ignorance could, however, prevent the prima facie duty from becoming a comprehensive duty. (It could be an excuse.)

${ }^{67}$ I add the phrase 'in certain cases' because there may be cases where no additional evidence is available, no additional evidence would help, or investigation is impossible.

${ }^{68}$ I will use "investigate whether p" as roughly interchangeable with "gather additional evidence for p." More precisely, 'gathering evidence' is probably a species of the genus 'investigating.'

${ }^{69}$ Goldman, Alvin, Knowledge in a Social World, p. $3 \mathrm{ff}$.
} 
various doxastic states on this basis. ${ }^{70}$ Taking $\mathrm{p}$ to be some true proposition, he assigns believing $p$ a value of 1 , withholding on $p$ a value of .5 and rejecting $p$ a value of 0 . Similarly, if $\mathrm{p}$ is false, then rejecting $\mathrm{p}$ has a value of 1 , withholding a value of .5 and believing a value of 0. (89) So, if we ought to maximize epistemic value (as Feldman suggests), then we shouldn't settle for a stance of withholding on any proposition because withholding does not maximize epistemic value, assuming that every proposition is either true or false. That is, I should not settle for a resulting value of .5 when I have some available means to achieve a resulting value of $1 .^{71}$ If I ought to maximize epistemic value, then it seems that I ought to try and find out whether $\mathrm{p}$ is in fact true or false, and then believe or reject it. ${ }^{72}$

Before proceeding, let me add one caveat. What I have argued above suggests that we may often have epistemic duties without knowing that we do. If our ignorance is blameless, this may count as an excuse for failing to investigate. In sections 2.3 and 2.5, I offer other arguments and conditions that generate duties that we know about. The cases described in 2.5, for instance, all involve an agent having some doubt about their doxastic state. In such a case, the agent would be aware of the factors generating the prima facie duty to investigate, and the ignorance excuse is unlikely to apply.

\subsection{Second Argument for Epistemic Duties}

\footnotetext{
${ }^{70}$ Goldman calls this kind of value "veritistic value" rather than epistemic, but this shouldn't matter too much for our purposes.

${ }^{71}$ Certainly there are some propositions that we ought to withhold on, but on my view, we shouldn't settle for such a position. We (prima facie) should continue investigation, all things being equal, until we can rationally believe or deny the proposition.

${ }^{72}$ See also Hall \& Johnson, 1998. Hall and Johnson do not assign values as Goldman does, but they do argue that given the fundamental epistemic goal (a la Chisholm) of "trying our best to bring it about that we believe $\mathrm{h}$ iff $\mathrm{h}$ is true," withholding is never a satisfactory attitude to take toward a proposition. (pp. 130132)
} 
In the previous section, I argued for the existence of epistemic duties on the assumption that believing truth and avoiding falsehood is an epistemically valuable goal. As we will see in later sections, evidentialists such as Richard Feldman reject this assumption. So, in this section, I argue that agents sometimes have epistemic duties due, in part, to the fact that having rational doxastic attitudes is epistemically valuable.

Suppose we take the valuable goal of having rational beliefs (doxastic attitudes supported by my evidence, roughly), and identify actions which are means to achieving that goal. Assuming that we all have this goal, it should turn out that we have a prima facie duty to perform those actions. For example, suppose I believe that (p) the polar icecaps are melting, but currently have no evidence for this belief. I have not yet achieved the epistemic goal of having a rational doxastic attitude with respect to $p$. Is there an action I can perform — an action within my direct, voluntary control—-that will help me achieve my epistemic goal? I do not think it is within my direct, voluntary control to adjust my doxastic attitude, perhaps to a state of withholding on $p \cdot{ }^{73}$ But rather than adjust my doxastic attitude to fit my current evidence, perhaps I can indirectly achieve evidential fit by gathering additional evidence. Gathering evidence for $p$ certainly seems within my direct, voluntary control. Thus, unless there is a better means available to me, I have an epistemic duty to gather evidence.

Consider an illustration. MOSES: Suppose that Moses rationally believes in God, but has never heard about the problem of evil. Lucy gives Moses an atheistic argument from evil, and Moses now has some serious doubts about his belief in God. If

\footnotetext{
${ }^{73}$ As I explained in Ch.1, I assume that doxastic voluntarism is false. Other philosophers, such as Alston (1988) and Feldman (2000), have given excellent arguments for this claim, so I won't endeavor to do so here.
} 
Moses' goal is to have rational doxastic attitudes, it seems that there are at least two different means to this goal available to him. (A) Moses can simply lower his confidence in God's existence such that he ends up withholding on the proposition, "The Hebrew God exists.” Or (B), Moses can seek out additional evidence for his belief in God that would restore his belief to its previous rational status, while in the meantime either maintaining his belief or withholding. Choice (B) seems like a perfectly acceptable way for Moses to try and bring it about that he has a rational attitude regarding the proposition in question. Not only that, but assuming a lack of direct control over beliefs, it seems like the only way.

At the risk of overkill, I offer a formal argument below. This seems the best way to walk through the argument carefully and clearly.

1. We have prima facie $\mathrm{x}$-ish duties to perform actions which are the means toward an x-ishly valuable goal. (Premise)

2. Having rational doxastic attitudes is an epistemically valuable goal.

3. A doxastic attitude is rational for $\mathrm{S}$ iff it is supported by $\mathrm{S}$ 's evidence. (Evidentialist assumption)

4. Thus, having attitudes supported by S's evidence is an epistemically valuable goal for S. (Substitution 2,3)

5. In some cases where we currently hold an attitude not supported by our evidence, the only possible means to having attitudes supported by our evidence are either gathering additional evidence for our current attitude or adopting a different doxastic attitude (or both). (Premise)

6. Thus, in these cases, we have a prima facie epistemic duty to either gather additional evidence for our current attitude or adopt a different doxastic attitude. (MP 1,5)

7. We cannot directly bring it about that we adopt a new attitude, but we can bring it about that we gather additional evidence. (Assumption of Doxastic Nonvoluntarism)

8. Thus, in these cases, we have a prima facie epistemic duty to gather new evidence. (DS 6,7)

Premise (2) is uncontroversial, especially given the assumption that rationality is knowledge-conducive. (Recall that in section 2.1 I claimed that epistemic goods are 
those things (roughly) which are knowledge-conducive.) Note that (2) says nothing about truth and is perfectly consistent with the epistemic goal of having all and only true beliefs.

Premise (3) is certainly controversial, but I am content to make this particular argument contingent on the truth of Evidentialism, since the primary opponents of ED are evidentialists. Premise (5) seems to exhaust the options for someone who currently holds a doxastic attitude which is not supported by her evidence. The valuable goal is rational belief, which is a state involving exactly two relata: (i) a belief and (ii) a body of evidence possessed by the believer. It seems that in order to achieve the desired state of rational belief (belief supported by evidence), one must either do something to adjust (i) or (ii) or both. So, if S currently holds an attitude toward a proposition $p$, but that attitude is not supported by her evidence, and she wants to bring it about that she holds an attitude supported by her evidence, then she can either adopt the attitude that is supported by her evidence or gather additional evidence until she has adequate support for her attitude (or she can do both). I prefaced the claim with the phrase "in some cases" to weaken it a bit, but it should still get us what we need.

One might object by suggesting an alternative action: gathering evidence against $p$. If I can gather good, new evidence against $p$, I might bring it about, indirectly, that I give up my belief in $p$. This would result in, presumably, my no longer holding a belief unsupported by evidence. However, this does not provide a true alternative because I would still be gathering new evidence, whether for or against $p$. 
Since (in at least some cases) these are the only available means toward the epistemically valuable goal of having a rational doxastic attitude, then it seems that an agent who finds herself in such a case would have a duty to exercise one or both of these means. However, adopting a different doxastic attitude is not in our direct, voluntary control. And while ought-claims do not require such voluntary control, duty-claims do. Thus, for any agent, it is false that they have a duty to adopt a different doxastic attitude toward some proposition $p$. And if this is correct, then by elimination, an agent who finds herself in a situation where her current attitude toward $\mathrm{p}$ is not supported by her evidence has a prima facie epistemic duty to gather more evidence.

Below, I explore what I take to be the most serious objection to my First Argument. I attribute it to Richard Feldman, but it is shared by other evidentialists as well. The objection is to premise (2). Precisely, Feldman rejects the claim that believing truth and avoiding falsehood is an epistemically valuable goal. Below is his line of argument followed by several responses.

\subsubsection{Feldman's Objection}

Feldman (2000) proposes three possible views about what is epistemically valuable: (a) Only believing truths \& avoiding falsehoods is epistemically valuable; (b) only knowing is epistemically valuable; and (c) only believing rationally is epistemically valuable (where 'rationally' is broadly construed as something akin to having evidence for one's beliefs or being epistemically justified). First, Feldman evaluates each candidate by asking whether it would serve as a good premise in an argument for his thesis about what one epistemically ought to do. His thesis is: 
O2: "For any person $\mathrm{S}$, time $\mathrm{t}$, and proposition $\mathrm{p}$, if $\mathrm{S}$ has any doxastic attitude at all toward $\mathrm{p}$ at $\mathrm{t}$ and $\mathrm{S}$ 's evidence at $\mathrm{t}$ supports $\mathrm{p}$, then $\mathrm{S}$ epistemically ought to have the attitude toward p supported by S's evidence at t." (679)

He refers to this thesis as "O2"- I will adopt this nickname. So, Feldman shows quite easily that (a) and (b) will not support O2, leaving only (c). But of course, what we want is an argument for the claim that (c) is the only thing that is epistemically valuable, regardless of its logical relation to O2. Feldman offers little here. He writes:

While true beliefs may have considerable instrumental value, a person who irrationally believes a lot of truths is not doing well epistemically. In contrast, a person who forms a lot of rational but false beliefs is doing well epistemically. While knowledge also has a kind of value, seeing it as the only thing of epistemic value fails to explain what is valuable about forming beliefs that fall short of knowledge. We avoid the problems associated with identifying epistemic value with true belief or with knowledge if instead we say that what has epistemic value are rational beliefs. (685)

So, on Feldman's view, the real locus of epistemic value is rational belief. But his argument relies on a peculiar claim that rational false belief is "epistemically" better than irrational true belief. Below, I examine this claim.

\subsubsection{Reply to Feldman's Objection}

Is it true that an irrational true believer isn't doing well "epistemically?" This is difficult to assess because the term 'epistemically' is unclear. Below I attempt to pinpoint the term's meaning and show that Feldman's argument is unsound on any plausible interpretation of 'epistemic.'

Let Ira be the person who has irrational true beliefs, and Rat be the person who has rational false beliefs. (Feldman thinks that Rat is doing better epistemically than Ira.) Now consider the following dilemma ${ }^{74}$ : by 'epistemically,' Feldman either means,

\footnotetext{
${ }^{74}$ Thanks to Andrew Moon for suggesting that I put this in dilemma form.
} 
'rationally' or he means something else. ${ }^{75}$ If he means 'rationally,' then his claim that Ira “isn't doing well epistemically" is trivial. So perhaps this isn't what Feldman means.

But if he means something else, then I can show that either Ira isn't doing well or Rat is doing well s false. Let's consider a few alternative meanings for 'epistemically.'

Suppose by 'epistemically' Feldman means (i) “with regard to attaining knowledge.” But then Feldman's claim that Ira isn't doing well epistemically seems false because Ira has at least two of the necessary components of knowledge - truth and belief - and someone with a true belief seems well on their way to attaining knowledge. We might worry that having just two necessary components of knowledge isn't enough to be "doing well epistemically," but then Rat isn't doing well either, since he also has only two necessary components of knowledge (rational belief). So, either both Ira and Rat are doing well epistemically or neither is. One could reply by saying that it isn't how many components you have, but which components you have, and rationality is better (epistemically) than truth. But that would take us right back to square one. We need some independent reason to think that rationality is epistemically more valuable than truth. Note that all I am suggesting here is that true beliefs may be just as valuable as rational beliefs.

Now suppose by ‘epistemically’ Feldman means (ii) “with regard to turning true belief into knowledge.” This seems more promising, but when we plug this interpretation into the claim that Rat is doing well, it seems false—Rat can't be doing well with regard to turning true beliefs into knowledge because he doesn't have any true beliefs.

\footnotetext{
${ }^{75}$ I take this to be a plausible interpretation given Feldman's earlier claims that what agents epistemically ought to do is take the rational attitude toward a given proposition (if they take any attitude at all).
} 
Similarly, a chef who lacks only beef for his tasty beef stew isn't doing well with regard to turning beef into a tasty beef stew. ${ }^{76}$ So, on either proposal (i) or (ii), one of Feldman's claims (Ira isn't doing well or Rat is doing well) comes out false. And since Feldman's whole argument depends on the claim that Rat is doing well, the argument is unsound on either interpretation (i) or (ii). ${ }^{77}$ Again, I am not claiming that true beliefs are the only things of epistemic value, nor am I claiming that rational beliefs and warrant are not epistemically valuable. I am simply saying that there doesn't seem to be a plausible interpretation of 'epistemic' that clearly picks out rationality as the only thing of epistemic value.

\subsubsection{Second Reply to Feldman's Objection}

Feldman's objection to my argument for ED consists in claiming that believing truth and avoiding falsehood is not epistemically valuable. Thus, if I can provide a positive argument for the epistemic value of believing truth and avoiding falsehood, I can rebut his objection. Below, I argue for something along these lines.

Showing that some $\mathrm{X}$ is valuable, full stop, isn't easy. However, a more feasible aim is to show that we value some $\mathrm{X}$. In this section I argue that we epistemically value having true beliefs and avoiding false ones. Here's the argument:

1. If we value $X$ instrumentally as a means to $Y$, then we also value $Y$.

2. We epistemically value having rational beliefs instrumentally as a means toward having true beliefs and avoiding false ones. ${ }^{78}$

\footnotetext{
${ }^{76}$ Thanks for the suggestion here by Matt McGrath.

${ }^{77}$ I also have some worries about premise (5). If we were to suppose that knowledge was the locus of epistemic value, it wouldn't necessarily follow that beliefs which fall short of knowledge lack epistemic value. It might be that as one moves down the path from mere believing that $p$ to knowing that $p$, the epistemic value of one's cognitive state increases. Or, it could be that having true belief or rational belief have instrumental epistemic value, which is a kind of epistemic value.

${ }^{78}$ This is compatible with the claim that we value rational beliefs for their own sake as well. Thanks to Matt McGrath for pointing this out.
} 
3. So, we epistemically value having true beliefs and avoiding false ones.

Premise (1) seems uncontroversial as a principle. It can be supported by looking at prudential and moral examples of the same principle. For example, we value vaccinations as a means to good health, thus we value good health just as much, if not more, than vaccinations. We value contributing to charity as a means to social welfare, thus we value social welfare just as much as, if not more than, contributing money to charity.

Premise (2) seems right when we reflect on why we want our beliefs to be rational (supported by evidence). We think that beliefs which have good evidential support are more likely to be true than beliefs without good evidential support. We don't typically take having rational beliefs as our epistemic goal, but rather as a means to the goal of finding the truth and avoiding falsehood. This is true no matter what concept of epistemic justification one is working from. We take all of the concepts involved in epistemic justification to be more or less unified (under normal circumstances) in their truth-conduciveness. Kvanvig notes that for concepts like reliability and power, "On the standard teleological conception of justification ... these concepts are not themselves the goal of cognitive activity, but are related to the epistemic goal of finding the truth and avoiding error as means are to ends." ${ }^{, 79}$ When we consider demon-world cases in which our doppelganger is systematically deceived but is identical to us with respect to evidential fit, we might see our doppelganger as justified, but we still see their situation as unfortunate. Why? Because their epistemic excellence isn't paying off — it isn't helping them reach their epistemic heart's desire. He may still have something of

\footnotetext{
${ }^{79}$ Kvanvig 2005 VOK, p. 162.
} 
epistemic value, but not all that he could have. Just imagine the emotional reaction if our doppelganger, at the end of his life, was told the truth! That is why, even if our doppelganger suffered no negative moral or practical consequences of false belief, we would not want to trade places with him.

So, assuming that we epistemically value rational beliefs, we should think that their being instrumental to truth implies that we epistemically value truth at least as much as rationality. Now this is one step short of showing that truth just is as valuable as rationality, but it is a fairly small and safe step. What we value is a fair indicator of what is valuable - they may even be one and the same thing.

What I've shown in this section is that the epistemic value of believing the truth (and avoiding falsehood) sometimes generates an epistemic duty to investigate a question further. I have also shown that Feldman's chief objection - that truth is not epistemically valuable - relies on arguments which are unsound. Thus, we have at least one good argument for the claim that (ED) agents sometimes have epistemic duties. In the section below, I present Feldman's direct argument against this thesis and several replies.

\subsection{Feldman's Argument Against ED}

Richard Feldman, in his 2000 paper, "The Ethics of Belief," argues that agents have no epistemic duties. I take Feldman's argument, which I will call the "No Duties Argument," to go as follows (I use F1, etc. to distinguish this argument from later ones):

F1. For any person $S$, believing rationally now (in the present moment) is the only epistemically valuable state of affairs. ${ }^{80}$ (Premise)

\footnotetext{
${ }^{80} \mathrm{I}$ am using 'now' as an indexical to represent the present moment, whatever the time.
} 
F2. For any $S$, the only proper means to believing rationally now is having the doxastic attitude toward $p$ which is supported by $\mathrm{S}$ 's evidence now. (Conjunction of $1 \&$ Feldman's Rationality Thesis, 685) ${ }^{81}$

F3. So, for any $S$, the only proper means to the only epistemically valuable state of affairs is having the doxastic attitude toward $p$ supported by $\mathrm{S}$ 's evidence now. (substitution F1, F2)

F4. 'Having a doxastic attitude' is not a voluntary action. (assumption of doxastic non-voluntarism)

F5. So, for any S, the only proper means to an epistemically valuable state of affairs is not a voluntary action. (from F3, F4)

F6. For all $\Delta, \Delta$ is an epistemic duty only if $\Delta$ is a voluntary action and $\Delta$ is a proper means to an epistemically valuable state of affairs. (Premise from Feldman's view of duty)

F7. So, there is no $\Delta$ such that $\Delta$ is a voluntary action and $\Delta$ is a proper means to an epistemically valuable state of affairs. (from F5, F6 )

F8. So, there is no $\Delta$ such that $\Delta$ is an epistemic duty. (MT F6, F7)

F9. So, it is false that agents have epistemic duties. (from F8)

Before I respond to this argument, let me offer some explanation of the premises. The first premise is a variation on the conclusion of Feldman's argument in the previous section. As I understand Feldman, he wants to avoid assigning epistemic value to any future doxastic state. All that matters epistemically for $\mathrm{S}$ is the present relation between S's belief and S's evidence. F2 represents an important feature of evidentialist views like those of Feldman, Foley (1987) and Dougherty (2010). According to such views, epistemic norms are norms of synchronic rationality, i.e., all that matters epistemically is the relation between my beliefs and my evidence at any given time $t$. Synchronic rationality "concerns questions of rationality at a given moment while [diachronic rationality] concerns rationality over time.” (Feldman, 689) F4 points out that, assuming the denial of doxastic voluntarism (the view that I have direct voluntary control over my beliefs, i.e., believing is an action), the only means available to an epistemically valuable state is not an action I can perform. In F6, I suggest two plausible necessary conditions

\footnotetext{
${ }^{81}$ I call the following claim "Feldman's Rationality Thesis:” “. . . rationality consists is making one's beliefs conform to one's evidence." (685)
} 
for something's being a duty. If these conditions are acceptable, then it follows that I couldn't possibly have a purely epistemic obligation to perform any action, because the consequences of any action on the rationality of my beliefs will all occur sometime after the present moment.

\subsubsection{First Reply to No-Duties Argument}

In this section I argue that $\mathrm{F} 1$, Believing rationally now is the only epistemically valuable state, is false. Consider the following puzzling case.

SPOCK: Mr. Spock has been exposed to the spores of a mysterious plant which he knows will produce in him an irrational bias toward believing the Inflationary Universe Hypothesis tomorrow. He also knows that tomorrow he will not realize he has this bias (he's seen it happened to others). But he also knows that if he gathers certain evidence today, this evidence will overwhelm his bias tomorrow and enable him to form rational beliefs. $^{82}$

Given F1, what should Spock do now, from a purely epistemic point of view? According to F1 (and F2), Feldman would have to say that Spock should (epistemically) simply believe now according to his evidence, and should do the same tomorrow. Sadly, this will result in Spock's having (presumably) rational beliefs today and irrational ones tomorrow. On the other hand, I imagine most red-blooded evidentialists want say that Spock should go get this evidence today in hope of believing rationally tomorrow (as well as today). It is hard to see how someone who is committed to the overall goal of having rational beliefs would not, for this very reason, feel epistemically obligated to acquire this evidence. What I am suggesting is a sort of reductio-if F1 implies that we should not bother collecting this bias-preventing evidence, then F1 is false.

\subsection{When Are Epistemic Duties Generated?}

\footnotetext{
${ }^{82}$ Thanks to Matt McGrath for suggesting a case like this.
} 
Even if the case given above for the existence of epistemic duties is persuasive, there is still a worry that remains. Under what conditions, exactly, do I have an epistemic duty? Chapter 1 argued that epistemic blameworthiness occurs when I have unexcused, unfulfilled epistemic duties, but it did not say much about how or when these duties are generated. In section $2.1 \mathrm{I}$ offered a sketch of the conditions for having an epistemic duty: I claimed that if you epistemically ought to A and A-ing is an action you can perform, then you have an epistemic duty to A. But this is too general and such duties would be typically excused due to ignorance. It also might generate hundreds of epistemic duties (or more) if it is always good to have more evidence for our beliefs. In this section, I give a set of conditions for having an epistemic duty that narrow down the cases and partition off those cases that could be excused due to ignorance. I also discuss how conflicts with other duties might limit our actual number of epistemic duties.

For a start, Richard Hall and Charles Johnson ${ }^{83}$ suggest the following:

(D) For any proposition that is less than certain on one's present evidence, one has an epistemic duty to seek more evidence about that proposition. (133)

To avoid having an overly-demanding duty, Hall and Johnson qualify (D) by seeing it as a prima facie duty that can conflict with and be overridden by other duties. Thus, they ostensibly narrow down the class of propositions that we are required to investigate to a more manageable subset. While they do not discuss conflicts between epistemic duties, they do think that "most moral and prudential duties would trump [(D)] in cases on conflict." (136)

\footnotetext{
${ }^{83}$ Hall \& Johnson, 1998.
} 
A second detailed account of when agents have a duty to investigate is from Neil Levy. ${ }^{84}$ Levy's thesis: $\mathrm{S}$ has a duty to gather further evidence for her belief that $\mathrm{p}$ iff

(1) $\mathrm{S}$ believes that $\mathrm{p}$, though she is less than morally certain that $\mathrm{p}$;

(2) $\mathrm{S}$ must believe that further evidence-gathering would or could enable me to better judge whether $\mathrm{p}$; and

(3) S must believe that the (prudential and moral) costs of such evidencegathering are outweighed by the moral value of knowing whether $\mathrm{p}$.

Levy's account adds a few details, but it is roughly in the same spirit as Hall's \&

Johnson's, though Levy seems to blur the distinction between epistemic and moral

norms. One worry is that both accounts lack a non-subject-sensitive criteria to determine when an individual has a duty to investigate. That is, agents might not doubt when they should, and agents might misjudge the costs of investigating.

I've already argued in section 2.2 that $\mathrm{S}$ has a prima facie duty to investigate simply in virtue of the fact that he has not yet believed the truth or avoided falsehood regarding $p$. So whether $\mathrm{S}$ is certain or doubting or even aware of the proposition in question is irrelevant, on such an argument. As I mentioned above, in such cases the agent may very well have an excuse for failing to investigate, assuming they are not culpable for their ignorance. But there are other kinds of cases where S has some doubt about her doxastic state, and in these cases, $\mathrm{S}$ will be aware of the factors generating his duty to investigate. Having some doubt about your doxastic state (plus other conditions) would be sufficient to generate a prima facie duty to investigate, and would make the excuse of ignorance unlikely. Here is a rough sketch of conditions for having a duty to investigate. Note that $1 \& 2$ are sufficient and 3 is necessary:

$\mathrm{S}$ has a prima facie epistemic duty to investigate whether $p$

${ }^{84}$ Neil Levy, “Doxastic Responsibility,” Synthese (2007) 155: 127-155. 
(1) If S has some doxastic attitude toward $p$ and $S$ has, or should have some doubt about whether she has the correct attitude; and

(2) Only if further evidence-gathering could enable $S$ to better judge whether $p$.

I agree with Hall and Johnson that this duty is a prima facie one (all things considered)

which can be overridden by other duties and nullified by impossibility. But even if overridden or nullified, a prima facie may re-emerge at a later time and become ultimate or comprehensive. A prima facie duty that is overridden or nullified at $\mathrm{t} 1 \mathrm{can}$ still become an ultimate epistemic duty or a comprehensive epistemic duty at $\mathrm{t} 2$ if competing duties are discharged or conditions change to make the duty possible. ${ }^{85}$ For example, suppose Sherlock has a duty to investigate, at $\mathrm{t} 1$, whether Smith is the killer. Suddenly, at $\mathrm{t} 2$, Sherlock discovers that his best friend Watson is in grave peril. Now his moral duty to Watson will override his duty to investigate, and he cannot be blameworthy for failing to investigate. Once Watson is safe at $\mathrm{t} 3$, assuming that Smith is still a viable murder suspect and Sherlock has nothing better to do, Sherlock's duty to investigate reemerges as an ultimate duty and the possibility of blameworthiness returns.

I have departed from the other accounts in that (1) is objective rather than subjective. On my view, if you should have some doubt but don't, you can be blameworthy. Also, if you think investigating would not help, but it would (in fact), then you can be blameworthy. I should also note that I take having some doubt about $p$ to preclude knowing that $p{ }^{86}$ Thus, there would not be a case in which $\mathrm{S}$ knows that $p$ but epistemically ought to investigate whether $p$.

\footnotetext{
${ }^{85}$ I discussed the distinction between prima facie, ultimate and comprehensive epistemic duties in section 2.1 .

${ }^{86}$ Andrew Moon has argued for this in his unpublished dissertation.
} 
Let me say a bit more about the latter part of condition (1). We all have an intuitive idea of what it means to have some doubt. I follow Andrew Moon in distinguishing having some doubt whether $p$ from doubting that $p{ }^{87}$ The former implies that I believe that $\mathrm{p}$ while the latter implies that I do not. But in our case, it is not simply the proposition in question that $\mathrm{S}$ doubts - it is her doxastic attitude. So what, exactly, does S have some doubt about? There are three potential kinds of cases: belief, withholding, and disbelief. I think they can all be treated in the same way. In each kind of case, when I have some doubt about my doxastic attitude toward $p$, I have some doubt about the following proposition: I'm right about whether $\mathrm{p}$. And being 'right' just means that my attitude toward $p$ is in accordance with my evidence for $p$. Of course, the belief case is even simpler, but still fits this model. For instance, suppose I believe that there are ghosts in my basement. But after talking to a scientist friend, I'm not so sure anymore. I have some doubt about the proposition there are ghosts in my basement. This would be sufficient to satisfy condition (1) above. But having some doubt about the proposition believed entails that I have some doubt about whether I'm right about whether $\mathrm{p}$. Second, suppose I disbelieve that there are ghosts in my basement. But after hearing strange noises and seeing movement in the corner of my eye, I begin to worry that I'm wrong. That is, I now have some doubt about the following proposition: I'm right about whether $\mathrm{p}$. Finally, perhaps I withhold on $\mathrm{p}$. I really unsure whether there are or aren't ghosts in my basement. But then I hear an interview with Stephen Hawking in which he asserts the existence of ghosts. If I continue to withhold, then I will very likely have doubts about whether I'm right to withhold. I have some doubt whether I'm right about whether $\mathrm{p}$.

${ }^{87}$ Andrew Moon, unpublished dissertation. 
But what about cases where agents don't have any doubt, but ought to have some doubt? The sorts of cases I am worried about are ones in which, due to wishful thinking or emotional commitment, agents have blocked off doubts from their mind. What is needed is a way of judging whether agents ought to have some doubt about their doxastic state. This requires a way of identifying the presence of biases that block rational doubts.

A possible solution to this problem can be found in John Rawls' A Theory of Justice. Rawls suggests a remedy for biased judgments by placing subjects in an initial situation in which they are behind a "veil of ignorance." 88 This is done in order to ensure that subjects choose the principles of justice without bias toward their own self-interest. In an epistemic analog, we could imagine an individual who examines a proposition behind a similar veil of ignorance in which they are ignorant of their own self-interest with regard to the truth of the proposition. In such a case, a totally impartial agent who is presented with a defeater for his belief that $\mathrm{p}$ would have some doubt about $\mathrm{p}$, assuming that he doesn't have overwhelming evidence in favor of p. I'll call this view impartial rationality. ${ }^{89}$

Alvin Plantinga suggests something similar in Warranted Christian Belief. ${ }^{90}$ In his account of defeat, Plantinga says that D is a defeater for a belief B only if someone who believed $\mathrm{D}$ and whose cognitive faculties were functioning properly would withhold on B. But he then adds that the "bit of the design plan governing the sustaining of B in her noetic [i.e., cognitive] structure is successfully aimed at truth (i.e., the maximization

\footnotetext{
${ }^{88}$ John Rawls, A Theory of Justice, Cambridge, MA: Harvard University Press. Revised edition, 1999, p. 11.

${ }^{89}$ One might worry about the biasing effects of an agents previous beliefs. For now, I will set aside this concern.

${ }^{90}$ Alvin Plantinga, Warranted Christian Belief (New York: OUP, 2000), 359-367.
} 
of true belief and minimization of false belief) and nothing more." (363) Thus, even if a properly-functioning person maintains belief $\mathrm{B}$ in light of $\mathrm{D}, \mathrm{D}$ may still be a defeater if the cognitive structure ("bit of the design plan") sustaining belief B is aimed at survival or comfort rather than truth. For example, if $\mathrm{S}$ believes that she will recover from a serious illness, despite having good statistical evidence to the contrary, and she maintains this belief due to a properly-functioning cognitive structure that aims at survival (chances of survival increase if she believes she will recover), the statistical evidence against recovery can still count as a defeater for her belief that she will recover. So, impartial rationality would simply subtract these non-truth-aimed cognitive structures and ask what S's attitude would be without them.

One worry about this account is what I will call the problem of forgotten evidence. Suppose at $\mathrm{t} 1$ that Batman and Robin both believe that $p$ and are both provided with evidence for not- $p$. Batman finds this deeply upsetting, because he does not want $p$ to be false, i.e., he wants to continue believing $p$. So, he concocts a pill that causes him to forget all the new evidence, including the fact that he took the pill. Robin finds the evidence intriguing, but before he can consider it, he is struck on the head by the Joker and forgets all the new evidence. Now, at $\mathrm{t} 2$, Batman and Robin still believe that $p$, and neither remembers ever having evidence for not- $p$. Do they have an unexcused, unfulfilled duty to investigate whether $p$ ? Intuitively, I think that Batman does and Robin does not. But how can I account for the difference? Their current doxastic states seem to be the same and an evidentialist would likely not be able to distinguish between them. The key here is in asking whether they should have some doubt about p. On my view, you should have some doubt about $\mathrm{p}$ when an impartially rational person in your situation 
would have some doubt about $p$. An impartially rational person would not have taken the pill that Batman took, would not have forgotten the evidence against $p$, and thus would have some doubt about $p$. In contrast, an impartially rational person in Robin's case would still have forgotten the evidence, since being hit on the head is not (ostensibly) affected by one's impartial rationality. Thus, it is not the case that Robin ought to have some doubt about $p$.

\subsection{Conclusion}

In this chapter, I have argued that agents sometimes have epistemic duties. The intuitive case is rather strong, but I have offered a formal argument as well. I claim that since we value believing truth and avoiding falsehood, we should make an effort to investigate our beliefs whenever feasible. I have responded thoroughly to arguments against my view from Richard Feldman, and I have dealt briefly with the opposing views of Mark Nelson and Trent Dougherty. Finally, I have given a plausible account of when agents have epistemic duties.

I leave several important and interesting questions open for further research. For instance, how exactly do competing duties get sorted out? Do moral and prudential duties always override epistemic duties? Also, depending on the importance of the proposition in question, could there be varying degrees of epistemic blameworthiness? Lastly, what of cases of irrational, persistent doubt? It seems that there could be cases where no matter how much investigation is done, the believer cannot shake their doubts about having the right attitude. Intuitively, we wouldn't want our view to require endless, uninterrupted investigation of a particular proposition. 


\section{CHAPTER 3: RELIGIOUS BELIEF AND EPISTEMIC BLAMEWORTHINESS}

\subsection{Introduction}

The great atheist philosopher Bertrand Russell was once asked (allegedly) what he would say if he found himself standing before God on the judgment day and God asked him, “Why didn’t you believe in Me?” Russell replied, “I would say, 'Not enough evidence, God! Not enough evidence!'” If it is true that God has provided humanity with insufficient evidence for his existence but nevertheless requires belief (under threat of eternal punishment), then the charge of divine injustice looms large. ${ }^{91}$ Intuitively, if I receive insufficient evidence for $p$, I should not be blamed for failing to believe that $p$.

In section 3.1 of this chapter, I present and explain the argument against God's justice from blameless non-belief. In sections 3.2-3.4, I explore two inadequate defenses against the "Russellian" argument: Universalism and Selectivism. In section 3.5, I explore and defend Responsibilism, which I take to be the best defense against Russell's charge. At the conclusion of 3.5, I discuss some implications and problems concerning blameworthy belief and the responsibilist view. In 3.6, I offer concluding remarks for the chapter.

\subsection{The Argument}

Below is the sort of argument I think Russell has in mind. Let ' $R$ ' be the set of propositions one is required to believe in order to go to heaven (I say a bit more about what might be in this set below).

\footnotetext{
${ }^{91}$ For convenience, I use the masculine pronouns 'him' and 'his' for God, though I do not think that God is gendered.
} 
(1) If the Christian God exists, then the Christian God requires every cognitively normal person (in their earthly life) to freely believe that $\mathrm{R}$ in order to avoid divine punishment.

(2) There are some cognitively normal humans who do not have sufficient evidence for $\mathrm{R}$, disbelieve that $\mathrm{R}$, and appropriately lack doubt about their disbelief.

(3) If (2), then there are some cognitively normal humans who are epistemically blameless in disbelieving that $\mathrm{R}$.

(4) If the Christian God exists, then it is wrong for the Christian God to punish someone for epistemically blameless disbelief.

(5) So, if the Christian God exists, then he acts wrongly.

\subsubsection{Explanation of the Argument}

In the following section, I explain each premise of Russell's argument. Premise (1) is simply an expression of the doxastic requirement for salvation. On the traditional Christian view, one cannot be saved from divine punishment unless one believes a particular set of propositions. I will call this claim the doxastic requirement. Exactly what is one expected to believe? All Christian traditions agree that there is a doxastic requirement for 'salvation' (where 'salvation' means going to heaven rather than hell), but they differ on the content of the required belief. Minimally, most would agree with the author of the Epistle to the Hebrews that "he who comes to God must believe that He is and that He is a rewarder of those who seek Him." 92 Mere theism, however, is insufficient, as St. James reminds us: "Even the demons believe that [the God of the Bible exists] — and shudder." ${ }^{93}$ But nailing down what else must be believed is notoriously difficult. Even though I am only considering "cognitively normal persons," which would exclude young children and cognitively impaired persons, it is still hard to say what they must believe to be saved. (By 'cognitively normal,' I mean those people whose cognitive faculties are fully developed and functioning without significant

\footnotetext{
92 The Epistle to the Hebrews, Chapter 11, verse 6. New American Standard translation.

${ }^{93}$ The Epistle of James, 2:19.
} 
impairment such that they can accurately assess the evidence for claims like R. Thus the exclusion of very young children.) Presumably, R would not include any sophisticated theological beliefs, such as the doctrine of the Trinity or the doctrine of penal substitution. R should be something a school-aged child could grasp. But rather than specifying $\mathrm{R}$, we will just use $\mathrm{R}$ as a place-holder for whatever set of propositions one is required believe.

It is important to point out that satisfying the doxastic requirement is necessary, but not sufficient for salvation. Various Christian traditions identify other necessary requirements (good deeds, baptism, repentance, faith in Jesus, etc.). I will simply set these other possible requirements aside and focus on the doxastic, since all agree that without the proper belief-state, one cannot be saved. The doxastic requirement also seems logically prior to the others, since baptism and good deeds might be the reasonable follow-up to one's belief.

Finally, one might wonder whether it is just for God to impose any doxastic requirement at all. This is an interesting question, but beyond the scope of this essay. There are many religions that focus almost exclusively on one's moral score card, so to speak, rather than on one's beliefs. The Abrahamic tradition (Judaism/Christianity/Islam) is somewhat unique in making faith (which entails some sort of belief) a central, if not the central, issue. But I am here interested in the sort of concern raised by our fictional Russell. Russell does not question the justice of the doxastic requirement itself-he might consider it perfectly just if ample evidence were supplied to everyone. He questions the justice of the requirement in the absence of sufficient evidence. 
The only support for (1) would be the writings of the Christian tradition, rather than philosophical argument. There may not be any logically necessary reason for God to have a doxastic requirement. Most traditional Christians hold to something like this, but there are some who reject it. They might think that people will be given multiple chances after death to believe R, or that there is no doxastic requirement at all. Since it is difficult to draw tight boundaries around which doctrines constitute "traditional Christianity," I will include the view that rejects (1) (to be discussed below) as a Christian response to Russell's argument.

Recall (2):

(2) There are some cognitively normal humans who do not have sufficient evidence for $R$, disbelieve that $R$, and appropriately lack doubt about their disbelief.

The claim that some cognitively normal persons do not have sufficient evidence is based on reports of people like Russell. Either they simply haven't ever received the needed evidence or their defeaters overwhelm what evidence they do have. Presumably, there are people (whether cognitively normal or not) who satisfy this description. If they disbelieve that $\mathrm{R}$, then their doxastic attitude is in accordance with their evidence and their lack of doubt is appropriate. Thus, they would not have a duty to investigate. If one has no duty to investigate whether R, then one can't be blameworthy for their doxastic attitude toward R.

Recall premise (3):

(3) If (2), then there are some cognitively normal humans who are epistemically blameless in disbelieving that $R$.

Premise (3) follows from (2) and EB.

Recall premise (4): 


\section{(4) If the Christian God exists, then it is wrong for the Christian God to punish someone for epistemically blameless disbelief.}

This seems intuitively true. If someone has sincerely done everything they can to rationally believe that $\mathrm{R}$ but still disbelieves, then it seems wrong to punish them for disbelief. ${ }^{94}$ The reasoning here seems to be along these lines: if I've done everything I can to bring it about that X, then I shouldn't be punished for failing to bring it about that $X$. But here's a worry: has Russell (or someone like him) done everything they can to believe that R? Couldn't they just believe, regardless of the evidence? There is good reason to think not.

For persons like Russell, it may be impossible to believe that $\mathrm{R}$ against their evidence. This is because people like Russell are deliberating about R. And when we deliberate about a proposition, only evidential reasons can lead us to believe. This is true even if we have good pragmatic reasons to believe, such as Pascal's wager. But there is a difference between deliberating whether $p$ and deliberating whether I ought to believe that $p$. In his essay, "A New Argument for Evidentialism," Nishi Shah has argued that

When we ask ourselves the deliberative question whether to believe that $\mathrm{p}$, this question gives way to the question whether $\mathrm{p}$ is true, and so the only way for us to answer the former question is by answering the latter. ${ }^{95}$

And since only evidential reasons have any relevance to the question of whether $\mathrm{p}$ is true, only evidential reasons have any relevance for deliberation about whether to believe that $\mathrm{p}$ (I take 'whether to believe that p' and 'whether p' to be roughly equivalent in this context). Shah claims that in order to count as a reason to believe that $\mathrm{p}$, the reason must

\footnotetext{
${ }^{94}$ By "done everything they can to rationally believe," I mean everything short of willing themselves to believe (which I don't think is in our power), or otherwise manipulating themselves cognitively or psychologically to believe in the absence of evidence. A person who has "done everything they can" has fulfilled all their epistemic duties regarding $p$, and this is all that can be appropriately expected.

${ }^{95}$ Nishi Shah, “A New Argument for Evidentialism," The Philosophical Quarterly, Vol. 56, No. 225, $p$. 487. For more on whether pragmatic reasons are reasons for belief, see Thomas Kelly's "The Rationality of Belief and Some Other Propositional Attitudes," Philosophical Studies 110: 163-196.
} 
be capable of disposing you or moving you toward believing that $\mathrm{p}$. And Shah thinks that only evidential reasons can dispose us toward belief. Pragmatic reasons might dispose you toward trying to believe that $p$, or believing that it is in your interest to believe that $p$, but not toward believing that $p$.

If we reject the idea that beliefs are under our direct, voluntary control, then it seems even clearer that we cannot decide to believe for pragmatic reasons or any other non-evidential reasons. We engage in a process of deliberation, which involves reflecting on evidence and inferential relations, and then beliefs either form or they do not. If the belief forms, it is due to the evidence and inferential relations (or at least how they seem to us). If I already believe that if the door opens, then it is not locked, and the door opens, then I will instantly come to believe that the door is not locked. In order to believe otherwise, I would have to cease believing the premises of my syllogism, or cease endorsing modus ponens as a valid rule of inference.

So if Shah is right, and if doxastic voluntarism is false, then we should think that it is simply a psychological fact about humans that when they deliberate about whether to believe $\mathrm{p}$, non-evidential reasons will have no ability to bring them to belief in $\mathrm{p}$. So, since people like Russell always deliberate about whether to believe that $\mathrm{R}$, it is impossible for them to believe without sufficient evidence for R.

So, if we agree that people like Russell simply can't bring themselves to believe (due to insufficient evidence), then it seems wrong of God to punish them. Let me say a bit more about why this is the case. First, the wrongness may be due to the absence of a duty to do the impossible. Most philosophers accept some version of the 'ought implies can' principle. Plausibly, one cannot have an obligation to do something they are not 
able to do. I cannot have a duty to jump over the Empire State Building, or to drink the Atlantic Ocean. And if I have no obligation to drink the Atlantic Ocean, then it is wrong for anyone to demand that I do it, under threat of severe punishment. Thus, if I cannot do $\mathrm{X}$, then it is wrong (even for God?) to require me to do $\mathrm{X}$ in order to avoid severe punishment. But are God's commands a special case? Perhaps we can have an obligation to do the impossible if God commands it. According to some versions Divine Command Theory, the simple fact that God commands me to do $\mathrm{X}$ gives me a pro tanto reason to do X. But the fact that I cannot do X seems to swamp the pro tanto obligation so that, all things considered, I have no duty to do X. I may have a duty to try to do X, but no more. So appealing to divine command theory does not seem to generate the obligation needed to justify the impossible requirement. So the wrongness of making such requirements violates some principle similar to 'ought implies can.' Perhaps we could call this the 'liability to punishment implies could have avoided' principle. In any case, premise (4) seems highly plausible. I deal with objections, including objections to OIC, in subsequent sections. This concludes my explanation of the premises in Russell's argument.

\subsection{The Defenses}

Regardless of what one thinks of the justice of eternal damnation (I myself am skeptical of this), the issue at hand is whether any sort of punishment is warranted when someone disbelieves blamelessly. While my primary strategy is to deny (2), that is, to argue that God has provided sufficient evidence to all cognitively normal humans, it will be helpful to explore two other traditional strategies that I find inadequate. The remainder of this 
chapter will be concerned with refuting the premises of Russell's argument. Recall the argument:

(1) If the Christian God exists, then the Christian God requires every cognitively normal person (in their earthly life) to freely believe that $\mathrm{R}$ in order to avoid divine punishment.

(2) There are some cognitively normal humans who do not have sufficient evidence for $\mathrm{R}$, disbelieve that $\mathrm{R}$, and appropriately lack doubt about their disbelief.

(3) If (2), then there are some cognitively normal humans who are epistemically blameless in disbelieving that $\mathrm{R}$.

(4) If the Christian God exists, then it is wrong for the Christian God to send someone to hell for epistemically blameless disbelief.

(5) So, if the Christian God exists, then he acts wrongly.

At various points in history, each of the four premises have been denied by Christian apologists, resulting in several distinct defenses against the charge of divine injustice. In the following sections, I describe in detail three defenses, raise objections, and respond to them.

\subsection{Defense \#1: Universalism}

The view that denies premise (1) is what I will call universalism. In this section, I describe universalism, explore some reasons in its favor, and then discuss several objections. Recall premise (1):

(1) If the Christian God exists, then the Christian God requires every cognitively normal person (in their earthly life) to freely believe that $R$ in order to avoid divine punishment.

Universalists reject (1) because (i) they are already committed to the claim that (U) all humans go to heaven — mankind will universally be saved —and (ii) it seems demonstrably false that all cognitively normal persons come to believe that $\mathrm{R}$ in their earthly life. The case for universalism, then, turns on showing that the reasons for accepting $\mathrm{U}$ are better than the reasons for accepting (1). Below I detail an argument for (U) and consider several objections. 


\subsubsection{Argument for Universalism}

So the universalist's defensive strategy boils down to making a case for: (U) All humans go to heaven. Consider the following argument for $U .{ }^{96}$

1. For any $\mathrm{S}$, if $\mathrm{S}$ spends eternity in hell, then they do not experience eternal happiness.

2. For any S, if they do not experience eternal happiness, then it is beyond God's power to bring about their eternal happiness.

3. For any S, if they spend eternity in hell, then it is beyond God's power to bring about their eternal happiness.

4. For any S, it is not beyond God's power to bring about their eternal happiness.

5. Thus, no one spends eternity in hell.

Premises (1)-(3) seem clear enough. Premise (4) of is the crux of the argument.

It claims that whatever the limits might be to God's abilities, bringing about true happiness for every human is within those limits. Let us assume that God has the power to cause any human to satisfy all the conditions required for salvation. On this view, God could cause me to do good deeds, to repent, to pray, even to have certain desires. God could change my beliefs instantly or even cause me to love God—whatever is required. And according to premise (2), if God could bring it about that I satisfy all the requirements, then God would do so, and I would avoid divine punishment, regardless of my original intentions, beliefs or desires. Let's call this understanding of (4) the strong universalist view.

There is another way that (4) could be understood. Rather than simply cause me to do, desire or believe certain things, God could indirectly facilitate these actions, desires and beliefs. Perhaps it is ignorance or bondage to certain desires, after all, that "causes" me to reject God. All God need do is remove these hindrances, as we might remove a

\footnotetext{
${ }^{96}$ Thomas Talbott argues something like this in his papers, "The Doctrine of Everlasting Punishment," Faith and Philosophy, VII, 1990, 19-42; and "Providence, Freedom and Human Destiny," Religious Studies, XXVI, 1990, 227-45.
} 
door stopper, and allow things to run their course freely. Talbott suggests that "once all ignorance and deception and bondage to desire is removed, so that a person is truly 'free' to choose, there can no longer be any motive for choosing eternal misery for onesself." 97 Let's call this understanding of (4) the weak universalist view.

\subsubsection{Critique}

The problem with the universalist argument lies with (4). Arguably, for some humans, it is beyond God's power to bring about their true happiness. This is because in order for a human to experience true happiness, they must enjoy a certain kind of freedom or autonomy, including freedom in the choices that lead them toward union with God. Below, I offer objections to both versions of (4)—strong and weak —and the corresponding views of strong and weak universalism.

\subsection{2a Against Strong Universalist View}

On the traditional Christian view, there are limits to what God 'can' do. It is standardly held that God cannot do that which is logically impossible, such as constructing a square circle, or making unmarried, adult, human, male non-bachelors. Famously included in this list is God's inability to (sufficiently) cause someone to freely choose to $\varphi^{98}{ }^{98}$ Thus, if a necessary condition for bringing about the true happiness of some human is that God (sufficiently) cause them to freely $\varphi$ (embrace God or whatever action is required), then God cannot bring about the true happiness of that human. And since there may be persons who do not freely choose to $\varphi$, there may be persons who will not avoid divine punishment. This seems to be a serious problem for strong universalism. ${ }^{99}$

\footnotetext{
${ }^{97}$ Talbott, 'The Doctrine of Everlasting Punishment', p. 37.

${ }^{98}$ For more on this, see Plantinga, A. C., 1974, God, Freedom, and Evil, New York: Harper \& Row.

${ }^{99}$ In section 3.4, I consider a universalist objection to this point - that divine coercion is morally acceptable.
} 


\subsection{2b Against Weak Universalist View}

Now what of the weak version of (4)? On this understanding, God need not directly cause me to believe or act in a certain way, but merely facilitate it indirectly? According to Talbott and other universalists, if God simply removes ignorance, deceit and bondage to disordered desire, effectively giving us our freedom, we will choose to embrace God. This seems to suggest the following principle:

Impediment Principle: Necessarily, if a human being is unhindered by sin, deceit and ignorance, then they will respond positively to God.

First, on a doctrinal basis, this principle is obviously false. Even if one takes the story of Adam and Eve to be metaphorical, it is clearly asserting that a lack of impediments does not guarantee that one will always respond positively to God. In Adam's case at least, no deception was involved. One might reply that some ignorance plagued Adam, since he was human and cognitively finite. But if omniscience is required in order to be free of impediments, and no human can be omniscient, then no human can be free of all impediments.

A second, more philosophical line of critique of the Impediment Principle is offered by William Lane Craig. ${ }^{100}$ Craig takes Talbott to be claiming the following:

it is not broadly logically possible that some creaturely individual essences suffer from . . . 'transworld damnation', that is to say, the property possessed by an essence if and only if the exemplification of that essence freely rejects God's grace and so is lost in every world feasible for God in which that exemplification exists. ${ }^{101}$

So, all that needs to be shown to refute Talbott is that it is broadly logically possible for there to be at least one human who, despite God's best efforts, remains defiant. (Note

\footnotetext{
${ }^{100}$ William Lane Craig, "Talbott's Universalism,” Religious Studies, Vol. 27, No. 3 (Sep., 1991), pp. 297308.

${ }^{101}$ Ibid., p. 298.
} 
that this has nothing to do with evidence-we are thinking of someone, who, even after being given sufficient evidence, continues in either disbelief or rebellion against God.) So, if there is no contradiction in imagining such persons, then such persons (logically) may exist. And if such persons may exist, then possibly, some persons go to hell despite any indirect facilitation on God's part and weak universalism is false.

In conclusion to this section, universalism is attractive as a solution to the problem of punishment for blameless disbelief, but it has significant doctrinal and philosophical problems. If one is willing to forego certain apostolic doctrines of the traditional Christian view, and one does not think it possible for any human to reject God once all impediments are removed, then universalism is a viable solution.

\subsection{Defense \#2: Selectivism}

A second approach to the problem of blameless disbelief denies premise (4):

(4) If the Christian God exists, then it is wrong for the Christian God to punish someone for epistemically blameless disbelief.

Selectivism is the view that God is within his rights to require some people-people for whom it is impossible to believe apart from sufficient evidence-to believe even though they have not been given sufficient evidence. I call this view selectivism because rejecting premise (4) while accepting premise (2) implies that God effectively selects those who will be saved from damnation by intentionally withholding sufficient evidence from some but requiring belief of all. Selectivism concedes to the Russellian that there are some people who do not get sufficient evidence for $\mathrm{R}$ in this life. Nevertheless, selectivists part ways with Russell in that selectivists deny that God's enforcement of the doxastic requirement on people like Russell is unjust. 
In this section, I offer one argument showing that (4) is unsupportable, followed by a positive argument for the justice of God's de facto selection of some humans but not others. I also offer some critique of each argument.

\subsection{1 (4) is Unsupportable}

As I explained in section 1.1, the intuitive argument in favor of (4) is something like this: since Russell (and people like him) has done all he can to believe, it is wrong to punish or threaten to punish him for failing to believe. This line of reasoning assumes something like the 'ought implies can' principle. Since I take this as the only possible reason for accepting (4), then showing that the 'ought implies can' principle is strictly false should lead us to reject (4) as unsupportable.

If I cannot do X, then I have no obligation to do X, and if I have no obligation to do $\mathrm{X}$, then God has no business demanding that I do $\mathrm{X}$ and punishing me for failing to do $\mathrm{X}$. So, using OIC as a premise in a hypothetical syllogism, we can derive something like premise (4). But if we can show that OIC has counterexamples, then one kind of support for (4) will have been eliminated. (I will take 'OIC is strictly true' to mean that there are no genuine counterexamples of any kind to OIC.)

Such counterexamples are easy to construct. We need only imagine a scenario where an agent who has an obligation to do $\mathrm{X}$ could do $\mathrm{X}$ at one time, but no longer can due to their own irresponsibility. Paul promised to repay Peter $\$ 100$ today, but Paul wasted all his money at the slot machines during lunch. Now Paul has no money, but his obligation to pay Peter today still stands—an obligation he cannot meet. Another example: George abandons his wife and family and takes a one-way, no return trip to Mars. We can imagine people saying of George, "He ought to be home with his wife and kids." So, plausibly, even though return is impossible, his obligation remains. 
One worry we might have: perhaps OIC doesn't have to be strictly true for premise (4) to work - maybe we only need it to work for cases of belief. Here's a modified version of OIC that would support (4):

OIC Belief: If $S$ has an obligation to believe that $p$, then $S$ can believe that $p$.

Assuming that we can have obligations to believe, can we construct a counterexample to OIC $_{\text {Belief }} ?^{102}$ Suppose Truman ought to believe that evolution is the correct theory of origins (he's been given overwhelming evidence), but because he was raised in a severely abusive religious home, he is psychologically incapable of forming this belief. Saying, "Truman really ought to accept evolution as true," sounds fine to me here, even though it isn't possible for him to do it. Another case: suppose Willie, a hyper-suspicious person by nature, has some evidence that his wife is being unfaithful-just enough to make him withhold on the proposition "My wife is faithful." He's not sure what to believe. Try as he might, he can't bring himself to believe that she is faithful. When he confides in his friend (who knows about Willie's hyper-suspicious nature), his friend tells him, "You ought to believe the best about her. You should give her the benefit of the doubt and trust that she is faithful." But Willie just doesn't believe this anymore, and can't force himself to do so. So, given these two counterexamples, I conclude that $\mathrm{OIC}_{\mathrm{Belief}}$ is false.

While I think that these two examples are enough to refute $\mathrm{OIC}_{\text {Belief }}$, we might still wonder if there is something special about Russell's case that would allow the argument to nevertheless go through. Instead of requiring something like OIC as a premise, could (4) instead rely on the simple intuition that you can't punish someone to failing to do the impossible, whether they were obligated to do it or not. I.e., $\mathrm{S}$ has an

\footnotetext{
${ }^{102}$ At this point, I'll leave open the question of whether this is a moral, prudential or epistemic obligation. We'll just think of it as an obligation "all things considered."
} 
obligation to do impossible action $\mathrm{A}$, but it is still wrong to punish $\mathrm{S}$ for failing to do $\mathrm{A}$. I.e., it isn't wrong to punish $\mathrm{S}$ because he wasn't obligated to A-instead, it is wrong simply because he can't A!

In response, the selectivist might introduce the concept of culpable inability. Whereas it would be unjust to punish someone for something they cannot and never could have done, it may not be unjust to punish someone for something they cannot do, but could have done. For example, suppose my current inability to pay a debt is the result of my having carelessly gambled away the money. It would be ridiculous for me to claim that I am exempt from punishment or obligation due to my current inability to pay. Perhaps this is the sort of doxastic inability that some persons possess (if one can be said to possess inability). Perhaps Russell cannot now believe that $\mathrm{R}$, but perhaps his inability to believe now that $\mathrm{R}$ is his own fault. Assuming that Russell's current inability is due to a lack of evidence, perhaps he had an opportunity in the past to receive this evidence, but culpably failed to act in such a way that would have caused him to receive it. So, if (4) relies on the intuition that Russell must now have the ability to believe in order to be justly punished for failing to believe, then (4) remains unsupported.

\subsubsection{A Positive Argument for the Justice of God's Selection: The Ownership Argument}

One way of arguing that God is not acting unjustly toward rationalists is to argue that God has no moral obligations toward his creation. I call this the Ownership Argument. This is a traditional Christian sort of response to claims like (4), but it involves claims that many non-theists (and some theists!) will find implausible. So, I take its function to be that of showing that the proponent of TCV is rational in rejecting (4), rather than to persuade non-theists to reject (4). 
According to St. Paul, God is not merely the rightful judge of every person, but also the owner of every person. As owner, he has special rights over them which make his actions necessarily immune to charges of injustice. Consider this passage from St. Paul's letter to the church in Rome.

What shall we say then? Is there injustice on God's part? By no means! For he says to Moses, "I will have mercy on whom I have mercy, and I will have compassion on whom I have compassion." So then it depends not on human will or exertion, but on God, who has mercy. For the Scripture says to Pharaoh, "For this very purpose I have raised you up, that I might show my power in you, and that my name might be proclaimed in all the earth." So then he has mercy on whomever he wills, and he hardens whomever he wills.

You will say to me then, "Why does he still find fault? For who can resist his will?" But who are you, O man, to answer back to God? Will what is molded say to its molder, "Why have you made me like this?" Has the potter no right over the clay, to make out of the same lump one vessel for honorable use and another for dishonorable use? ${ }^{103}$ [emphasis mine]

St. Paul is responding to the charge that God's mysterious selection process is unjust.

Initially, this response appears to be an appeal to God's authority, but then Paul describes an analogy with a potter. There is no injustice in the potter's treatment of the vessels because the potter has made them and owns them. Presumably, just as there is no possibility of injustice in how I treat my body, there is no possibility of injustice in how I treat other things that I own. Similarly, God owns us and has absolute rights over us, and so cannot treat us unjustly. It still may be possible to truly accuse God of other moral transgressions in his treatment of persons, but not injustice. The ownership argument runs something like this:

\section{Ownership Argument}

O1. If $\mathrm{S}$ makes $\mathrm{X}$ out of resources which $\mathrm{S}$ owns, then $\mathrm{S}$ owns $\mathrm{X}$ and anything which issues from $\mathrm{X}$.

O2. God made the initial human beings from resources which God owns.

O3. So, God owns human beings and everything that issue from them (e.g., their descendents).

${ }^{103}$ St. Paul, Epistle to the Romans, Chapter 9, verses 14-21. (English Standard Version) 
O4. If $\mathrm{S}$ owns $\mathrm{X}$, then $\mathrm{S}$ has the right to dispose of $\mathrm{X}$ as $\mathrm{S}$ wills.

O5. Thus, God has the right, for any human being, to dispose of that human being as he wills.

John Locke agreed with steps (O1)-(O3), at least, as seen in his Two Treatises.

"[F]or men being all the workmanship of one omnipotent and infinitely wise Maker; all the servants of one sovereign Master, sent into the world by His order and about His business; they are His property, whose workmanship they are made to last during His, not one another's pleasure." (Emphases mine.) ${ }^{104}$

But what of premise $(\mathrm{O} 4)$ ? Counterexamples seem easy to construct: I own the Mona Lisa, but it seems prima facie wrong for me to burn it. I own my dog, but it seems prima facie wrong for me to kill it. But is God is a special case? We would modify (O4) to get $(\mathrm{O} 4 *)$ :

O4*. If God owns $\mathrm{X}$, then God has the right to dispose of $\mathrm{X}$ as $\mathrm{S}$ wills.

Granting (O4*), God has the right to dispose of any human being however he wishes, and there can be no legitimate moral criticism of God when he makes impossible requirements and condemns someone to hell for failing to satisfy those requirements.

In reply to $(\mathrm{O} 4 *)$, we might ask what, exactly, makes God a special case. Why is he entitled to kill his dog, but I am not? Perhaps it is the fact that God created the dog (or its ancestors). So, if $\mathrm{S}$ creates a being $\mathrm{X}$, then $\mathrm{S}$ has absolute rights over $\mathrm{X}$. This seems intuitively false. Imagine a scientist who creates a dog in a lab via cloning, keeps it as a pet for several years, and then destroys it simply because he wished to. The scientist's destroying of the dog seems wrong because once the dog becomes a living, breathing being, it seems prima facie wrong to kill it. ${ }^{105}$ Perhaps there is a more robust sense of 'created' that describes God's actions and not the scientist's, but absent such an

\footnotetext{
${ }^{104}$ John Locke, Two Treatises on Government, Book II, Ch. 2, par. 6. (On-line edition: http://www.lonang.com/exlibris/locke/loc-202.htm)

${ }^{105}$ The wrongness seems even clearer if you consider God's subjecting a human to eternal torment. Thanks to Peter Vallentyne for this point.
} 
argument, there does not seem to be any good reason to consider God a special case. So, (O4) (in the ownership argument) seems false and (O4*) seems unjustified, rendering the Ownership Argument dubious at best.

In conclusion, I think the selectivist is right that (4) is unsupportable, but to complete the case against (4), more needs to be said. Requiring the impossible from certain persons is just only if those persons suffer from culpable inability. The selectivist has not argued that some persons are, in fact, culpably unable to believe that R. So, I think the responsibilist case against (4) needs work. The Ownership Argument, I think, has very little thrust, even among those who already accept TCV. Below, I offer what I take to be the best defense against Russell's argument: responsibilism. 


\subsection{Defense \#3: Responsibilism}

In this section, I describe the position called "responsibilism," offer an argument in its favor, and then respond to several objections. The responsibilist strategy is to deny premise (2) of Russell's argument:

(2) There are some cognitively normal humans who do not have sufficient evidence for $R$, disbelieve that $R$, and appropriately lack doubt about their disbelief.

The responsibilist claims, contra Russell, that no cognitively normal person lacks sufficient evidence for (2). Any cognitively normal person who ultimately fails to believe that $\mathrm{R}$ does so with sufficient evidence "in hand." More precisely, in this section I argue for what I call the sufficient evidence thesis (SE):

SE: God provides every cognitively normal human with sufficient evidence for $R$. There are several challenges in making a case for (SE). First, the responsibilist needs to give a plausible account of what "sufficient evidence" is. Second, the responsibilist needs to show that the evidence we all have satisfies the proposed criteria for sufficiency. Third, the responsibilist needs to explain why the evidence seems insufficient to people like Russell. The following section is broken into two main parts. In 3.5.1, I argue for what I call the Sufficient Evidence Thesis (SE). In 3.5.2, I consider several objections to SE.

\subsubsection{Argument for the Sufficient Evidence Thesis}

There are two ways to get enough. One is to continue to accumulate more and more. The other is to desire less. G.K. Chesterton.

In this section, I argue that God provides every cognitively normal person with sufficient evidence by doing two things: (a) predisposing us to believe that $\mathrm{R}$ so that only a modest amount of evidence is needed to produce belief in a cognitively normal person; and (b) 
providing a modest amount of evidence. This satisfies what I take to be God's primary goal in evidence-provision - producing non-coercive belief that R in as many people as possible. This also helps to explain why the evidence seems meager to many people. Let me explain.

The basic argument is this: the amount of evidence one has is not the only factor involved in sufficiency. Even a modest amount of evidence for $\mathrm{R}$ will be enough to achieve sufficiency when the person in question is highly predisposed to believe that $\mathrm{R}$. So, it may turn out that the reason the evidence seems insufficient to people like Russell is that such persons lack the predisposition to believe. Such persons, however, are not cognitively normal. Thus, people like Russell may very well be blameless in their disbelief. But cognitively normal person, who have the predisposition to believe, remain blameworthy in their disbelief because the modest evidence they have is sufficient.

Below I explain and defend an argument for the sufficiency thesis (SE).

\section{The Predisposition Argument}

1. If cognitively normal humans are predisposed to believe that $\mathrm{R}$, then only a modest amount of evidence is required to produce belief that $\mathrm{R}$ in open-minded, cognitively normal humans.

2. All cognitively normal humans are predisposed to believe that $\mathrm{R}$.

3. So, only a modest amount of evidence is required to produce belief that $\mathrm{R}$ in open-minded, cognitively normal humans.

4. God provides every human with a modest amount of evidence for R.

5. So, God provides every human with enough evidence to produce belief that $\mathrm{R}$ in open-minded, cognitively normal humans.

6. If God provides every human with enough evidence to produce belief that $\mathrm{R}$ in open-minded, cognitively normal humans, then God provides every cognitively normal human with sufficient evidence for $\mathrm{R}$.

7. So, God provides every cognitively normal human with sufficient evidence for R.

In what follows, I walk through the premises of the Predisposition Argument. 
Premise (1) seems quite intuitive. The more inclined I am to believe that $p$ (prior to having any evidence), the less total evidence for $p$ I need to come to believe $p$. By analogy, the cheaper a widget is at Big Mart, the less money I need to buy it. This assumes, of course, that I do not have an outstanding balance at Big Mart. If I have $\$ 10$ in hand, but owe Big Mart \$20, I won't be able to purchase the $\$ 10$ widget. I'm going to need more money. Similarly, I may have sufficient evidence for R, but because of counter evidence ("evidential debt"), I am unable to form the belief that R. However, I don't think is a serious worry for SE. Cognitively normal persons typically form belief that $\mathrm{R}$ as children, before any "evidential debt" can be accrued. ${ }^{106}$ Debt may be accrued later, of course, but this is a different matter. Adults who begin to grapple with counter arguments such as the problem of evil also have vast amounts of additional evidence (as I explain below) for R available to them. ${ }^{107}$ This means that cognitively normal adults who accrue evidential debt, causing them to disbelieve or withhold on $\mathrm{R}$, have some responsibility to investigate additional evidence for R. On the view defended in chapters one and two of this project, $\mathrm{S}$ has a duty to investigate their doxastic attitude toward $p$ when S has or should have some doubt about the correctness of their doxastic attitude toward $p$. It seems that any adult who previously held that $\mathrm{R}$ but has been moved toward

\footnotetext{
${ }^{106}$ Justin Barrett, Born Believers: The Science of Children's Religious Beliefs (New York: Free Press, 2012). Henceforth: Barrett (2012). Barrett cites numerous studies showing that גi-type beliefs form as early as five months. See also Elizabeth S. Spelke, Ann Phillips and Amanda L. Woodward, "Infant's Knowledge of Object Motion and Human Action," in Causal Cognition: A Multidisciplinary Debate, ed. Dan Sperber, Davie Premack and Ann James Premack (Oxford: Oxford University Press, 1995); W.A. Ball, "The Perception of Causality in the Infant" (paper presented at the meeting of the Society for Research in Child Development, Philadelphia, April 1973); Michele Molina et al., "The Animate-Inanimate Distinction in Infancy: Developing Sensitivity to Constraints on Human Actions," Journal of Cognition and Development 5 (2004): 399-426; Gyorgy Gergely et al., "Taking the Intentional Stance at 12 Months of Age," Cognition 56 (1995): 165-193; Gergely Csibra, "Goal Attribution to Inanimate Agents by 6.5Month-Old Infants," Cognition 107 (2008): 705-717. Dozens of additional studies are cited by Barrett (2012).

${ }^{107}$ I say more about what this evidence might be in a later section.
} 
disbelief by counterevidence ought to have some doubt about their doxastic state, given evidence in hand and her predisposition to believe that $\mathrm{R}$.

Let me say a bit about the 'open-minded' condition. Even if I am strongly predisposed to believe that $\mathrm{R}$, I can, of course, (consciously or unconsciously) resist such a belief. This is why I added the condition of 'open-mindedness' in the consequent. 'Predisposed,' in our context does not mean anything like 'determined.' So, a person who is cognitively normal and yet closed-minded toward $p$ would require more evidence than someone who is open-minded toward $p$. 'Closed-mindedness' would perhaps be characterized by a strong desire to not believe that $p$, or a strong desire that $p$ be false, or an unwillingness to consider evidence for $p$. Put another way, a person who is closedminded would try to continue denying $p$ even if they suspected that the evidence was in $p$ 's favor. For example, there are many politically ultra-conservative people who refuse to seriously consider the evidence for global warming because they are so committed to the contrary position. Such a person might not believe in global warming unless they saw Florida underwater. On the other hand, a politically ultra-liberal might come to believe that 9/11 was an inside job with almost no evidence. These are negative examples, but they illustrate the point. I will have more to say about open-mindedness and cognitive normality later.

There is a growing body of empirical research supporting (2). Evolutionary psychologists and cognitive scientists, in increasing numbers, argue that normal human beings are cognitively hard-wired for belief in God and religious behavior. ${ }^{108}$ Social and cognitive scientist Dan Sperber (Central European University) argues that "people seem to be

${ }^{108}$ For more on this, see Barrett (2012); or less recently E. O. Wilson's On Human Nature (2004). 
naturally receptive to religious concepts." ${ }^{109}$ Psychologist Justin Barrett claims that "the cultural phenomena typically labeled as 'religion' may be understood as the product of aggregated ordinary cognition." ${ }^{110}$ Deborah Keleman, Director of the Child Cognition Lab at the University of Arizona, writes that "young children have a broad tendency to reason about natural phenomena in terms of purpose and an orientation toward intentionbased accounts [i.e., 'god did it'] of the origins of natural entities." ${ }^{111}$ According to Will Gervais, Professor of psychology at the University of Kentucky, there is "converging evidence suggesting that this regularity in god concepts exists in part because the ability to represent gods emerges as a cognitive by-product of the human capability to perceive minds."112 Robert McCauley, Director of the Center for Mind, Brain, and Culture at Emory University, argues that "religion and its characteristic forms of explanation are a "natural" outgrowth of the character and content of human association and cognition.",113 Sociobiologist E. O. Wilson has written that "the predisposition to religious belief is the most complex and powerful force in the human mind and in all probability an ineradicable part of human nature."114 A predisposition toward religious belief is also part of an excellent explanation for the pervasiveness of religious belief across cultures and time. So there is excellent support for the claim that belief in God is cognitively

\footnotetext{
${ }^{109}$ Dan Sperber, (1996) Explaining Culture: A Naturalistic Approach, Blackwell.

${ }^{110}$ Justin Barrett, "Exploring the Natural Foundations of Religion," Trends in Cognitive Sciences - Vol. 4, No. 1, January 2000, pp. 29-34.

${ }^{111}$ Deborah Keleman, "Are Children "Intuitive Theists"? Reasoning About Purpose and Design in Nature," Psychological Science May 2004 vol. 15 no. 5 295-30.

${ }^{112}$ Will Gervais, "Perceiving Minds and Gods: How Mind Perception Enables, Constrains, and Is Triggered by Belief in Gods," Perspectives on Psychological Science July 2013 vol. 8 no. 4 380-394.

${ }^{113}$ Robert McCauley, "The naturalness of religion and the unnaturalness of science." In Explanation and Cognition (Keil, F.C. and Wilson, R., eds), MIT Press, 2000. See also, Robert McCauley, Why Religion Is Natural and Science Is Not, (Oxford, 2011).

${ }^{114}$ E. O. Wilson, On Human Nature (Harvard: 2004), p. 169.
} 
normal, in this ordinary sense. Some take this to be an unfortunate feature of human nature, but a feature nonetheless.

But, to be clear, I am not claiming that all humans are so predisposed—only those who are cognitively normal. I am using 'normal' primarily in a statistical sense here. 'Cognitively normal' would exclude persons with certain conditions: Alzheimer's Disease, Autism-spectrum disorders (even mild forms ${ }^{115}$ ), Moderate Cognitive Impairment, or any condition that significantly affects certain kinds of perception, thinking, reasoning, or remembering. ${ }^{116}$ I would also exclude any person, i.e., infants and very young children, whose cognitive faculties are not sufficiently developed to the degree needed to grasp the relevant religious concepts. It may sound odd to call a perfectly normal infant "cognitively non-normal," but let us grant this stipulation for the sake of simplifying the argument. Nothing significant rides on this. It is important to emphasize that it is not necessarily bad to be cognitively non-normal. Certain autismspectrum disorders are often correlated with unusually high intelligence or competency in science and math. ${ }^{117}$ But persons who fall into the category of cognitively non-normal may not be predisposed toward religious belief. In fact, there is some evidence for the claim that certain kinds of cognitive non-normality may actually inhibit one's ability to form religious beliefs. Recent work by Norenzayan, Gervais and Trzeniewski has shown

\footnotetext{
${ }^{115} \mathrm{CDC}$ estimates that about 1 in 68 children has been identified with autism spectrum disorder (ASD). Based on a U.S. population of 300 million, that would suggest as many as 4.4 million Americans with ASD.

${ }^{116}$ Mosby's Medical Dictionary, $8^{\text {th }}$ edition. (Mosby, 2008)

${ }^{117}$ See, Baron-Cohen, Wheelwright, Skinner, Martin, and Clubley, "The Autism-Spectrum Quotient (AQ): Evidence from Asperger Syndrome/High-Functioning Autism, Males and Females, Scientists and Mathematicians," Journal of Autism and Developmental Disorders, Volume 31, Issue 1, pp 5-17; also, Ghaziuddin and Mountain-Kimchi, "Defining the Intellectual Profile of Asperger Syndrome: Comparison with High-Functioning Autism," Journal of Autism and Developmental Disorders, Volume 34, Issue 3 , pp $279-284$.
} 
that there is a link between atheism and certain mentalizing deficits commonly associated with the autism spectrum. ${ }^{118}$ They write:

Cognitive approaches to religion emphasize that a reliably developing social cognitive mechanism - mentalizing or theory of mind - is a key foundation that supports the intuitive understanding of God or gods. Present findings bolster this hypothesis, and further demonstrate that mentalizing deficits undermine not only intuitive understanding of God, but belief as well.

Similar conclusions have been drawn in other studies. Jesse Bering, former director of the Institute of Cognition and Culture at Queen's University Belfast, in his 2002 study, found that "in autobiographical accounts written by people with high-functioning autism, God is more a principle than a person." ${ }^{119}$ In a similar vein, Saler and Ziegler, in their 2006 paper, "Atheism and the Apotheosis of Agency," suggest that atheists may be less likely (due to genetic factors) to attribute events in their environment to intentional agency. ${ }^{120} \mathrm{~A}$ 2012 study by Caldwell-Harris, et al. reported that survey respondents with highfunctioning autism had a higher likelihood of atheism and that atheists scored higher on the autism spectrum than religious believers. ${ }^{121}$

So, given the prevalence of religious belief across culture and time, evolutionary theories of how religion could be adaptive, and recent empirical research in cognition, it seems reasonable to think that cognitively normal humans are predisposed to form the relevant religious beliefs.

\footnotetext{
${ }^{118}$ Norenzayan A, Gervais WM, Trzesniewski KH (2012) Mentalizing Deficits Constrain Belief in a Personal God. PLoS ONE 7(5): e36880. doi:10.1371/journal.pone.0036880

119 Jesse M. Bering, “The existential theory of mind," Review of General Psychology, Vol 6 (1), Mar 2002, 3-24. Quotation taken from Matthew Hutson's essay, "Does Autism Lead to Atheism?” in Psychology Today, May 30, 2012. ${ }^{120}$ Benson Saler and Charles A. Ziegler, "Atheism and the Apotheosis of Agency," Temenos 42 (2006): 7 14.

${ }^{121}$ Caldwell-Harris, C, Murphy C, Velazquez, T, and McNamara, P. 2012. "Religious Belief Systems of Persons with High Functioning Autism," Presented at the 2011 Annual Meeting of the Cognitive Science Society, Boston, MA.
} 
In this section, I argue that God provides the modest amount of evidence needed to produce belief that $\mathrm{R}$ in cognitively normal, open-minded humans. If we take experience to be a kind of evidence and consider the prevalence of modest religious experience in the world, then it seems that every normal person would have plenty of evidence in hand. To begin, think of a person's evidence as a set of beliefs and experiences that person has. ${ }^{122}$ So, when we say that people have enough evidence for $\mathrm{R}$ (where $\mathrm{R}$ is the set of propositions which must be believed for salvation), we mean that they have the beliefs and experiences needed. ${ }^{123}$ This is not the same notion of evidence used in a courtroom or on a TV show like CSI. But when we look closer, we see that fingerprints and DNA are not what support beliefs. Rather, fingerprints, murder weapons, DNA and eyewitness testimony only become evidence when you have certain experiences and form certain beliefs about them. Bob's fingerprints on the gun aren't what support your belief that Bob is guilty. Rather, it is your visual experience of the fingerprints on the gun, your belief that Bob's fingerprints are on the gun and your belief that his fingerprints wouldn't be there if he were innocent. So, ultimately, it is your experiences and beliefs that serve as your evidence for believing something.

Second, there can be a disconnect between the evidence one has and one's beliefs about one's evidence or one's beliefs in general. There are numerous ways this can happen. One can have evidence without being (consciously) aware of it, just as one can have propositional justification for some $\mathrm{p}$ without being aware of having it. ${ }^{124}$ No one can be simultaneously aware of everything they believe, so it is quite easy to imagine

\footnotetext{
${ }^{122}$ For now, I will table the question of whether those beliefs must be justified or not.

${ }^{123}$ I will also table, for the moment, the question, "needed for what?" We could just think, "to support a belief that $\mathfrak{k}$ " for now.

${ }^{124}$ Ref??
} 
someone having evidence of which they are not currently aware (perhaps they've forgotten they have it, but could be easily reminded). Thus, it may be true that $\mathrm{S}$ has evidence to believe that $p$ even though $\mathrm{S}$ may not realize or readily agree that this is the case, especially if $\mathrm{S}$ has not formed the belief that $p$. Similarly, one may be aware of certain evidence (beliefs, experiences) but fail to see the logical relations between the evidence and $p$. I may know that $\mathrm{p}$ and know that $\mathrm{p} \rightarrow \mathrm{q}$, but don't believe that modus ponens is a valid deductive inference. Thus, I may have evidence for $p$ but fail to see that I do. So, the following is false: If $S$ has evidence for $p$, then it will be evident to $S$ that she has evidence for $p$. Another kind of disconnect occurs when I don't believe the deliverances of my perceptual faculties. While peering over the side of my rowboat, I may (visually) experience an oar as bent in the water, but not form the belief that the oar is bent because of other background beliefs that I have. Still, the experience of the oaras-bent counts as evidence, albeit misleading evidence. So I have evidence for $p$, but I do not have the belief that $p$. Similarly, I may have a perceptual experience of my teenage child buying drugs at school, but because this is too painful for me to bear, I somehow refrain from forming the belief that my child is buying drugs (perhaps I form the belief that he is buying candy or that it isn't my child). Still, the perceptual experience counts as part of my evidence.

Understanding the possible disconnect between belief and evidence is important because certain kinds of experiences I have can count as evidence for propositions like $\mathrm{R}$ even if I do not believe that R or even if I do not see them as evidence for R. I am making a conditional claim: if $S$ has certain perceptual experiences, then those experiences count as part of $S$ 's evidence for $R$ even if $S$ does not believe that $R$ or $S$ does 
not think the experiences are evidence for $R$. So, my experiences (and beliefs) can count as evidence for R, and I can be mistaken about the evidence that I have for R. Below, I say more about what experiential evidence for $\mathrm{R}$ might look like and how much the average person might possess.

Like other kinds of evidence, evidence for R can take the standard forms: ordinary perceptual $^{125}$, testimonial, memorial, inferential, etc. Some persons have reported literally seeing or hearing God. Most people have received others' testimony about God, whether written or oral. Philosophical arguments for God's existence can provide inferential evidence. But probably none of these have been acquired by all cognitively normal humans. More common is a kind of perceptual experience in which people "feel God's love" or "sense God's presence." Following William Alston (1991), I'll call this sort of perceptual experience mystical perceptual experience. ${ }^{126}$ The resulting beliefs we may call mystical perceptual beliefs. According to Alston, mystical perceptual experience can come in two kinds, direct and indirect. Consider an analogy of ordinary perceptual experience that $p$. Suppose we are wondering whether it is true that my dog has fleas. Then two things happen. (i) I have a visual experience of my dog scratching himself vigorously and repeatedly; and (ii) I inspect my dog and have a visual experience of several tiny black objects on his skin, which I then recognize as fleas. In both (i) and (ii), I perceive that my dog has fleas, but in the first case I perceive it indirectly, and in the second I perceive it directly. We can also say that the visual experiences in (i) and (ii) support (in some sense not specified here), or serve as evidence

\footnotetext{
${ }^{125}$ I have in mind here something like certain manifestations of God that could be experienced with the five senses.

${ }^{126}$ William Alston, Perceiving God: The Epistemology of Religious Experience, (Ithaca: Cornell University Press, 1991).
} 
for, the proposition that my dog has fleas. (i) supports the flea proposition indirectly, while (ii) supports it directly. I take this account of how perceptual experience serves as evidence to be fairly straightforward. When I have a perceptual experience of $X$, that perceptual experience (absent defeaters) serves as direct evidence for X. When I have a perceptual experience of some $Y$, where $\mathrm{Y}$ is evidence for $\mathrm{X}$, that perceptual experience of $Y$ counts as indirect evidence for $\mathrm{X} .{ }^{127}$

Now suppose I am wondering whether $\mathrm{R}$ is true. Then suppose that two things happen. (i') I look up at the night sky in a rural area and I am overcome with a sense of awe and wonder concerning the beauty and order of the cosmos. Then, as I am contemplating my experience, (ii') I have a sudden experience of a benevolent and powerful presence surrounding me. These are instances of mystical perceptual experience. The mystical perceptual experiences of the night sky and of the unseen presence support, or serve as evidence for, $\mathrm{R}^{128}$ (i') supports R indirectly, while (ii') supports it directly. So mystical perceptual experience comes in two forms, direct and indirect. ${ }^{129,130}$

It seems that these kinds of mystical experiences, broadly construed, are very common, even if the accompanying mystical beliefs (regarding R-type propositions) are not as common. The Pew Research Center's Religion \& Public Life Project claims that

\footnotetext{
${ }^{127}$ I'm assuming something like the notion of evidential support mentioned by Brandon Fitelson (2012): $E$ (evidentially) supports $p$ iff $E$ raises the (epistemic) probability of $p$.

${ }^{228}$ The perception of the night sky is mystical because it is a perception of the cosmos as beautiful and ordered. The beauty and orderedness of the cosmos cannot be perceived merely by visual experience.

${ }^{129}$ Alston uses a slightly different notion of indirect mystical perceptual experience (MP) in his 1991 (pp. 25-28). He grants the possibility that God Himself is the object perceived through the cosmos or the sunset. In both direct and indirect MP, for Alston, God is the object of perception. On my version of indirect MP, God is not the object being presented to the mystical senses.

${ }^{130}$ For more on the nature of religious experience and beliefs, see Swinburne 1979, 1981; Plantinga 1981, 2000.
} 
$49 \%$ of Americans report having some religious or mystical experience. ${ }^{131,132}$ But since these are self-reported, I take the $49 \%$ to reflect how many people have both had the mystical experience and formed a mystical belief. I suspect a much higher percentage of people have had mystical or religious experiences but did not form any mystical or religious beliefs.

Even in the least-religious countries, religious experiences are still common. A recent study done on religious experience in China by the University of Wales' Alister Hardy Religious Experience Research Centre found that

though only $8.7 \%$ Chinese describe themselves as "religious" . . . 56.7\% have experienced the influence of "a kind of power that people cannot control or explain clearly". They identify this power with a religious being or force. ${ }^{133}{ }^{134}$

So it seems reasonable to think that mystical perceptual experiences are very commonperhaps more common than we might initially think-even if they do not necessarily result in mystical perceptual beliefs. If we include perceptual experiences of certain internal states, such as moral guilt over one's actions, as evidence for $\mathrm{R}$, then mystical perceptual experiences would be even more ubiquitous. ${ }^{135}$

But quantity is not the only axis of evaluation relevant to sufficiency. Quality is also important in evaluating the adequacy of the available evidence. One need not have hundreds or even dozens of such experiences in order to believe that R. One 'item' of evidence (an experience or belief of sufficient quality and absent defeaters) may be sufficient for belief in the relevant proposition for a properly functioning (henceforth,

\footnotetext{
${ }^{131}$ http://www.pewforum.org/2009/12/09/many-americans-mix-multiple-faiths/\#6

132 See also, Yamane and Polzer, "Ways of Seeing Ecstasy in Modern Society: Experiential-Expressive and Cultural-Linguistic Views," Sociology of Religion (1994) 55(1): 1-25.

${ }^{133}$ Religious Experience in Contemporary China, University of Wales Press (2007).

${ }^{134}$ Note that the kind of religious experience described here can supply evidence for $\mathfrak{l}$, since the experiences needed are quite generic.

$135 \mathfrak{A}$ probably includes something like the following: I am incapable of living up to my own moral standards or God's moral standards.
} 
'normal ${ }^{136}$ ') human, even in the face of a large amount of counterevidence. Suppose you were shipwrecked in the Pacific with only a simple, one-way radio. Over the course of weeks, you hear numerous accounts of your death, and even a story about your funeral. Perhaps the story even claims that your body was found. I think that the simple experiential evidence of your own self-awareness would trump any testimonial evidence in support of your death. Put another way, your experience in this case is sufficient for believing that you are alive, even in the face of multiple defeaters. Like Ellie in the novel Contact who believes in the veracity of her questionable interstellar journey on the basis of her powerful experience (powerful enough to overcome all normal defeaters), we may believe that $\mathrm{R}$ on the basis of our powerful experience. ${ }^{137}$ Remember that here I am only arguing that every cognitively normal person has at least a modest amount of evidence in hand.

To conclude this section on evidence, it seems that once we take into account both direct and indirect experiential evidence for R, along with other ordinary kinds (testimonial, inferential, etc.), we should think that every human has a modest amount of evidence for $\mathrm{R}$.

Recall premise (6):

If God provides every human with enough evidence to produce belief that $R$ in open-minded, cognitively normal humans, then God has provided every cognitively normal human with sufficient evidence for $R$.

\footnotetext{
${ }^{136}$ I am using a statistical notion of 'normal,' here, rather than a normative one. Research supports the claim that the vast majority of children will form theistic belief. Whether this is good or bad is another matter. Of course, my view is that this is good, but this is an assumption.

${ }^{137}$ Carl Sagan, Contact, (New York: Simon and Schuster, 1985).
} 
Now the rubber meets the road. (1)-(6) entail that God provides us with sufficient evidence. But have we defused Russell's original complaint? Russell's original complaint is both an epistemic and a moral one. Not only do we not have enough evidence to believe that God exists, Russell claims, but God has failed to do what he ought, viz., he ought to provide more evidence. I have argued that we do have enough evidence if we are cognitively normal and open-minded, and now I want to argue that this is exactly the amount of evidence God should provide. Certainly, God could have provided more and thus produced more beliefs that $\mathrm{R}$, but there are good reasons for him not to do so. Below I argue for a particular way of understanding the term 'sufficient evidence' that will support my overall view.

\subsubsection{What is Sufficient Evidence?}

Before we can constructively argue about the truth of SE, we need to clarify the truth conditions for SE. (I will use the terms 'sufficient,' 'plenty' and 'enough' to be synonymous.) In her paper, "The Meaning of Too, Enough, and So . . That*," Cécile Meier offers a way of understanding 'sufficient' that gives us clear truth conditions. Meier suggests that sentences using quantifiers like sufficient or enough contain a hidden conditional with a modal expression. So, on her view, statements such as Bertha is old enough to drive a car can be understood as follows:

The value $v$ such that Bertha is v-old is GREATER than or equal to the MINIMUM of all values $v^{*}$ such that, if Bertha is $v^{*}$-old, she is able to drive a car.

This seems plausible. Here, the implicit modal expression is to be able, which can be inserted into the original statement without change of meaning: Bertha is old enough to be able to drive a car. Of course, being v-old isn't a sufficient condition, unless we're 
simply talking about satisfying the legal age requirement for driving. ${ }^{138}$ We could probably understand the expression to imply this.

So what is the implicit modal expression in SE? God provides every cognitively normal human with sufficient evidence to be able to believe that $R$. This doesn't seem to change the meaning of SE. Using this model, we can restate SE as follows:

(SE*) The value $v$ such that God gives v-evidence is GREATER than or equal to the MINIMUM of all values $v^{*}$ such that, if God gives $v^{*}$ evidence, cognitively normal humans are able to believe that $R$ on that evidence.

I've added the phrase on that evidence to rule out cases where someone has the provided evidence but comes to believe that $\mathrm{R}$ due to a bump on the head, an epileptic seizure or some non-epistemic process. For the evidence to be sufficient for R, it must be involved in (non-deviantly) causing their belief that R. I should also add that when I claim that God gives $E$ to $S$, I mean this to entail that $\mathrm{S}$ actually has $\mathrm{E}$, rather than E merely being available or something of that sort.

So, now we can tackle the first important question: What is the minimum value of $v$ ? There are a few ways of thinking about this question. It probably won't be helpful to try and talk about quantities of evidence in terms of units, since we have no idea how many units of evidence for some $p$ it takes to enable some $\mathrm{S}$ to believe that $p$ on that evidence. But we do have some more coarse-grained ways of quantifying evidence. ${ }^{139}$ For instance, different amounts of evidence are required for certainty, justification and believability. First, let us assume, for the sake of simplicity, that our subjects all have roughly the same background beliefs. Now, let $C$-evidence be: enough evidence for certainty that $p$, and let J-evidence be enough evidence for justified belief that $p$.

\footnotetext{
${ }^{138}$ Thanks to Matt McGrath for pointing this out.

${ }^{139}$ These ways of talking include both quantity and quality of evidence, I think.
} 
Intuitively, $\mathrm{J}<\mathrm{C}$. Let B-evidence be enough evidence to make p believable. We frequently use expressions like, "that's believable," or "that's unbelievable." What I take "p is believable" to mean is something like this: if an average $S$ were to consider $p, S$ would form the belief that $p$. I say 'an average S,' because this is not a universal claim, but rather a claim about how the average or normal person would respond doxastically to $p$. Writers of fiction frequently talk in these terms when they consider the believability of their stories - a good story has a certain amount of believability. A witness in a trial may be believable, which means that the average person is likely to believe what they say. We may form a belief that $p$ based on some experience without any reflection or conscious reasoning. Such a belief may not be certain or justified (or even true), but clearly $p$ was believable.

Intuitively, B $<\mathrm{J}<\mathrm{C}$. There are other quantified concepts of evidence, but these will do for now. I think we can follow our ordinary language here and say that believability is the minimum value of $v$, i.e., the amount of evidence that enables us to believe that R. Let's substitute (B) for $v$ such that 'B-evidence' = enough evidence to make $R$ believable for cognitively normal humans.

(SE*) The value B such that God gives B-evidence is GREATER than or equal to the MINIMUM of all values $v^{*}$ such that, if God gives $v^{*-}$ evidence, cognitively normal humans are able to believe that $R$ on that evidence.

By providing B-evidence, God has made it possible for all cognitively normal humans to believe that $\mathrm{R}$ on that evidence. I am able to believe that $\mathrm{R}$ on the evidence $\mathrm{I}$ have in the same way that I am able to get a tax refund from the government (assuming I qualify). All that is required is a relatively easy, voluntary action on my part. In the refund case, I must fill out and send in the form. If I qualify and I send in the completed form, I will 
get a refund check. In the belief case, I must exercise open-mindedness. Being openminded (trying to fairly assess the evidence, reflecting, engaging with peers on the subject, correcting for their own biases, seeking out additional evidence, etc.) is in the voluntary control of the subject. If $\mathrm{S}$ is cognitively normal and open-minded, then they will form the belief that $\mathrm{R}$ on the evidence they have (including any additional evidence gained through investigation). Being open-minded also involves an attitude, but the attitude alone is not sufficient for being open-minded.

What might open-mindedness look like? Blaise Pascal famously describes what I have in mind when he offers advice to those who would like to believe that $\mathrm{R}$ but find that they cannot:

But at least learn your inability to believe, since reason brings you to this, and yet you cannot believe. Endeavour, then, to convince yourself, not by increase of proofs of God, but by the abatement of your passions. You would like to attain faith and do not know the way; you would like to cure yourself of unbelief and ask the remedy for it. Learn of those who have been bound like you, and who now stake all their possessions. These are people who know the way which you would follow, and who are cured of an ill of which you would be cured. Follow the way by which they began; by acting as if they believed, taking the holy water, having masses said, etc. Even this will naturally make you believe, and deaden your acuteness. "But this is what I am afraid of." And why? What have you to lose? But to show you that this leads you there, it is this which will lessen the passions, which are your stumbling-blocks. ${ }^{140}$

If a person can honestly say that they have fulfilled all their epistemic duties, examined all the putative evidence, participated in religious activities, sincerely cultivated openmindedness—not just for a season but as a way of life, and that person still finds themselves in unbelief, then they are blameless and may reasonably consider themselves among the "cognitively non-normal." If this all sounds merely hypothetical but impossible in real life, consider this excerpt from a recent essay by political pundit Kirstin Powers in which she describes her own journey to faith:

\footnotetext{
${ }^{140}$ Blaise Pascal, Pensées, 233.
} 
"Do you think you could ever believe it?" . . . I said I didn't want to mislead him - that I would never believe in Jesus.

Then he said the magic words for a liberal: "Do you think you could keep an open mind about it?" Well, of course. "I'm very open-minded!" Even though I wasn't at all. I derided Christians as anti-intellectual bigots who were too weak to face the reality that there is no rhyme or reason to the world. I had found this man's church attendance an oddity to overlook, not a point in his favor.

[. . .] After about eight months of going to hear Keller [pastor of a church in NY], I concluded that the weight of evidence was on the side of Christianity. But I didn't feel any connection to God, and frankly, I was fine with that. I continued to think that people who talked of hearing from God or experiencing God were either delusional or lying. In my most generous moments, I allowed that they were just imagining things that made them feel good.

Then one night in 2006, on a trip to Taiwan, I woke up in what felt like a strange cross between a dream and reality. Jesus came to me and said, "Here I am." It felt so real. I didn't know what to make of it. ${ }^{141}$

There is much more to her story, but this is not an isolated case. Many people have found their way to faith in this manner, including myself.

One might object by pointing out that because Pascal's and Powers' cases were marked by powerful religious experiences or exposure to sophisticated arguments, they cannot be compared to the cases of typical skeptics who don't have similar evidence. Those without such evidence cannot be expected to form the same beliefs as those with it. However, if it is true (as Richard Feldman claims) that evidence of evidence is evidence, then even those who merely hear the report of such experiences and arguments have valuable evidence in their possession. ${ }^{142}$ Moreover, it is very likely that they have an epistemic duty to investigate such evidence. If they fail to fulfill such a duty, then they cannot rightly blame God for their lack of belief that $\mathrm{R}$.

So, I have argued that God need only provide enough evidence for R such that any cognitively normal, open-minded human would come to believe that $\mathrm{R}$ on that evidence. I argued in the previous section that it takes a very modest amount of evidence

\footnotetext{
${ }^{141}$ http://www.christianitytoday.com/ct/2013/november/fox-news-highly-reluctant-jesus-follower-kirstenpowers.html?paging=off

${ }^{142}$ Richard Feldman, "Reasonable religious disagreements," in L. Antony (ed.), Philosophers without God: Meditations on Atheism and the Secular Life, (Oxford University Press, 2007).
} 
to meet this condition, since cognitively normal humans are highly predisposed to believe that R. I also argued that if we consider the prevalence of religious experience (both direct and indirect) and religious belief, in addition to other numerous kinds of evidence for R (testimonial, inferential), then we ought to conclude that God provides the modest amount of evidence needed. Thus, God provides sufficient evidence for R. In the next section, I will respond to several objections to SE.

\subsubsection{Objections to SE}

\subsection{3a Argument from Nonbelief}

\section{Consider:}

1. If God provides every cognitively normal human with sufficient evidence for R, then for any cognitively normal S, S believes that R. ${ }^{143}$

2. There is some cognitively normal S who doesn't believe that R.

3. So, God doesn't provide every cognitively normal human with sufficient evidence for R.

Such an argument seems problematic in that it assumes all humans are ideal reasoners. Below I give two responses. First, I argue that no matter how good our evidence for R is, it is still possible for humans to come to the (epistemically) wrong conclusion about R. Second, I argue that God has good reason not to provide irresistible evidence to all humans, i.e., a quantity or quality of evidence that would preclude nonbelief. Thus, sufficient evidence must be something less than irresistible evidence.

\section{Response \#1: The Problem(s) with Human Reasoning}

On any plausible notion of 'sufficient,' S's having sufficient evidence for some $p$ is no guarantee that $\mathrm{S}$ will believe that $p$. There are two reasons for this. First, humans are not perfect reasoners. Mistakes in reasoning are common, even with sufficient evidence. Jon

\footnotetext{
${ }^{143}$ Below, in section 3.2.2 I consider a revised version of 1. that assumes reasonable assessment of evidence.
} 
Kvanvig writes, “. . I see no reason to think that such mistakes are not possible about even absolutely conclusive evidence ... No matter how good the evidence is, it still appears possible to mistake its quality." ${ }^{\text {144 }}$ Such mistakes may be due to random neural misfiring, but they can also be caused by interference from our own mental states. Phenomena such as cognitive penetration can interfere with the normal belief-formation process and prevent us from believing as we ought. There is no reason to think this can't happen with regard to $\mathrm{R}$, even if we have sufficient evidence. Below I describe the nature of such phenomena and why we should expect such phenomena to occur with regard to $\mathrm{R}$ in particular.

\section{Cognitive Penetration}

While we take our perception and cognition to be, for the most part, reliable, most of us realize that our judgments are frequently distorted by various internal states, such as beliefs and desires. We sometimes refer to this distortion as "wishful thinking" or "confirmation bias." Susana Siegel, in her paper "Cognitive Penetrability and Perceptual Justification," uses the example of early preformationist biologists (mistakenly) seeing tiny embryos in sperm cells because they already believed they were there. Siegel calls the distortion of perception and belief formation by other mental states (such as previous beliefs, desires, moods) cognitive penetration. The phenomenon of negative cognitive penetration-experiencing objects as we want or expect them to be, rather than as they are-is well-documented and has been discussed at length as it relates to epistemic matters (Siegel, 2012). Self-deception (Van Leeuwen, 2007) and "motivated reasoning" (Kunda, 1990) are also common phenomena.

\footnotetext{
${ }^{144}$ Jon Kvanvig, "Divine Hidenness: What is the Problem?" in Daniel Howard-Snyder and Paul K. Moser (eds) Divine Hiddenness: New Essays(Cambridge: Cambridge University Press, 2002).
} 
In cases of good belief formation, evidential input is converted into appropriate beliefs. By 'evidential input' at a time $t$, I am including my beliefs and experiences acquired both at $t$ and previous to $t$. As discussed previously, I need not be aware of all these beliefs and experiences. This evidential input is then processed by my cognitive faculties, which can result in modifications of my doxastic states. I take this process to be nearly automatic in most instances, depending on the complexity of the evidence and relevant propositions involved. But even if the cognitive faculties are in good working order, other internal states can interfere with appropriate belief-formation. These are cases in which we would say that someone has not believed as they ought to believe.

Plausibly, we are sometimes culpable for such cases of belief malformation. We certainly treat people as if this was the case. The person who believes what he reads in the tabloids, or the person who believes everything the salesman tells him will often be told, "You should have known better." Even scientists can be guilty of believing irresponsibly. It isn't hard to imagine a scenario in which the preformationist is culpable for the cognitive penetration and is thus culpable for the bad belief that forms as a result.

Similarly, these same phenomena occur regarding religious belief formation. Given the natural tendency of humans to let desires and social-pressures affect their perceptual and cognitive processes, this claim should not be controversial. Thinkers like Sigmund Freud and Karl Marx have notoriously argued that theistic belief is not the result of careful, rational thinking or perception, but rather due to wish-fulfillment or other irrational processes. But the knife cuts both ways. Atheists who want atheism to be true may very well be cognitively penetrated themselves. Thomas Nagel famously describes his own case: 
I want atheism to be true and am made uneasy by the fact that some of the most intelligent and well-informed people I know are religious believers. It isn't just that I don't believe in God and, naturally, hope that I'm right in my belief. It's that I hope there is no God! I don't want there to be a God; I don't want the universe to be like that. ${ }^{145}$

Possibly, such powerful desires for the world to be a certain way can infect one's perception and reasoning. I am not claiming that it has, in Nagel's case, nor am I

claiming that such penetration implies that the beliefs are false. I am merely arguing that given the nature of human beings, we should expect quite a bit of cognitive penetration to occur, and especially with regard to beliefs about which we care deeply. So it should be plausible that some cases of atheism (and theism) are due to culpable cognitive penetration. The atheist acquires evidence via experiences, but the process that takes this evidence and produces appropriate beliefs is interfered with due to some culpable epistemic failure on the part of the subject. The process is cognitively penetrated, and the mind fails to produce the appropriate beliefs given the evidence in hand.

This hypothesis fits well within the TCV. Jesus, quoting the prophet Isaiah, offered the following criticism of certain members of his audience:

You will indeed hear but never understand, and you will indeed see but never perceive. For this people's heart has grown dull, and with their ears they can barely hear, and their eyes they have closed. ${ }^{146}$

Presumably, he was chiding certain listeners who, despite the evidence, were culpably unable to form the appropriate (R-type) beliefs. St. Paul describes something similar:

For the wrath of God is revealed from heaven against all ungodliness and unrighteousness of men, who by their unrighteousness suppress the truth. For what can be known about God is plain to them, because God has shown it to them. For his invisible attributes, namely, his eternal power and divine nature, have been clearly perceived, ever since the creation of the world, in the things that have been made. So they are without excuse. For although they knew God,

\footnotetext{
${ }^{145}$ Thomas Nagel, ”The Last Word", Oxford University Press: 1997

${ }^{146}$ Matthew 13:14-15; Isaiah 6:9-10, English Standard Version.
} 
they did not honor him as God or give thanks to him, but they became futile in their thinking, and their foolish hearts were darkened. ${ }^{147}$

John Calvin, commenting on this very passage, writes:

Yet let this difference be remembered, that the manifestation of God, by which he makes his glory known in his creation, is, with regard to the light itself, sufficiently clear; but that on account of our blindness, it is not found to be sufficient. ${ }^{148}$

It is a common idea in Judeo-Christian teaching that how the evidence seems to us can be affected by our current beliefs and desires. Thus, in some cases, evidence that should be enough appears insufficient. Jesus tells such a story about a man in hell who asks Abraham to send someone back from the dead to warn his brothers of their impending judgment. Abraham says, "They have Moses and the Prophets; let them hear them."149 I.e., they have enough evidence already. If they fail to respond, it is their own fault.

\section{Response \#2: The Problem with Irresistible Evidence}

Now, let me offer a second reply to the Argument from Nonbelief. Recall that this argument assumes that if God provides sufficient evidence for $p$, then this guarantees that $\mathrm{S}$ will believe that $p$. Above I argued that regardless of how good the evidence is, we can still come to the wrong conclusions through errors in human reasoning. But it is also possible that having sufficient evidence does not preclude nonbelief, even if our reasoning is ideal. Perhaps God has given every person an amount of evidence $E$, which he considers sufficient (in the sense described in section 3.1), but $E$ is also somewhat ambiguous or something less than conclusive. This is clearly possible, but is it plausible? One might be tempted to think that 'sufficient evidence' just means 'enough evidence to

\footnotetext{
${ }^{147}$ Romans 1:21-22, English Standard Version.

148 Calvin's Commentary on Romans

${ }^{149}$ Luke 16:19-31.
} 
guarantee persistent belief,' which would make (1) true. ${ }^{150}$ Let us call such a notion of evidence irresistible evidence. But, given God's respect for human autonomy and doxastic freedom, it seems unlikely that God would provide irresistible evidence. If someone does not wish to believe, or wants to avoid the consequences of belief (such as relational union with God, or submission to God's authority), then God ought to make it possible for that person to disbelieve. ${ }^{151}$ Perhaps God wants a certain kind of relationship with humans that, necessarily, is entered into voluntarily. ${ }^{152}$ I am not suggesting here that belief is voluntary. Rather, I am suggesting that by providing something less than irresistible evidence, God leaves room for non-evidential factors to influence our belief formation. (I discuss this voluntary component as 'open-mindedness' above in section 3.1.) This preserves autonomy in the sense that I am not forced to believe something I find so loathsome. Additionally, Michael Murray has argued that irresistible evidence would also preclude our ability to develop morally significant characters. ${ }^{153}$ So, it seems that God is not obligated to provide irresistible evidence. This means that the argument from nonbelief fails to support (2) of Russell's argument, which raises doubts about the Russellian argument.

Can we modify the argument to better support (2)? A modified version of the argument from nonbelief is suggested by J. L. Schellenberg in his Divine Hiddenness and

\footnotetext{
${ }^{150}$ I say 'persistent belief' because premise (1) uses the present simple tense 'believes,' which implies that $\mathrm{S}$ believes that $\mathrm{p}$ at any given time $\mathrm{t}$.

${ }^{151}$ Note that disbelief in this case is not purely the result of deliberation. Cognitive penetration occurs unconsciously in most cases. For more on this, see Michael J. Murray, "Deus Absconditus," Divine Hiddenness: New Essays, Daniel Howard-Snyder and Paul Moser, eds. (Cambridge University Press, 2002). Also see Hick (1985) and Swinburne (1981).

${ }^{152}$ See Peter Van Inwagen, The Problem of Evil (Oxford, 2006), p. 85. Also, see my unpublished paper, "Love, Freedom and Evil" (2008), presented at Midwestern Society of Christian Philosophers, 2008. In this paper I argue that the kind of love God desires from humans is essentially voluntary (in a libertarian sense).

${ }^{153}$ Murray (2002), p. 83.
} 
Human Reason. ${ }^{154}$ Rather than the existence of mere nonbelief serving as evidence for

(2), it is the existence of reasonable nonbelief. Thus:

\subsection{3b Argument from Reasonable Nonbelief}

1. If God provides every cognitively normal human with sufficient evidence for R, then for any cognitively normal $\mathrm{S}$ who reasonably assesses the evidence, $\mathrm{S}$ believes that $\mathrm{R}$.

2. There is some cognitively normal $\mathrm{S}$ who reasonably assesses the evidence and doesn't believe that $\mathrm{R}$.

3. So, God doesn't provide every cognitively normal human with sufficient evidence for R.

Premise (1) is problematic here in a way that also applies to the Argument from Nonbelief, but I did not address it above. (1) assumes that every living (cognitively normal) $\mathrm{S}$ already has sufficient evidence for $\mathrm{R}$ in their possession. But there is no reason to suppose this is the case. Let's call a cognitively normal, open-minded atheist a CRatheist. (I'm using 'open-minded' interchangeably with 'reasonably assesses the evidence.') For any putative CR-atheist, it may very well be the case that they have not yet received sufficient evidence for $\mathrm{R}$. There is nothing in the predisposition argument or in the original Russellian argument that requires God to provide sufficient evidence at any given time, as long as it precedes death. As the ancient Greeks said, "call no man happy until he is dead," so the Christian theist might say, "call no man a CR-atheist until he is dead." So, suppose we modify (2) to read:

(2') There is some cognitively normal S who has sufficient evidence, reasonably assesses that evidence, and doesn't believe that $\mathrm{R}$.

I think the correct attitude to take toward (2') is to withhold. There seems to be no way to know, for any putative CR-atheist, whether they have all the evidence they will ever get, or whether they may still come to believe that $\mathrm{R}$ in the future.

${ }^{154}$ J. L. Schellenberg, Divine Hiddenness and Human Reason (Ithaca: Cornell Press, 1993), p. 83. 
I should also note that on the responsibilist view, there may be reasonable, openminded people who fail to believe that $\mathrm{R}$ and are nevertheless blameless. Such persons may have certain cognitive deficiencies (of the sort discussed in earlier sections) that simply make it impossible for them to form the relevant beliefs.

\subsubsection{General Objections to Responsibilism}

\subsection{4a Why Are Humans Such Bad Reasoners?}

According to the responsibilist view, human beings are notoriously prone to errors in reasoning, especially when it comes to R. But the skeptic may ask, "Why did God make us so prone to errors, especially when it comes to R?" Surely God could have given us more reliable cognitive faculties and still protect our autonomy with regard to faith. Possibly, God could have simply made the evidence ambiguous or less than conclusive so that belief could avoided without violating principles of sound reasoning.

In reply, I will clarify the responsibilist view and show that this objection misses the mark. It is not the responsibilist view, or the traditional Christian view, that God created humans with faulty reasoning or a proclivity for irrational thinking. On TCV (and by extension, responsibilism), humans were created with properly-functioning, yet finite, cognitive abilities. Dysfunction arose due to an event called "the fall." Understood either literally or metaphorically, the fall explains the origins of all dysfunction in the world. Taken literally, Adam and Eve (the first humans) chose to violate one of God's commands and were thus corrupted irreversibly. (It isn't exactly clear how this violation brought about the corrupting effect, but I don't think this makes a difference.) This corruption did not ruin human beings entirely, but resulted in a natural tendency towards self-centered thought, desire and action that was passed on to all their progeny. Taken metaphorically, this is the story of every human being. At some point, 
we choose to violate God's commands and our nature is irreversibly corrupted. So, God is not guilty of some illogic in requiring belief despite our corrupted reasoning capacities. Our malfunction is culpable malfunction.

\subsection{4b Evidence Cannot Coerce}

A second objection to the responsibilist view challenges the idea that it would violate our freedom somehow to provide more evidence. Intuitively, I could get a lot more evidence than I have now without being epistemically coerced into belief. And if that is the case, then it seems that should have provided more evidence. The maxim being appealed to here is something like, God should provide as much evidence as he appropriately can. After all, the more evidence I have, the greater the chance that I will believe, right? In reply, I agree that there is probably a significant gap between 'sufficient evidence for belief' and 'coercive evidence.' But why should we think that God is obligated to provide anything more than what is sufficient? He may provide more in some cases, but it does not seem that he is obligated to do so. I have already suggested that those who fail to believe on sufficient evidence are either cognitively non-normal or closed-minded (guilty of some failure in epistemic virtue). The former are not culpable, and it seems that the latter have no grounds to argue that they deserve additional evidence. As is often the case with money, the more irresponsible we are, the more we think we need. But this hardly obligates God. Furthermore, if an individual fails to honestly consider the evidence she has now, it is not at all clear that providing more evidence will have a different result.

A similar line of response to the more evidence objection is proposed by Paul Moser. In his book The Elusive God, Moser agrees that intuitively, we expect God to 
provide more evidence. ${ }^{155}$ "Wouldn’t a perfectly loving God appear convincingly in order to dispel doubts, or at least reasonable doubts, about God's reality and about God's help available to humans? ... A perfectly loving God whose reality is incognito: that seems farfetched, if not incoherent." ${ }^{156}$

Moser argues that the reason we don't get more evidence is because you cannot receive the needed evidence unless you are willing to let God have his way with you. This is because evidence, by its very nature, will have certain effects upon the person who receives it. The effect depends on the state of the recipient: those who are willing to submit themselves to God's authority would be helped and those who are not so willing would be harmed. And since God does not want to harm us, he will only give evidence to those that will be helped by it.

Formally, I take Moser's argument to be the following (roughly):

\section{The Harmful Evidence Argument}

1. For some $\mathrm{S}$, the belief that there is a God who is a genuine moral authority over $\mathrm{S}$ would engender hatred toward God.

2. For any $\mathrm{S}$, as S's confidence that $\mathrm{p}$ increases, $\mathrm{S}$ 's affective attitudes toward p's being true or toward the object of $p$ also increase. (Affect Thesis)

3. So, for some S, as S's confidence in God's existence and moral authority increases, S's hatred toward God also increases.

4. Hate toward God is terminally harmful for humans, since it prevents humans from experiencing friendship with God. (Friendship with God is a necessary condition for true happiness.)

5. God would not promote anything that is terminally harmful for humans.

6. So, for some S, God would not give S more evidence for God's existence as a moral authority over $S$.

7. So, for some S, God is justified in withholding evidence of God's existence as a moral authority over $\mathrm{S}$ from $\mathrm{S}$.

So, I take the idea to be that there are some humans who have sufficient evidence to believe that $\mathrm{R}$, but other mental states are interfering with their cognitive processes and

${ }^{155}$ Paul K. Moser, The Elusive God: Reorienting Religious Epistemology, Cambridge UP, 2008.
${ }^{156}$ Ibid., p. 20. 
preventing them from forming the belief that R. More evidence would only increase the interfering force of those mental states, even if that evidence also increased the plausibility of R. Thus, the net epistemic effect would be close to zero.

\subsection{4c Divine Coercion is Morally Acceptable}

Some skeptics of theism might also wonder how evidence could be coercive, or how evidence could be coercive in a way that would be morally wrong. The claim that the responsibilist makes is that a certain strength or amount of evidence would compel some humans to believe against their will, and that this violation of freedom or autonomy is morally out-of-bounds for God. The problem with this seems to be that our ordinary concept of coercion does not involve the use of evidence to compel belief. Our ordinary concept of coercion usually involves the use of physical force or threat of harm to compel another person to perform some action. But presenting someone with evidence does not seem to coerce in this way. So, how would the responsibilist explain this use of the term 'coercion?'

There are various ways to understand coercion. For example, a person who is physically pushed into a room by another agent against their will has been coerced to go into that room. But a person who is threatened by an agent in such a way that they walk into the room under their own power, but against their will, may also have been coerced to go into that room. ${ }^{157}$ Let us call the former physical coercion and the latter psychological coercion. In psychological coercion, A coerces B to $\varphi$, but B still $\varphi s$ intentionally. In physical coercion, there is no relevant intentional action on B's part at all. The sort of coercion that would happen if God were to overwhelm our senses with

\footnotetext{
${ }^{157}$ For more on the nature of threats and coercion, see Alan Wertheimer, Coercion, Princeton: Princeton University Press, 1987.
} 
undeniable evidence of his existence is more like physical coercion, because there would be no intentional act of believing involved. In fact, there would be no relevant intentional action of any kind (on our part) involved. This is similar to what happens when I open my eyes upon waking in the morning and instantly come to believe that the sun has risen due to the light streaming through the window. Here at least, though, I may have intentionally opened my eyes. God would require no such action on my part.

Now, to be considered coercion, it must also be the case that ping is against my will. By 'against my will' I mean that my will and intentions are under undue influence. I may find myself wanting to $\varphi$, but I do not want to want to $\varphi$. In our case, it seems quite reasonable to suppose that there are many people who do not want to believe that God exists, or any other proposition contained in $\mathrm{R}^{158}$ So, for many people, if God were to overwhelm the senses with undeniable perceptual evidence for his existence, the result would be their coming to believe, according to no intention of their own, something that they do not wish to believe. This seems like coercion.

Now, some may argue that this sort of divine doxastic coercion would be morally justified and thus morally permissible for God. Putatively, it would be justified because the consequence of eternal bliss outweighs any evil of being coerced. However, if I am right that a relationship with God, and thus some beliefs about God, must have a voluntary component, then a coerced belief that $\mathrm{R}$ would have no good consequences. A person who is coerced into believing that $\mathrm{R}$ and then desires a relationship with God would be like the person who is given a love potion and then desires to enter a

\footnotetext{
${ }^{158}$ I have already mentioned the example of Thomas Nagel above, but surely his case is not unique. There are a number of reasons why people might find belief in God unbearable: a fear of judgment, a refusal to submit to God's moral authority, a fear of ridicule by one's peers, etc.
} 
relationship with the one who administered the potion. Such a relationship fails to be a genuine love relationship. So, divine doxastic coercion would not be morally justified.

Rather than use coercion by undeniable perceptual (or any other sort) evidence, God give us epistemic room to believe or not. We cannot help but believe in the external world, but belief in God is different. John Hick writes:

We do not choose whether consciously to relate ourselves to our physical environment and adapt our activities to its character, because it forces itself so irresistibly upon our attention that we cannot seriously doubt its reality; but in contrast to this the dawning religious sense of existing in God's presence is such that we can either welcome it and permit it to grow upon us, or repress and reject it. We have a freedom in the latter case which is absent in the former. ${ }^{159}$

Presumably, God could have revealed himself in such a way that the perceptual evidence for his existence was as strong as the perceptual evidence for the existence of the external world. If God had done this, we could say that God "forces [himself] so irresistibly upon our attention that we cannot seriously doubt [God's] reality." But God keeps his “epistemic distance" to preserve freedom and autonomy.

\subsubsection{Implications \& Problems Concerning Blameworthiness}

So, in section 3 I have argued that Russell's premise (2)-There are some cognitively normal humans do not have sufficient evidence for $R$, disbelieve that $R$, and appropriately lack doubt about their disbelief - is false. God has provided evidence to every person which is sufficient to enable cognitively normal persons to believe that $\mathrm{R}$. But does this mean that Russell's complaint was completely off the mark? No. Presumably, what Russell was mistaken about was his own cognitive condition. It seems very plausible to suppose, given the research cited in the sections above, that Russell

\footnotetext{
${ }^{159}$ John Hick, "Faith and Coercion,” Philosophy. Vol. 42, No. 161 (Jul., 1967), p. 273.
} 
lacked the predisposition to believe that $\mathrm{R}$ enjoyed by the majority of people. Thus, his evidence was insufficient, and he may very well have been epistemically blameless.

Still, even if Russell is ultimately off the hook, there are worries about other kinds of cases. For instance, suppose No-god is someone who disbelieves that God exists, but also has some doubt about his doxastic attitude. (I will assume for all the following cases that the person is cognitively normal.) But also suppose that No-god is justified in believing (falsely) that investigating will not help. Perhaps he thinks that he lacks the ability to believe in God, or perhaps he thinks that he has already considered all the evidence there is (and both beliefs are justified). Thus, he does not investigate. Is NoGod blameworthy for his doxastic attitude? Intuitively, it seems not. But on my view, since investigation would, in fact, help him better judge whether God exists, he has a duty. However, his false, but justified, belief that investigation is futile would count as an excuse. So, I do not think No-god is blameworthy. Had things been slightly different, he would not be excused. For instance, if he had doubts about whether investigation was futile, but did not investigate. I also have worries about the possibility of a justified belief that investigation into God's existence is futile. Every person can rationally ponder reasons for and against. Also, anyone could investigate through experimental prayer, viz., "God, if you're there, then send a sign!" or "God, help me to believe!" Another problematic case might be someone who has doubts, investigates, but still comes up short of doubt-free belief. Suppose Eva disbelieves that R, has some doubt about her attitude, and begins to investigate. After days of reading and reflecting, she feels just the same: "R seems false, but I have some doubt." Is she now blameworthy? On my view, she should continue the investigation, assuming no overriding duties or 
impossibility, until she settles into a doxastic attitude that is relatively doubt-free. If a question is important enough, as in the case with God, then it may very well continue to be a comprehensive duty for decades. Only when she no longer has doubts about her attitude, or when an excuse condition is met, or when investigation would be futile, will her duty to investigate be quelled.

The upshot of my view is that it makes sense of how things seem to many intelligent, thoughtful adults - especially philosophers. Given the data from recent research in cognitive science of religious belief, it is quite likely that many intelligent, highly educated atheists are cognitively non-normal and lack the predisposition to believe. Thus, when they look at nearly the exact same evidence for R that a Christian colleague has, they draw a drastically different conclusion. Russell may have fallen into this category. Such people may very well be epistemically blameless in their lack of belief for the very same reason that infants and cognitively disabled persons are blameless: non-culpable inability. And since most theists believe that God would not punish infants and cognitively disabled persons for nonbelief, they should also think that God would not punish cognitively non-normal adult atheists.

However, it is unlikely that every adult atheist falls into this category. Surely there are many cognitively normal persons who have both the predisposition to believe and sufficient evidence. But for whatever reason they have resisted, denied or suppressed the evidence and persisted in disbelief. On my view, such persons either have some doubt about their attitude of disbelief, or they should. And if they fail to investigate while their doubt persists, then they are epistemically blameworthy. Thus, God seems justified in holding them responsible for their disbelief. 


\subsection{Conclusion}

Russell raises an important, intuitive worry about God's justice. Many people find themselves not believing the content of $\mathrm{R}$ because of what seems to be a lack of evidence. Surely God should not condemn those who are epistemically blameless. I have offered three possible responses to this line of argument. First, according to the universalist view, it might be the case that God makes no doxastic requirement, or that he provides efficacious evidence that guarantees universal belief. Second, on the selectivist view, we may argue that it is just for God to impose impossible requirements. We may very well have obligations to do the impossible, or it may be the case that God has good reasons, which are beyond our ken, for imposing impossible requirements. Third, according to the responsibilist view, God has provided sufficient evidence to everyone who is capable of forming the relevant beliefs, and those who are not capable are blameless. I find this third approach the most plausible. When we take into account the ubiquity of religious experience, together with the natural human predisposition to believe in $\mathrm{R}$, the evidence possessed by all cognitively normal humans is sufficient to render cognitively normal non-believers epistemically blameworthy. 


\section{CHAPTER 4: FINAL CONCLUSIONS}

In Chapter 1, I argued that a person is epistemically blameworthy for their doxastic state D just in case they hold D and have unexcused, unfulfilled epistemic duties regarding D. Clifford's ship owner is a classic case. The ship owner ignored doubts about the seaworthiness of his ship and persisted in his belief that the ship would be fine. While we may also hold him morally blameworthy for the ship's tragic fate, we hold him epistemically blameworthy for failing to do his epistemic duty of checking the ship's condition more thoroughly. The ship owner is a clear case of having a duty to investigate one's doxastic attitude. But more needs to be said about the nature of these putative duties.

In Chapter 2, I first argued that epistemic duties exist and cannot be reduced to either moral or prudential duties. This seems clear when we consider the epistemic value of truth and assume the general principle that we have $\mathrm{X}$-ish duties to pursue things that are $\mathrm{X}$-ishly valuable. I then argued that a person $\mathrm{S}$ has a prima facie epistemic duty to investigate one's doxastic attitude D only if S holds D, S has some doubt, or should have some doubt about the correctness of $\mathrm{D}$, and further evidence-gathering could enable $\mathrm{S}$ to better judge whether p. Humans, such as the ship owner, are notoriously prone to suppress doubts and have unwarranted confidence in their beliefs, often because of nonepistemic factors (desires, etc.) influencing their attitude. We can say that a person $\mathrm{S}$ should have some doubt about their doxastic attitude D if an impartially rational person with the same evidence would have some doubt. An impartially rational person is someone who has no interest in the truth of the matter. Furthermore, prima facie 
epistemic duties only become comprehensive epistemic duties when they are neither impossible to perform nor overridden by other duties.

In Chapter 3, I consider the especially significant case of religious beliefs. On the traditional Christian view, those who fail to believe certain propositions may be liable to divine judgment. But if the evidence for the relevant propositions is insufficient, then such judgment seems unjust. I argued that when we take into account both the ubiquity of religious experience and the natural human predisposition to form the relevant religious beliefs, the evidence is in fact sufficient. However, only cognitively normal humans, i.e., humans with fully-formed, properly functioning cognitive faculties, can be held blameworthy for failing to form the relevant beliefs. Young children, cognitively disabled persons and certain kinds of adult atheists (like Russell, perhaps) are epistemically blameless for failing to believe and thus not liable to divine punishment. Such persons would not be condemned by God.

The proposed view of epistemic blameworthiness enables us to get clearer on several fronts. First, as mentioned above, it clarifies who is liable to divine judgment for nonbelief. Second, it might help determine when a defendant possesses the mens rea required for culpability, or when someone has not done their due diligence. Third, it could help guide our attitudes or blame or praise toward others whose beliefs seem unjustified or otherwise inappropriate. In a world where diverse cultures and religions clash more frequently, having standards by which to judge a persons' epistemic culpability could prevent hostile attitudes and actions. Finally, my account could help individuals better judge the aptness of their own beliefs and encourage them to keep an open mind. 


\section{Bibliography}

Adams, Robert Merrihew. "Involuntary Sins." The Philosophical Review 94: 3-31.

Alston, William P.. Perceiving God: the epistemology of religious experience. Ithaca, N.Y.: Cornell University Press, 1991.

Alston, William P.. "The Deontological Conception of Epistemic Justification." Philosophical Perspectives 2: 257-299.

Alston, William P.. Beyond "Justification": Dimensions of Epistemic Evaluation. Ithaca: Cornell University Press, 2005.

Aristotle. Nicomachean Ethics, trans. Terrence Irwin. $2^{\text {nd }}$ ed. Indianapolis: Hackett Publishing, 1999.

Ball, W.A., "The Perception of Causality in the Infant" (paper presented at the meeting of the Society for Research in Child Development, Philadelphia, April 1973).

Baron-Cohen, Wheelwright, Skinner, Martin, and Clubley, "The Autism-Spectrum Quotient (AQ): Evidence from Asperger Syndrome/High-Functioning Autism, Males and Females, Scientists and Mathematicians," Journal of Autism and Developmental Disorders, Volume 31, Issue 1, pp 5-17.

Barrett, Justin, "Exploring the Natural Foundations of Religion," Trends in Cognitive Sciences 4: 29-34.

Barrett, Justin, Born Believers: The Science of Children's Religious Beliefs. New York: Free Press, 2012.

Bergmann, Michael, "Skeptical Theism and Rowe's New Evidential Argument from Evil," Noûs, 35: 278-296.

Bergmann, Michael. Justification Without Awareness: A Defense of Epistemic Externalism. Oxford: Oxford University Press, 2006.

Bering, Jesse M., "The existential theory of mind," Review of General Psychology 6: 324. Quotation taken from Matthew Hutson's essay, "Does Autism Lead to Atheism?" in Psychology Today, May 30, 2012. 
Bonjour, Lawrence and Sosa, Ernes. Epistemic Justification: Internalism vs. Externalism, Foundations vs. Virtues. Malden, MA: Blackwell, 2003.

Caldwell-Harris, C, Murphy C, Velazquez, T, and McNamara, P. "Religious Belief Systems of Persons with High Functioning Autism," Presented at the 2011 Annual Meeting of the Cognitive Science Society, Boston, MA.

Clifford, W.K. "The Ethics of Belief," in Lectures and Essays, Vol. II. London: Macmillan, 1879.

Code, Lorraine. Epistemic Responsibility. Hanover: University Press of New England and Brown University Press, 1987.

Craig, William Lane, “Talbott's Universalism," Religious Studies, 27, No. 3 (Sep., 1991), pp. 297-308.

Csibra, Gergely, "Goal Attribution to Inanimate Agents by 6.5-Month-Old Infants," Cognition 107 (2008): 705-717.

Davis, Wayne. "Implicature,” Stanford Encyclopedia of Philosophy, 2010.

Dennett, Daniel. Elbow Room: The Varieties of Free Will Worth Wanting, Cambridge, Mass: MIT Press, 1984.

Descartes, Rene. Meditations, trans. Cress, $3^{\text {rd }}$ ed. Indianapolis: Hackett Publishing, 1993.

Dole, Andrew and Chignell, Andrew. God and the Ethics of Belief. Cambridge: Cambridge Press, 2005.

Dougherty, Trent. 2010. 'Reducing Responsibility: An Evidentialist Account of Blame,' European Journal of Philosophy, Vol. 20, Issue 4, pages 534-547.

Feldman, Richard, "Reasonable religious disagreements," in L. Antony (ed.), Philosophers without God: Meditations on Atheism and the Secular Life, Oxford University Press, 2007.

Feldman, Richard. 2006. "Clifford's Principle and James' Options." Social Epistemology, Vol. 20, No. 1, January—March, pp. 19-33. 
Feldman, Richard. "Modest Deontologism in Epistemology." Synthese 161: 339-355.

Fischer, John and Ravizza, Mark. Responsibility and Control: A Theory of Moral Responsibility. New York: Cambridge, 1998.

Gergely, Gyorgy et al., "Taking the Intentional Stance at 12 Months of Age," Cognition 56 (1995): 165-193.

Gervais, Will, "Perceiving Minds and Gods: How Mind Perception Enables, Constrains, and Is Triggered by Belief in Gods," Perspectives on Psychological Science, July 2013 vol. 8 no. 4 380-394.

Ghaziuddin and Mountain-Kimchi, "Defining the Intellectual Profile of Asperger Syndrome: Comparison with High-Functioning Autism," Journal of Autism and Developmental Disorders, Volume 34, Issue 3, pp 279-284.

Greco, John. "Virtue epistemology,” Stanford Encyclopedia of Philosophy, 2009.

Greco, John. "Internalism and Epistemically Responsible Belief," Synthese, Vol. 85, No. 2, pp. 245-277.

Hick, John, "Faith and Coercion," Philosophy. Vol. 42, No. 161 (Jul., 1967), p. 273.

James, William. [1896]. “The Will to Believe.” Reason and Responsibility, Joel Feinberg and Russ Shafer-Landau, eds. Belmont, CA: Thomson Wadsworth, 2008.

Kane, Robert. The Significance of Free Will. Oxford Press, 1996.

Kane, Robert. A Contemporary Introduction to Free Will. Oxford Press. Locke, J. 1975. An Essay Concerning Human Understanding, ed. Peter H. Nidditch. Oxford: Clarendon Press, 2005..

Keleman, Deborah, "Are Children "Intuitive Theists"? Reasoning About Purpose and Design in Nature," Psychological Science May 2004 vol. 15 no. 5, pp. 295-30.

Kelly, Thomas "The Rationality of Belief and Some Other Propositional Attitudes," Philosophical Studies 110: 163-196. 
Kvanvig, Jon, "Divine Hidenness: What is the Problem?" in Daniel Howard-Snyder and Paul K. Moser (eds) Divine Hiddenness: New Essays. Cambridge: Cambridge University Press, 2002.

Locke, John, Two Treatises on Government, Book II, Ch. 2, par. 6. (On-line edition: http://www.lonang.com/exlibris/locke/loc-202.htm)

McCauley, Robert, "The naturalness of religion and the unnaturalness of science." In Explanation and Cognition (Keil, F.C. and Wilson, R., eds), MIT Press, 2000.

McCauley, Robert, Why Religion Is Natural and Science Is Not, Oxford, 2011.

Molina, Michele et al., "The Animate-Inanimate Distinction in Infancy: Developing Sensitivity to Constraints on Human Actions," Journal of Cognition and Development 5 (2004): 399-426.

Montmarquet, James. Epistemic Virtue and Doxastic Responsibility. Lanham, MD: Rowman \& Littlefield, 1993.

Moon, Andrew, “Gibbons on Internalism,” Mind, 119 (473): 143-151.

Mosby's Medical Dictionary, 8th edition. (Mosby, 2008)

Moser Paul K., The Elusive God: Reorienting Religious Epistemology, Cambridge: Cambridge UP, 2008.

Nagel, Thomas, The Last Word, Oxford University Press: 1997.

Norenzayan A, Gervais WM, Trzesniewski KH (2012) Mentalizing Deficits Constrain Belief in a Personal God. PLoS ONE 7(5): e36880. doi:10.1371/journal.pone.0036880

Nottelmann, Nikolaj. Blameworthy Belief: A Study in Epistemic Deontology. Dordrecht: Springer, 2007.

Pascal, Blaise, Pensées.

Plantinga, A. C. God, Freedom, and Evil, New York: Harper \& Row, 1974. 
Russell, Bruce, "Defenseless," in The Evidential Argument from Evil, ed. Daniel HowardSnyder. Bloomington: Indiana University Press, 1996.

Sagan, Carl, Contact, New York: Simon and Schuster, 1985.

Saler, Benson and Ziegler, Charles A., "Atheism and the Apotheosis of Agency," Temenos 42 (2006): 7-14.

Scanlon, Thomas. Moral Dimensions. Cambridge: Belknap Press, 2008.

Schellenberg, J. L., Divine Hiddenness and Human Reason. Ithaca: Cornell Press, 1993.

Shah, Nishi “A New Argument for Evidentialism," The Philosophical Quarterly, Vol. 56, No. 225, p. 487.

Sher, George. Who Knew? New York: Oxford Press, 2009.

Spelke Elizabeth S., Phillips, Ann and Woodward, Amanda L., "Infant's Knowledge of Object Motion and Human Action," in Causal Cognition: A Multidisciplinary Debate, ed. Dan Sperber, Davie Premack and Ann James Premack (Oxford: Oxford University Press, 1995);

Sperber, Dan. Explaining Culture: A Naturalistic Approach, Blackwell, 1996.

Steup, Matthias, ed. Knowledge, Truth and Duty: Essays on Epistemic Justification, Responsibility, and Virtue. New York: Oxford Press, 2001.

Talbott, Thomas, "Providence, Freedom and Human Destiny," Religious Studies, XXVI, 1990, 227-45.

Talbott, Thomas, "The Doctrine of Everlasting Punishment," Faith and Philosophy, VII, $1990,19-42$

Van Inwagen, Peter, The Problem of Evil. Oxford: Oxford University Press, 2006.

Wilson, E. O., On Human Nature. Boston: Harvard University Press, 2004.

Yamane and Polzer, "Ways of Seeing Ecstasy in Modern Society: ExperientialExpressive and Cultural-Linguistic Views," Sociology of Religion (1994) 55(1): $1-25$. 
Zagzebski, Linda. Virtues of the Mind. New York: Cambridge, 1996. 


\section{VITA}

Christopher T. Gadsden has spent most of his 44 years in school. In fact, during only 15 of those years, including pre-school years, was he not enrolled as a full-time student somewhere. Chris spent the first 13 years of school in Tampa, Florida where he graduated from A.P. Leto High School. The next 5 years happened in Tallahassee, where he obtained a Bachelor of Music Education in 1992. Chris ventured through the next 22 years as field staff with Campus Crusade for Christ, doing double-duty (as a student) during exactly half of them. He earned his first Master's degree in philosophy from Biola University (Talbot School of Theology) in 2003, his second Master's degree in philosophy from the University of Missouri in 2009, and his $\mathrm{PhD}$ in philosophy (also from Missouri) in 2014.

Chris' survival during these past 22 years is primarily due to divine intervention and the support of his gracious wife, Kristin, and his four children: Phoebe, Clark, Will and Julia. They continue to put up with him daily at their home in Columbia, Missouri. Now that he is done with this dissertation, he will spend all his time with his family, watching Doctor Who, attending Sporting Kansas City matches, and coaching/playing soccer. 